\title{
ANALYSIS AND DESIGN OF INTERLEAVING MULTIPHASE DC-TO-DC CONVERTER WITH INPUT LC FILTER
}

\author{
A Thesis \\ presented to \\ the Faculty of California Polytechnic State University, \\ San Luis Obispo
}

\author{
In Partial Fulfillment \\ of the Requirement for the Degree \\ Master of Science in Electrical Engineering
}

By

Kevin Thomas DelRosso

December 2008 
(C) 2008

Kevin Thomas DelRosso

All Rights Reserved 
TITLE:

AUTHOR:

DATE SUBMITTED:

COMMITTEE CHAIR:

COMMITTEE MEMBER:

COMMITTEE MEMBER: Dr. Dennis Derickson

Analysis and Design of Interleaving Multiphase DC-to-DC Converter with Input LC Filter

Kevin Thomas DelRosso

December 2008

Dr. Taufik

\author{
Dr. Dennis Derickson
}

Dr. Wayne Pilkington 
Analysis and Design of Interleaving Multiphase DC-to-DC Converter with Input LC Filter

Kevin Thomas DelRosso

The future of microprocessors is unknown. Over the past 40 years, their historical trend has been for adopting smaller and more powerful designs that drive the world that we live in today. The state of the microprocessor business today faces a crossroad, wishing to continue on the historical trend of doubling the number of transistors on a chip every 18 months (Moore's Law) but also facing the realistic task of needing to power these sophisticated devices. With the low voltages and high currents that are required for these microprocessors to operate, it poses a difficult task for the future designers of the voltage regulators that are used to power these microprocessors. The technique that has been widely adopted as the preferred method to power these devices is called a multiphase buck converter, or multiphase voltage regulator.

This thesis is a continuation of and is aimed to improve previous work done by two former Cal Poly students, Kay Ohn and lan Waters. A new design that uses an interleaving control scheme, careful component selection, an input LC filter, and a reduction in board size seeks to improve the efficiency, input current noise, and increase the current density of the original design. Research was first conducted to determine how to best make such improvements. The design phase ensued, which used design calculations and simulations to test if the proposed multiphase topology was plausible. Once the theory was fully proven, a real hardware circuit was created and tested to confirm the results. 
The results yield a multiphase design with improved input noise filtering, greater efficiency, more equal current sharing, and higher current density as compared to previous topologies in this field. Parameters such as output voltage ripple, load and line regulation, and transient response remained excellent, as they were with the previous work. 


\section{ACKNOWLEDGMENTS}

I would like to start by thanking my family and friends for all of their loving support not only during this thesis project but throughout my journey through college and into graduate school. I know without them not only would the journey not have been worth it, but I don't think I would have made it half as far as I did. To my family, there is no way I can ever repay them for all that they have given me over the years, but I shall try my hardest. To all my friends, they made it awfully tough to stay in the lab during all those late nights, but the times that we did spend together that last year are some of the greatest moments of my life, and I will never forget them.

Next, I would like to thank Dr. Taufik for all that he has given me. His love of power electronics and his ability to convey that message to his students is what inspired me to continue with the curriculum of more advanced power electronics courses and eventually a thesis project. I wish to state my appreciation for his dedication not only to myself and the other graduate students he advises, but the compassion he shows towards all his students, it is something to marvel over and admire. Thank you Dr. Taufik, I truly cherished our time together over the last year.

Finally I would like to thank the other master's students that worked on the multiphase team. I remember spending numerous late nights in the lab with Arief Hernadi, Furqan Saleemi, and Sean Zich. They are all wonderful people and I would like to wish them all the best of luck in whatever lies ahead. 


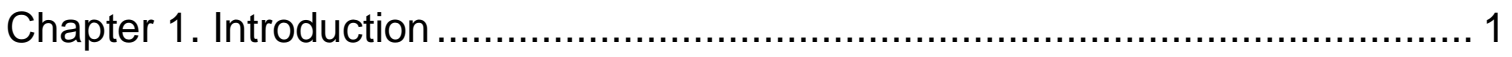

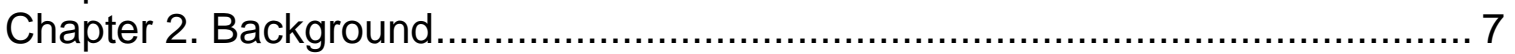

2.1 Overview of Power Electronics ........................................................ 7

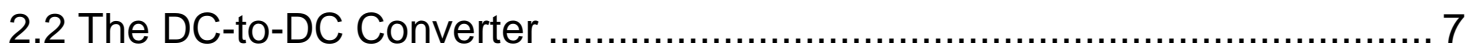

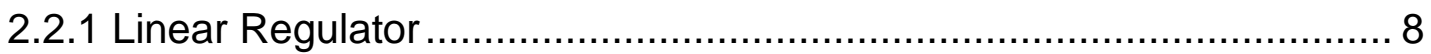

2.2.2 Pulse-Width Modulation............................................................ 9

2.2.3 Resonant Converter (Soft-Switching) ............................................ 11

2.2.4 Power Supply Design Specifications ............................................. 13

2.2.5 Switching Power Supply Components......................................... 15

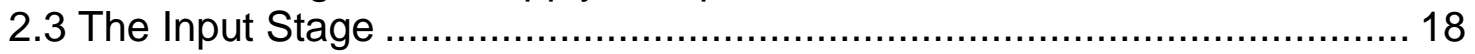





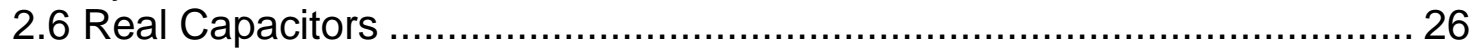

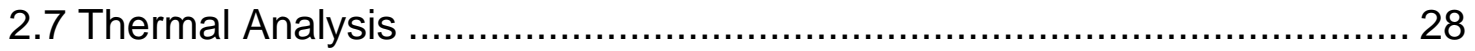

2.8 The Multiphase Buck Converter ........................................................... 32

2.9 Multiphase Literature Review......................................................... 38

2.9.1 A Self-Driven Soft-Switching Topology …….................................. 39

2.9.2 Multiphase Coupled-Buck Converter ........................................... 42

2.9.3 The Two-Stage Solution .......................................................... 47

2.9.4 Looking Ahead...................................................................... 48

Chapter 3. Interleaving Multiphase DC-DC Converter with Input LC Filter ......... 49

3.1 Proposed Multiphase Topology ...................................................... 49

3.2 Design Equations and Loss Analysis ................................................... 51

3.2.1 Deriving the Transfer Function (output current/input current) ............. 51

3.2.2 Finding the Non-Ideal Duty Cycle ................................................... 53

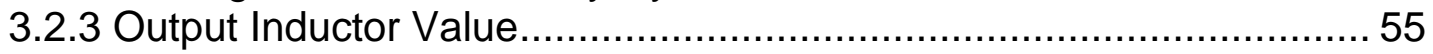

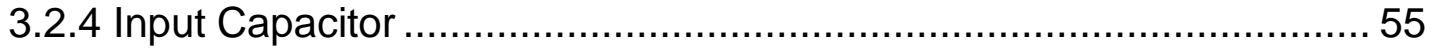

3.2.5 Main Switch Peak Voltage and Conduction Loss ............................... 56

3.2.6 Synchronous Switch Peak Voltage and Conduction Loss .................. 57

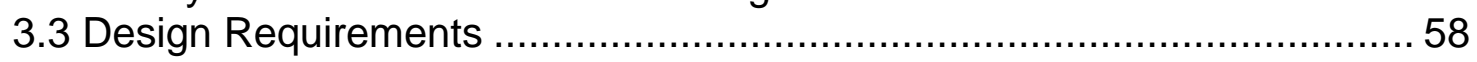

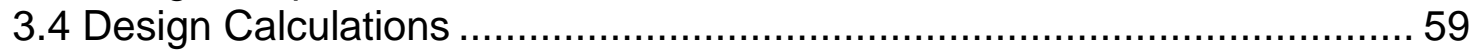

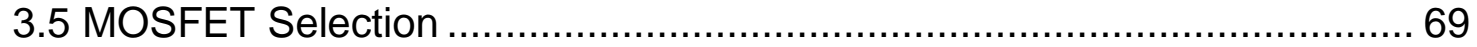

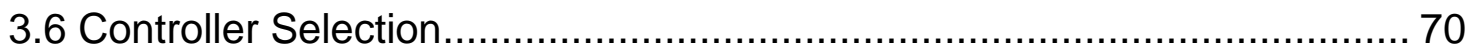

Chapter 4. Design and Simulation Results ................................................. 71

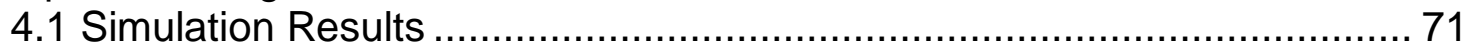

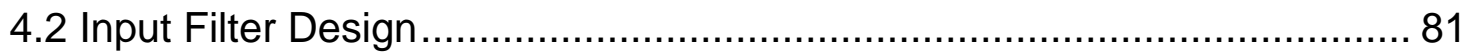



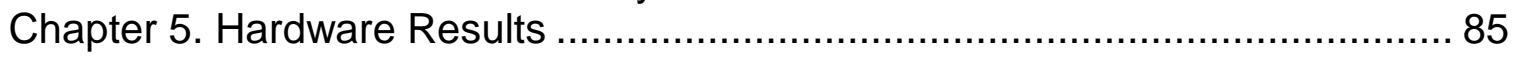

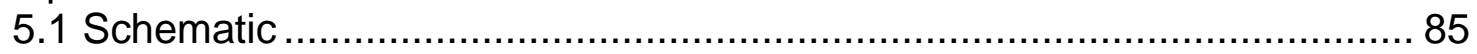

5.2 Design Equations for Real World Circuit.................................................. 88

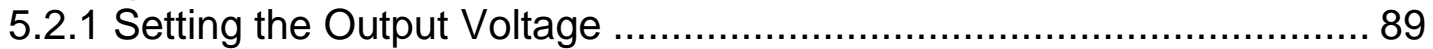

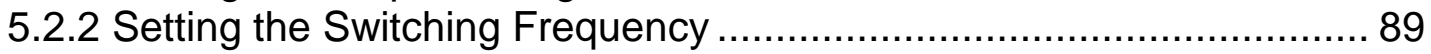

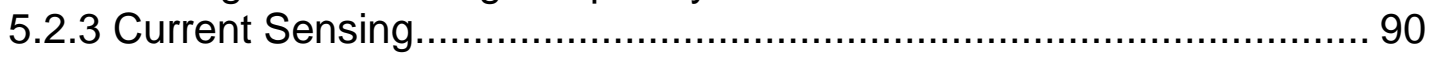

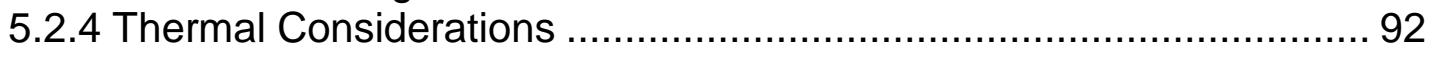




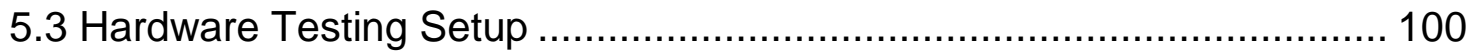

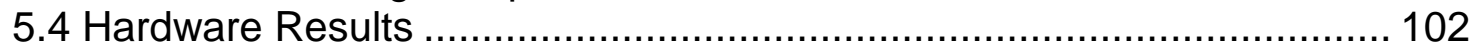

5.5 Hardware Results Summary ....................................................... 114

Chapter 6. Conclusions \& Future Work ………..................................... 116

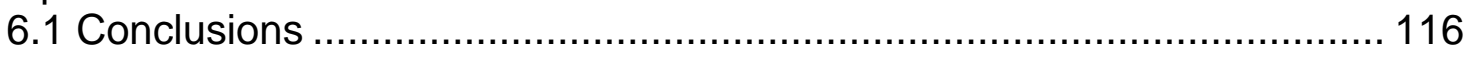

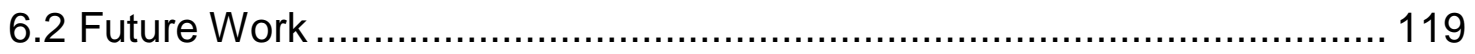

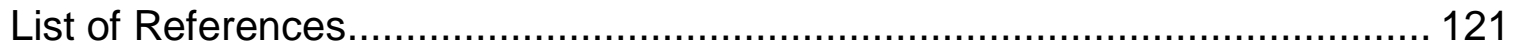

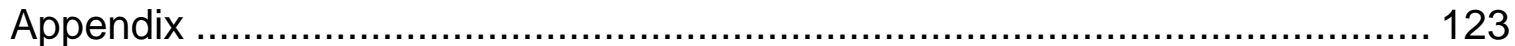

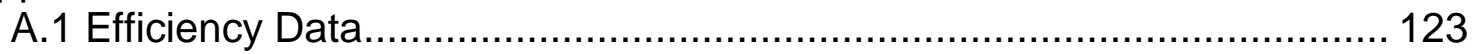

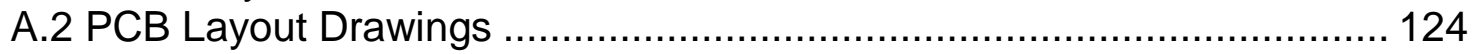

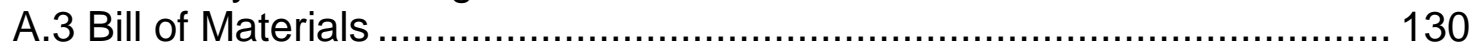




\section{LIST OF TABLES}

Table 2-1. Comparison of DC-to-DC conversion types [19] ........................ 13

Table 3-1. Design Requirements ........................................................... 58

Table 4-1. Summary of Simulation Results ............................................... 84

Table 5-1. Guidelines for PCB trace widths for different currents [3] ................ 86

Table 5-2. Hardware testing equipment............................................. 101

Table 5-3. Load regulation data.......................................................... 105



Table 5-5. Inductor current sharing ...................................................... 111

Table 5-6. Summary of hardware results.............................................. 114

Table 6-1. Comparison of results with previous multiphase projects [15][24] ... 117

Table A-1. Efficiency data............................................................... 123

Table A-2. Bill of materials (BOM) ....................................................... 130 


\section{LIST OF FIGURES}

Figure 1-1. History of number of transistors on a chip (Moore's Law) [6] ............. 1

Figure 1-2. Increasing power requirements for microprocessors [19] .................. 2

Figure 1-3. Voltage and current requirements for microprocessors [6] ................ 2

Figure 1-4. Optimization process for new design.............................................. 3

Figure 2-1. Circuit representation of a linear regulator ................................... 8

Figure 2-2. Basic switching regulator circuit .............................................. 9

Figure 2-3. Pulsed output of switching regulator......................................... 9

Figure 2-4. Zero-current switching resonant buck converter ........................... 11

Figure 2-5. Resonant waveforms for the ZCS buck converter ........................ 12

Figure 2-6. Magnitude and phase plots for control stage of converter [22] ........ 17

Figure 2-7. Typical input current waveform in a buck converter [9] ................... 18

Figure 2-8. Input capacitor voltage and current waveforms [2] ....................... 19

Figure 2-9. Normalized input capacitor current ripple for one to six phases [21] 20

Figure 2-10. LC Filter with RC damping ........................................................ 21

Figure 2-11. Gain plot of LC filter with RC damping [19] ............................... 22

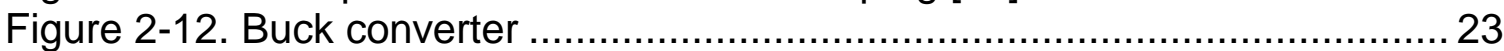

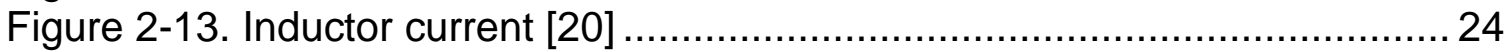

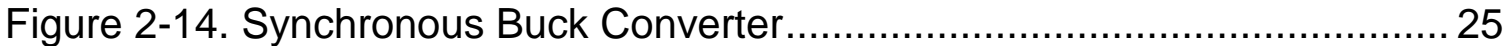

Figure 2-15. Equivalent circuit of a real capacitor..........................................26

Figure 2-16. Model for the heat flow of a typical power MOSFET .................... 29

Figure 2-17. Multiphase Buck converter ...................................................... 32

Figure 2-18. Phase pulse waveforms and composite ................................... 33

Figure 2-19. N-phase multiphase buck converter ............................................34

Figure 2-20. Inductor current of individual phases and their sum ..................... 35

Figure 2-21. Normalized current ripple factor for one to six phases [21] ............ 37

Figure 2-22. Output capacitor current waveform [20] .....................................38

Figure 2-23. Peak and average PWM signals with duty cycle extension [26] ..... 39

Figure 2-24. Proposed ZVS self-driven 12V VR [26] ..................................... 40

Figure 2-25. Self-driven topology modes of operation, (a) mode 1,

(b) mode 2, (c) mode 3, and (d) mode 4 [26] ......................................... 41

Figure 2-26. Basic coupled-buck converter [25] ........................................ 43

Figure 2-27. Multiphase tapped-inductor buck with active clamp [25] ............... 44

Figure 2-28. Coupled buck topology modes of operation, (a) mode 1,

(b) mode 2, (c) mode 3, and (d) mode 4 [25] ........................................ 45

Figure 2-29. Block diagram of two-stage operation ......................................4 47

Figure 2-30. Two stage multiphase converter [6]....................................... 47

Figure 3-1. Interleaving multiphase DC-DC converter with input LC filter........... 49

Figure 3-2. Block diagram of four phase operation....................................... 50

Figure 3-3. Non-Ideal Buck Converter .........................................................51

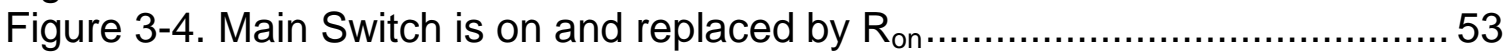

Figure 3-5. Main switch is off, synchronous switch is on and replaced by $R_{0 n} \ldots .54$

Figure 3-6. Buck converter then the main switch is off ..................................5 56

Figure 3-7. Buck converter then the main switch is on .................................. 57

Figure 3-8. Theoretical Efficiency plot versus load current ................................ 68 
Figure 3-9. Theoretical power loss plot versus load current ............................69 69

Figure 4-1. Open-Loop schematic of proposed multiphase buck converter........ 71

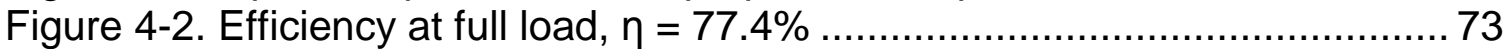

Figure 4-3. Output voltage and current waveforms at full load ....................... 74

Figure 4-4. Output voltage peak-to-peak ripple at full load, $\mathrm{V}_{\mathrm{pp}}=483.9 \mu \mathrm{V} . \ldots \ldots . . .75$

Figure 4-5. Inductor current through phase 1, phase 3, and their sum (L6)........ 76

Figure 4-6. Inductor current through phase 2, phase 4, and their sum (L7) ........76

Figure 4-7. Inductor current through phase $1-4$, showing interleaving .............77

Figure 4-8. Output current showing ripple .................................................. 78

Figure 4-9. Input voltage and current waveforms ....................................... 79

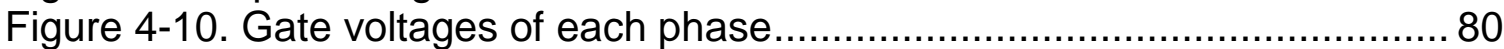

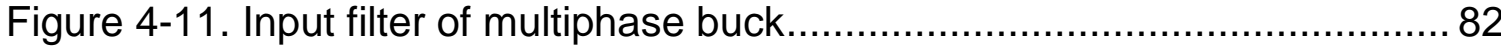

Figure 4-12. Frequency response of input LC filter................................... 83

Figure 5-1. TPS40090 pin out and functional block diagram [22] ................... 88

Figure 5-2. Technique used for inductor current sensing ............................... 90

Figure 5-3. Input stage and PWM controller schematic ...................................94

Figure 5-4. Drivers and switches schematic ................................................ 95

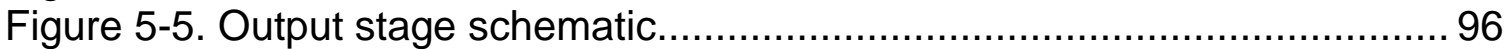

Figure 5-6. Silk screen showing components ...............................................97

Figure 5-7. Side view of interleaving multiphase buck converter....................... 98

Figure 5-8. Top view of interleaving multiphase buck converter .......................98

Figure 5-9. Zoomed in top view showing control and power stages ..................99

Figure 5-10. Block diagram of test setup for hardware results ....................... 101

Figure 5-11. Efficiency versus output current plot....................................... 102

Figure 5-12. Power loss versus output current plot .................................... 103

Figure 5-13. Average output voltage and output peak-to-peak ripple .............. 104

Figure 5-14. PWM signals: phase 1 with (a) phase 2 (b) phase 3 and

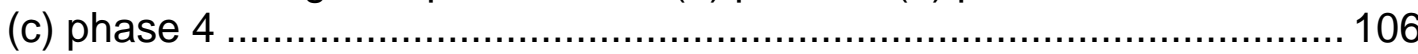

Figure 5-15. Excel composite of PWM signals .......................................... 107

Figure 5-16. Inductor currents ............................................................... 109

Figure 5-17. Phase 1 PWM signal with (a) phase 1 (b) phase 2 (c) phase 3 and $(d)$ phase 4 inductor currents....................................................... 109

Figure 5-18. Excel composite of inductor currents...................................... 110

Figure 5-19. Transient response to changing loads................................... 112

Figure 5-20. Input voltage ripple with (a) LC filter and (b) electrolytic capacitor 113

Figure A-1. Top Layer...................................................................... 124

Figure A-2. Inner Ground Layer........................................................ 125

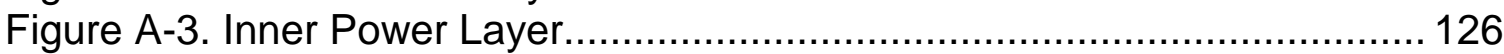

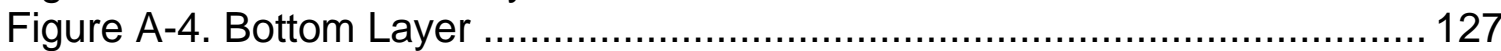

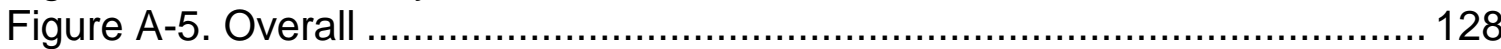

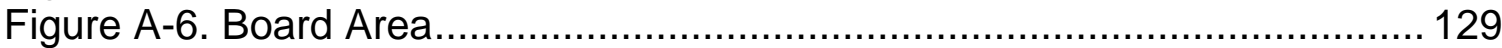




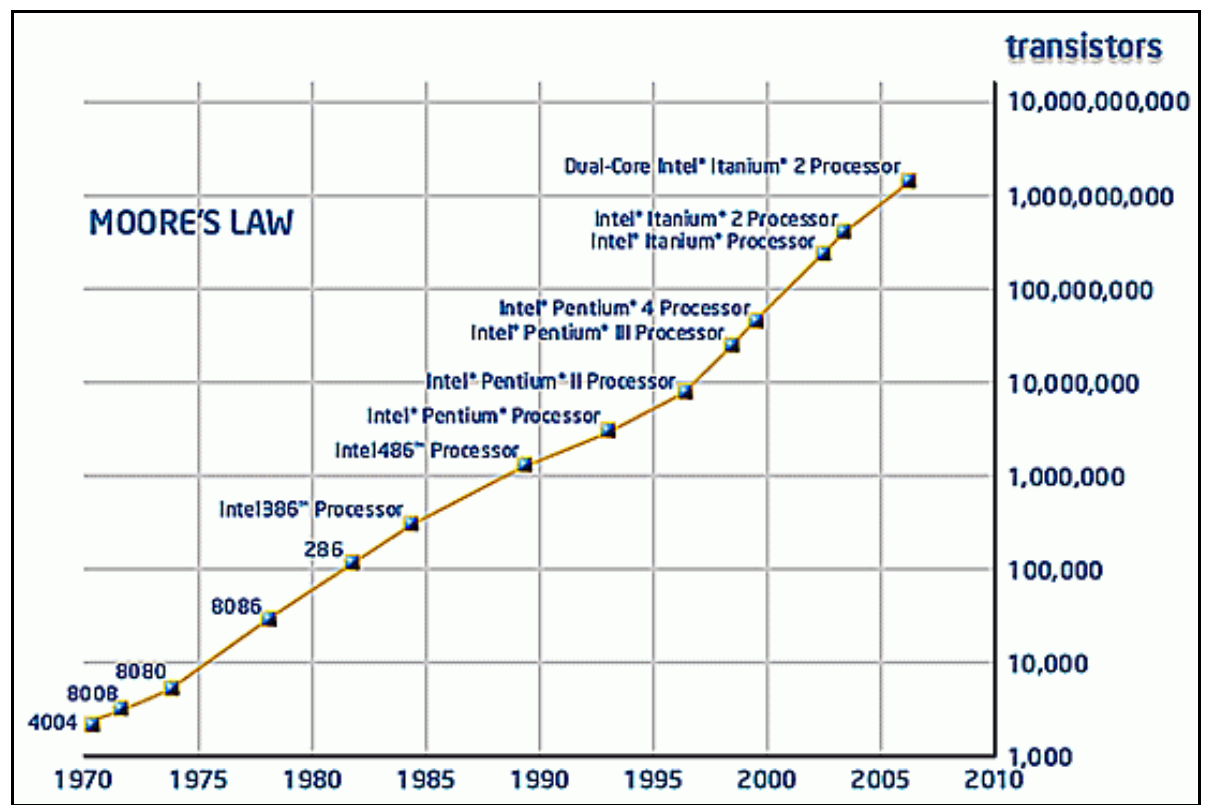

Figure 1-1. History of number of transistors on a chip (Moore's Law) [6]

The prediction that Gordon L. Moore made in a 1965 paper, known today as Moore's Law, that the number of transistors on a chip will double every 18 months is one that has continued to agree with the historical data, see Figure 11. Moore simply made an observation and predicted the way he saw the semiconductor business heading into the future. Since it is not a physical law, it does not have to continue on this trend forever. One possible deviation from the historical trend of the number of transistors per-chip may result from the ever so difficult task of powering these microprocessors [6]. For example, the average power per transistor for a Pentium chip today is approximately $1.3 \mu \mathrm{W}$. This small amount of power becomes a relatively large problem because the number of transistors on a chip has already surpassed 1 billion. The current power requirements are around 200 watts for a single microprocessor, see Figure 1-2 for past and future power requirements of microprocessors [19]. 


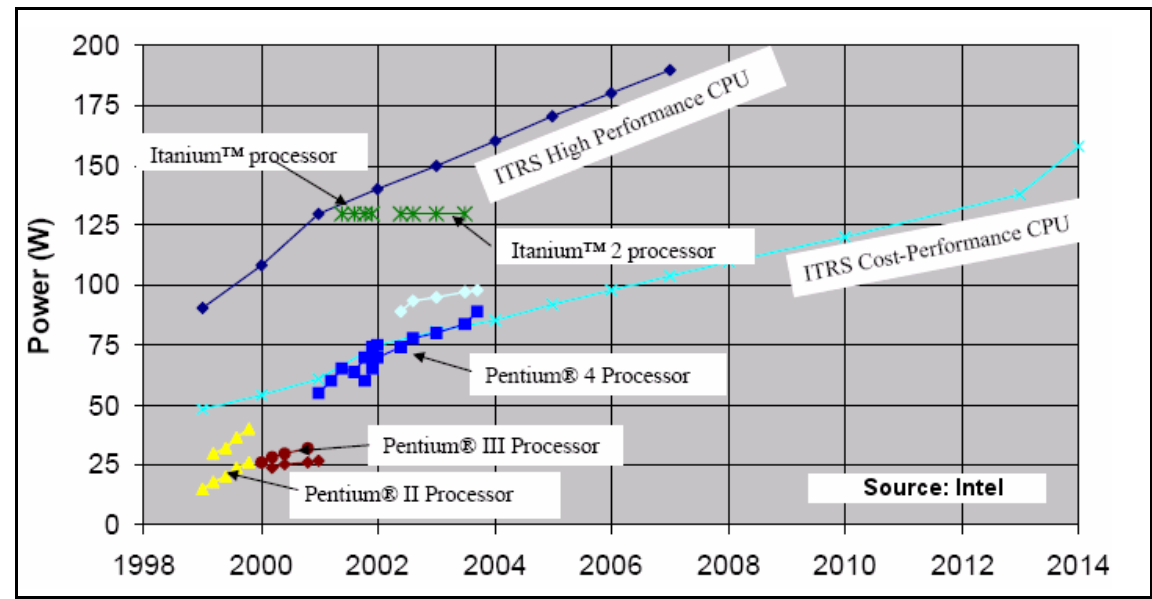

Figure 1-2. Increasing power requirements for microprocessors [19]

The increasing power requirements, however, do not tell the whole story. In order to understand the real challenge we have to look at the current and voltage requirements as well. In order to reduce power consumption of transistors, a lower voltage is needed. The voltage is currently on the order of 1V. Taking into account the increasing power requirements for future microprocessors with the reduction in voltage $\left(\mathrm{V}_{\mathrm{cc}}\right)$, the current must therefore increase. For high performance CPUs, currents are presently upwards of 230A increasing into the range of $270 \mathrm{~A}$ in 2010 as shown in Figure 1-3 [19].

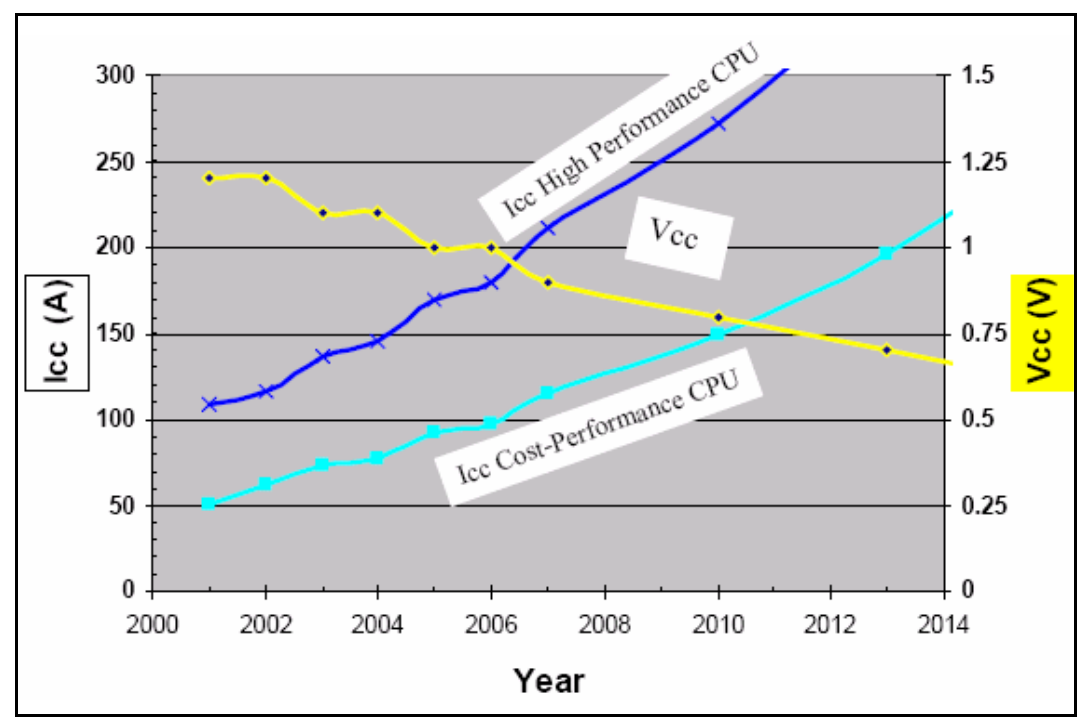

Figure 1-3. Voltage and current requirements for microprocessors [6] 
If these requirements were not tough enough, it is also required that the solution has high current density and high efficiency. Finally, it should have fast transient response and react quickly to adjust for changing load conditions.

Like any other design solution, there is not a single correct answer but a multitude of solutions that make tradeoffs between the key requirements. For the microprocessor power supply, the optimum design solution should effectively balance efficiency, size, and cost, see Figure 1-4.

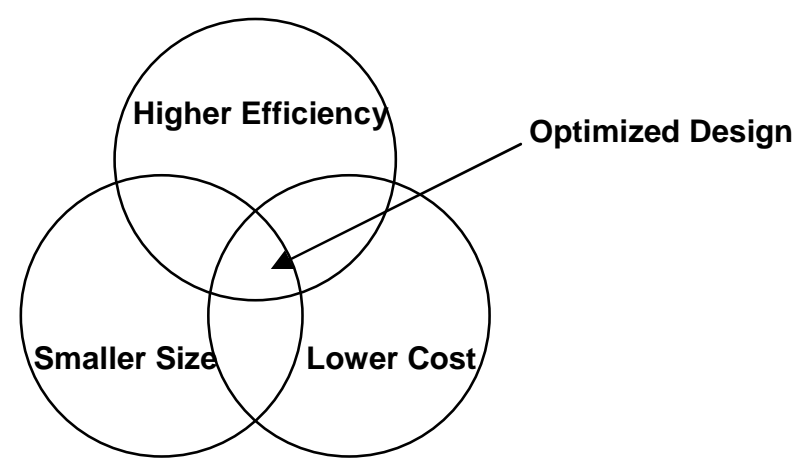

Figure 1-4. Optimization process for new design

The solution to this problem is solved by a creative use of buck converters that are placed in parallel with their control signals offset by a phase angle, or commonly known today as a multiphase Voltage Regulator Module (VRM).

The main challenge to the designers for voltage regulator modules of future microprocessors is creating a high-efficiency, high current density, and low cost solution to the ever changing and more demanding requirements of microprocessors. Typically, present VRMs will take a $12 \mathrm{~V}$ input and convert it to $1 \mathrm{~V}$ at some high current such as $100 \mathrm{~A}$. However, the trend has been that the output voltage is moving towards smaller and smaller levels, down to sub-volts 
such as $0.75 \mathrm{~V}$ with increased power consumption and even higher currents. These requirements pose a number of problems. The transfer function of an ideal buck converter is $V_{\text {out }}=D V_{\text {in }}$, where $D$ is the duty cycle of the main switch. If the input voltage remains constant at $12 \mathrm{~V}$ and the output voltage is becoming smaller, the duty cycle will decrease as well. A duty cycle of $D=V_{\text {out }} / V_{\text {in }}=$ $1 \mathrm{~V} / 12 \mathrm{~V}=8.3 \%$ means that the main switch of the buck converter is on for only $8.3 \%$ of the period, while the synchronous switch is on for $91.7 \%$ of the period. This vast discrepancy leads to many problems and losses in efficiency [6].

Many papers have been written over the past few years that attempt to solve the problems that multiphase interleaving technology has yet to eliminate. Examples of issues that need to be addressed are duty cycle extension, improvements in transient response, optimizing the current ripple in each channel of both the input and output currents, and raising the switching frequency $[6][26][1][25]$.

This thesis project is a continuation of initial designs done by two former Cal Poly students, Kay Ohn and lan Waters. Both students performed initial simulation, design, and testing of a prototype board capable of supplying $1 \mathrm{~V}$ at 40A. The first attempt by these students had several limitations regarding the overall efficiency, input current waveform, and board size. This project aims to improve upon the previous designs by making several changes that take into consideration and address these limitations [15][24].

The remainder of this thesis report will cover the following topics: background material, analysis of the proposed multiphase topology, simulation 
results, hardware results, and recommendations for the future work on this project.

The second chapter contains the background material for this thesis and it covers a wide variety of topics. It starts with a basic overview of power converters and then dives into the details of DC-to-DC converts and covers all the stages of operation for these converters. The input stage and waveform are key for this thesis and there a section in the background material dedicated towards further explaining it. The background material also covers the basic buck and synchronous buck converters. We will take a look at real world considerations that must be addressed when making an operational circuit, issues namely with real capacitors, real switches, and thermal considerations with the parts chosen for the design. The final major topic of the background section thoroughly explains the multiphase buck converter. A subsection of the multiphase buck converter is a literature review that is the result of research that was conducted to determine the current state of development in the field of multiphase buck converters. Three different circuits were chosen and analyzed in this section.

The third chapter contains the design equations and analysis used to develop the proposed multiphase buck converter. In this chapter the operation of the circuit is fully explained and all of the design equations used are shown in full. This chapter also contains the design requirements and the selection of key components, such as MOSFETs and controllers. 
The fourth and fifth chapters show the results for the simulation and hardware portions of the project respectfully. In each case, how the data was gathered and conclusions that can be drawn from this data are fully explained. In each case there is a summary of the results. Specifically for the hardware section, more detail is given in explaining the process of creating the printed circuit board, selecting key control components for the circuit, and specifics for how different hardware tests were run.

The sixth and final chapter of the report contains conclusions and recommendations for future work on this project. The results of this thesis show that the objectives were accomplished, but only to a limited degree. The efficiency was improved, but needs to be improved to a greater extent. The input current was improved (especially with the simulation) but the results did not entirely transfer over to the real circuit. The board size requirement was accomplished, but the board could be made even smaller by using two gate drivers instead of four, or better yet a controller IC that has integrated gate drivers. Importantly, the improvements in the circuit did not come at the cost of any of the previous successes for this project, namely line regulation, load regulation, and transient response. Those attributes were again excellent with this circuit. 


\section{ChAPTER 2. BACKGROUND}

\subsection{Overview of Power Electronics}

Power electronics is the technology dealing with the efficient conversion, transfer, and control of energy. Devices such as these can be found almost everywhere. The four types of power conversion are:

- AC-to-AC

- AC-to-DC

- DC-to-AC

- DC-to-DC

Since this thesis project only deals with DC-to-DC conversion, the specifics of AC-to-AC, AC-to-DC, and DC-to-AC will not be covered in any sort of depth in the report. The basic idea behind these types of conversion is controlling the transfer of energy through the use of solid-state switches such as diodes and thyristors. For the remainder of the report, exclusively DC-to-DC converters and specifically buck converters and variations will be discussed and analyzed [20].

\subsection{The DC-to-DC Converter}

In general, when selecting a conversion topology several important issues must be considered. The cost, size, power, noise tolerance, battery life, and time to market are all factors that must be addressed before selecting a topology. The three major types of DC-to-DC conversion are:

- Linear type (linear regulator)

- Pulse-width modulation (PWM)

- Resonant switching (soft-switching)

Each will be discussed in detail in the following subsections [20]. 


\subsubsection{Linear Regulator}

The simplest and most cost effective option is the linear type converter. The basic circuit is shown in Figure 2-1.

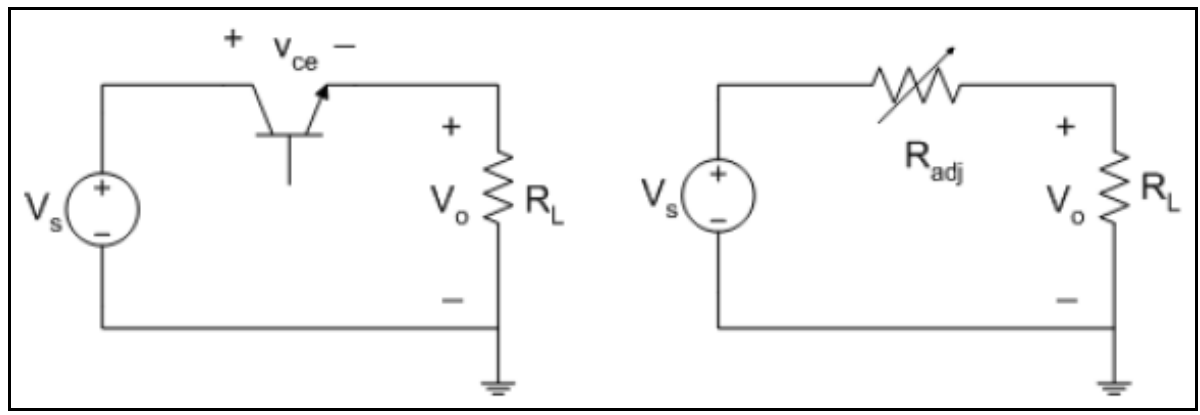

Figure 2-1. Circuit representation of a linear regulator

A linear regulator works like a voltage divider, with the output equaling:

$V_{o}=V_{s}-V_{c e}$ where $V_{o}$ is the output voltage, $V_{s}$ is the supply voltage, and $V_{c e}$ is the voltage across the transistor. By changing $\mathrm{V}_{\text {ce }}$, which is controlled by the base current of the BJT, the output voltage can be maintained at a constant voltage even with changing loads. It has very quiet operation as well as fast dynamic load response because it does not use switching. The linear regulator is little more than a fancy voltage divider and as such it has several key disadvantages. First, the circuit only works well when the input and output voltages are close in value. If their values are far apart, the regulator suffers from poor efficiency. The efficiency of a linear regulator is typically in the $35 \%$ to $50 \%$ range and its losses are dissipated as heat. The second main disadvantage is that the output voltage must be lower than the input voltage. The linear type regulator works great for some applications; however another option which is smaller and has fewer losses is the pulse-width modulated type regulator [19]. 


\subsubsection{Pulse-Width Modulation}

Pulse-width modulation (PWM) is a fancy name for switching regulator, the basic switching regulator circuit is shown in Figure 2-2.

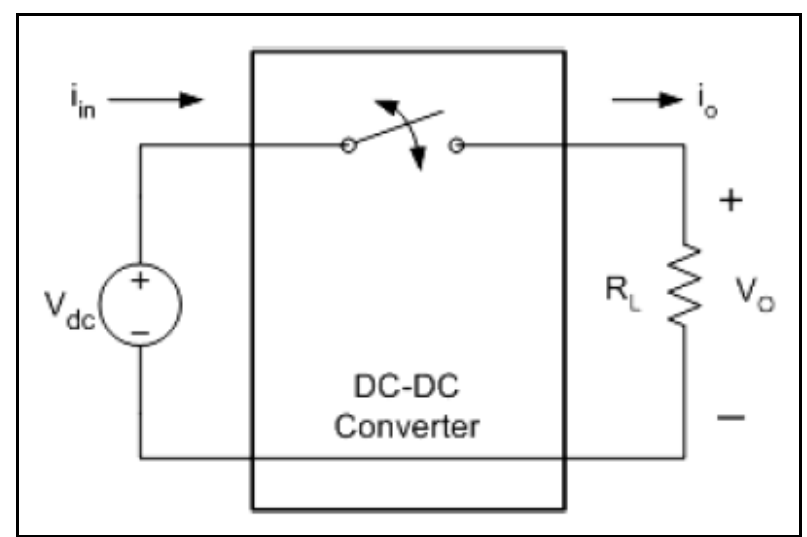

Figure 2-2. Basic switching regulator circuit

Either the switch is fully on and the output voltage is equal to the input voltage, or the switch is fully off and the output voltage is equal to zero. The switch is periodically opened and closed resulting in a pulsed waveform that when the average value is taken, it gives the output voltage which is shown in Figure 2-3.

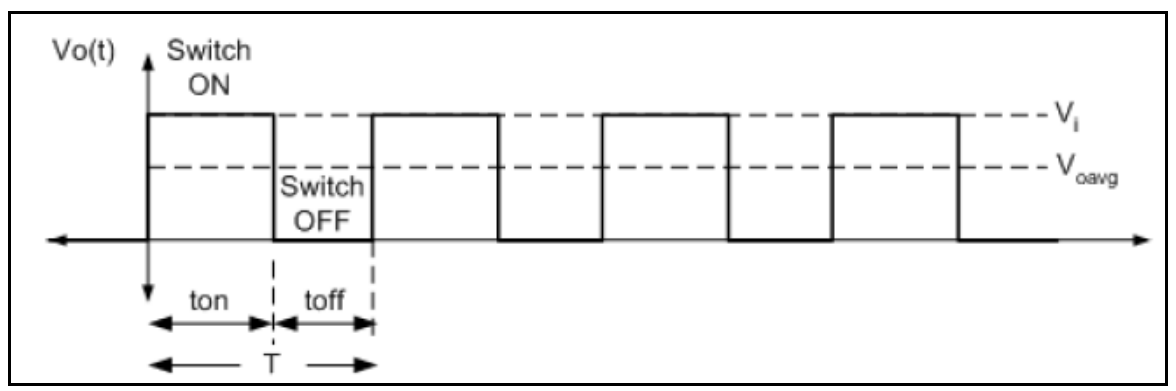

Figure 2-3. Pulsed output of switching regulator

Some of the parameters used to describe a switching regulator are switching frequency and duty cycle. The duty cycle (D) has the following relationship that is related to either the period $(T)$ or the switching frequency 
$\left(1 / T=f_{s}\right)$ and the on-time of the switch $\left(t_{o n}\right)$.

$$
D=\frac{t_{\text {on }}}{t_{\text {on }}+t_{\text {off }}}=\frac{t_{\text {on }}}{T}=t_{\text {on }} f_{s}
$$

The average output voltage is found by integrating the waveform in Figure 2-3 over one period as shown:

$$
V_{o}=\frac{1}{T} \int_{0}^{T} v_{o}(t) d t=\frac{1}{T} \int_{0}^{D T} V_{i} d t=V_{i} D
$$

The average output current is found using Ohm's law and the result from equation (2-2) as shown:

$$
I_{o}=\frac{V_{o}}{R}=\frac{V_{i} D}{R}
$$

A PWM uses switches operating at high frequency to efficiently transfer energy from one voltage to the next. Operating at a high frequency (in the $\mathrm{kHz}$ to $\mathrm{MHz}$ range) allows for the use of smaller components, but has the negative effect of adding noise to the system. The switching also contributes to a much higher efficiency (typically $70 \%$ to $85 \%$ ) but suffers from a slower dynamic load response. PWM regulators are more complicated than the linear type and require longer engineering development time increasing their cost. It is quite evident that PWM leads to a smaller and more efficient regulator, as compared to the linear type, but if noise reduction and efficiency are a premium in a system then another regulator type should be chosen [20]. 


\subsubsection{Resonant Converter (Soft-Switching)}

A resonant switching power supply (or soft-switching) attempts to eliminate switching losses (Power $=$ Voltage $\times$ Current while switching). This is accomplished by using a resonant circuit using either a series or parallel combination of a capacitor and an inductor. Without going into too much detail, the capacitor voltage and inductor current will be in the form of sines and cosines meaning they oscillate and reach zero naturally. An example to illustrate this point will involve the zero-current switching (ZCS) resonant buck converter shown in Figure 2-4.

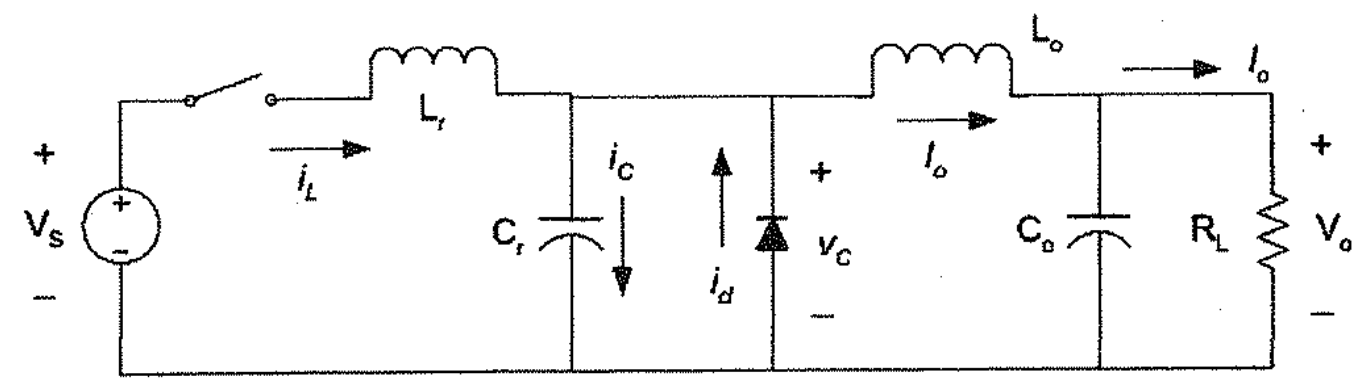

Figure 2-4. Zero-current switching resonant buck converter

The resonant inductor and capacitor, $L_{r}$ and $C_{r}$ respectfully, are added to the standard buck topology as shown in Figure 2-4. With this addition, the resonant inductor current and resonant capacitor voltage will go to zero naturally as shown in Figure 2-5. 


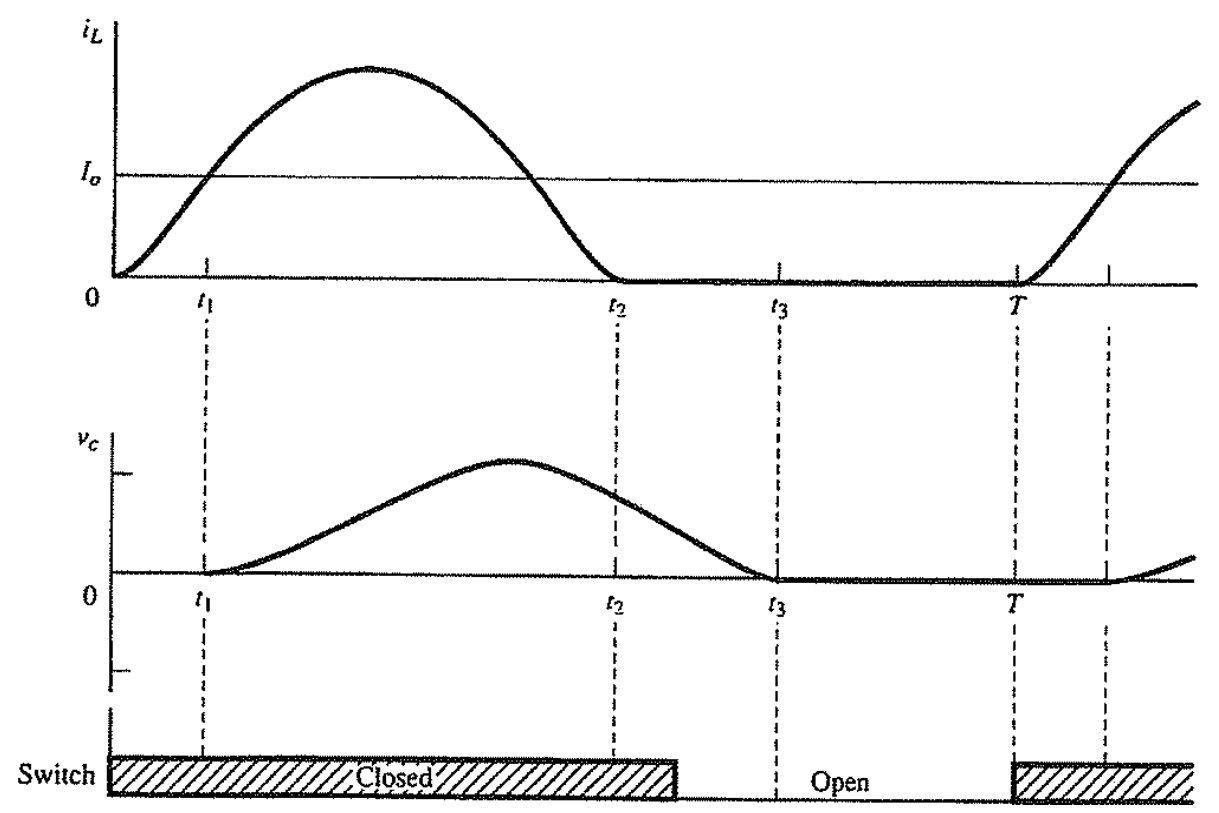

Figure 2-5. Resonant waveforms for the ZCS buck converter

Again without going into too much detail, because the main switch and the resonant inductor are in series they share the same current. It is now easy to see that if the switch is turned on or off anytime in which the resonant inductor current is zero, switching will occur at zero current and hence without any power loss [18].

This method also dramatically reduces noise because switch voltages and currents are not forced to be on or off as is the case with PWM. The result is an improvement in efficiency (to the mid 90 percent range), a reduction in noise, a design with even higher switching frequency (higher than PWM), but has long development time leading to a high cost design. A summary of the three basic types of converters is shown in Table 2-1. 


\begin{tabular}{|l|c|c|c|}
\hline & $\begin{array}{c}\text { Linear } \\
\text { Regulator }\end{array}$ & $\begin{array}{c}\text { PWM } \\
\text { Converter }\end{array}$ & $\begin{array}{c}\text { Resonant } \\
\text { Converter }\end{array}$ \\
\hline Cost & Low & High & Highest \\
\hline Weight & High & Low-Medium & Low-Medium \\
\hline RF Noise & None & High & Medium \\
\hline Efficiency & $35 \%-50 \%$ & $70 \%-85 \%$ & $78 \%-92 \%$ \\
\hline Multiple Outputs & No & Yes & Yes \\
\hline Development Time & 1 week & 8 months & 10 months \\
\hline
\end{tabular}

Table 2-1. Comparison of DC-to-DC conversion types [19]

\subsubsection{Power Supply Design Specifications}

The design specifications for a power supply are the performance goals for the converter to meet in order to be considered a properly operating regulator. Measurements are typically taken in the areas of input voltage, input current, output voltage, and output current. For the input voltage the key parameters are: $V_{\text {in(nom) }}$ the nominal (typical) input voltage, $V_{\text {in(Low) }}$ the lowest anticipated input voltage, and $V_{\text {in(High) }}$ the highest anticipated input voltage. For the input current the key parameter is $\mathrm{l}_{\text {in }(\operatorname{Max})}$ the maximum input current. For the output voltage the key parameters are: $V_{o(\text { rated })}$ the nominal (typical) output voltage, $V_{o(\text { Min })}$ the load should be turned-off if output voltage drops below this threshold, $\mathrm{V}_{\mathrm{o}(\mathrm{Max})}$ the highest allowable output voltage, and $\mathrm{V}_{\mathrm{o} \text { (ripple) }}$ the output voltage peak-to-peak ripple. For the output current the key parameters are: $I_{o(\text { rated })}$ the average maximum current that will be drawn at the output and $\mathrm{I}_{\mathrm{o}(\mathrm{Min})}$ the minimum current that will be drawn at the output [19].

Other important system parameters are transient response time (also called dynamic load response time), load regulation, line regulation, and overall efficiency. Transient response time is a measure of the time it takes for the voltage regulator to recover to within output voltage limits from a step change in 
the load. Load regulation is a measure of the system's ability to maintain the proper output voltage while the load is changing. Measurements are made for the output voltage during full-load (sometimes $90 \%$ load) and no-load (sometimes $10 \%$ load) and used to find the load regulation as shown:

$$
\text { Load Regulation }=\frac{V_{o(\text { Full_Load })}-V_{o(\text { No_Load })}}{V_{o(\text { Full_Load })}} \times 100 \%
$$

Line regulation is a measure of the system's ability to maintain the proper output voltage while the input voltage is changing. Measurements are made for the output voltage during highest input, lowest input, and nominal input voltages. Line regulation is calculated as shown:

$$
\text { Line Regulation }=\frac{V_{o(\text { High_Input })}-V_{o(\text { Low_Input })}}{V_{o(\text { nominal_input })}} \times 100 \%
$$

The overall efficiency of a system determines the amount of power that is dissipated in the components of the system and can be a good indication if a heatsink will be required (more on heatsinks in section 2.7) [18]. The overall efficiency is a measure of the average output power divided by the average input power as shown:

$$
\text { Efficiency }=\eta=\frac{P_{\text {out }}}{P_{\text {in }}} \times 100 \%
$$




\subsubsection{Switching Power Supply Components}

Although there are different types of DC-to-DC converters, each type can be broken down into several different stages, each with a different role in the system. The four basic components of a switching power converter are:

- Input stage

- Power stage

- Control Stage

- Output Stage

The input stage will be discussed in great detail in section 2.3 but its primary goal is for filtering noise. An electromagnetic interference (EMI) filter and storage capacitor is often used at the input stage. The EMI filter typically consists of a small LC filter which acts to block both high frequency noise from passing from the source to the circuit and high frequency switching noise from the input current back to the source. A storage capacitor is also used at the input and is typically made up of an electrolytic or tantalum capacitor. It stores high and low frequency energy and delivers high-frequency current when needed by the supply [2].

The power stage differs from circuit to circuit based on system requirements, but it typically consists of difference combinations of switches, diodes, and inductors. The buck converter, the synchronous buck, and the multiphase buck (sections $2.4,2.5$, and 2.8 respectively) are all examples of different power stages. Details on these power stages will be discussed further in each of their respective sections [20]. 
The control stage is centered on the integrated circuit (IC) controller that is used in a real world circuit. It is connected to the gate of the main switch and its goal is to maintain stable regulation of the output voltage by controlling the duty cycle of the switch. It accomplishes this task in a number of ways. The control stage has an error amplifier that amplifies the difference between the sensed output voltage (from the output stage) and the desired voltage (which is set by the user). The controller can either increase or decrease the duty cycle slightly to maintain the desired output voltage. Along with the error amplifier is compensation which used to ensure the output does not go into an unstable condition. Figure 2-6 shows how the addition of a compensation network affects the converter's overall gain. The goal of compensation is to create a linear relationship between the frequency and gain. Looking at the magnitude plot on the left in Figure 2-6, the solid line labeled modulator is the overall gain of the converter without compensation. The magnitude plot of the error amplifier, labeled EA, is used to offset the overall gain of the converter such that the sum of the modulator gain and EA gain yields a linear relationship between frequency and gain, which is desired. The phase plot on the right in Figure 2-6 is useful when actually performing the calculations for the error amplifier. For this thesis this calculation was not performed, so the phase plot is simply included for reference. One aspect to note is that just as the overall converter gain results in a linear relationship between gain and frequency, the overall converter phase results in a relatively flat relationship between frequency and phase. The control stage also has an oscillator that sets the switching frequency. Often the 
controller also has a soft-start condition, which reduces the inrush current during startup [19].
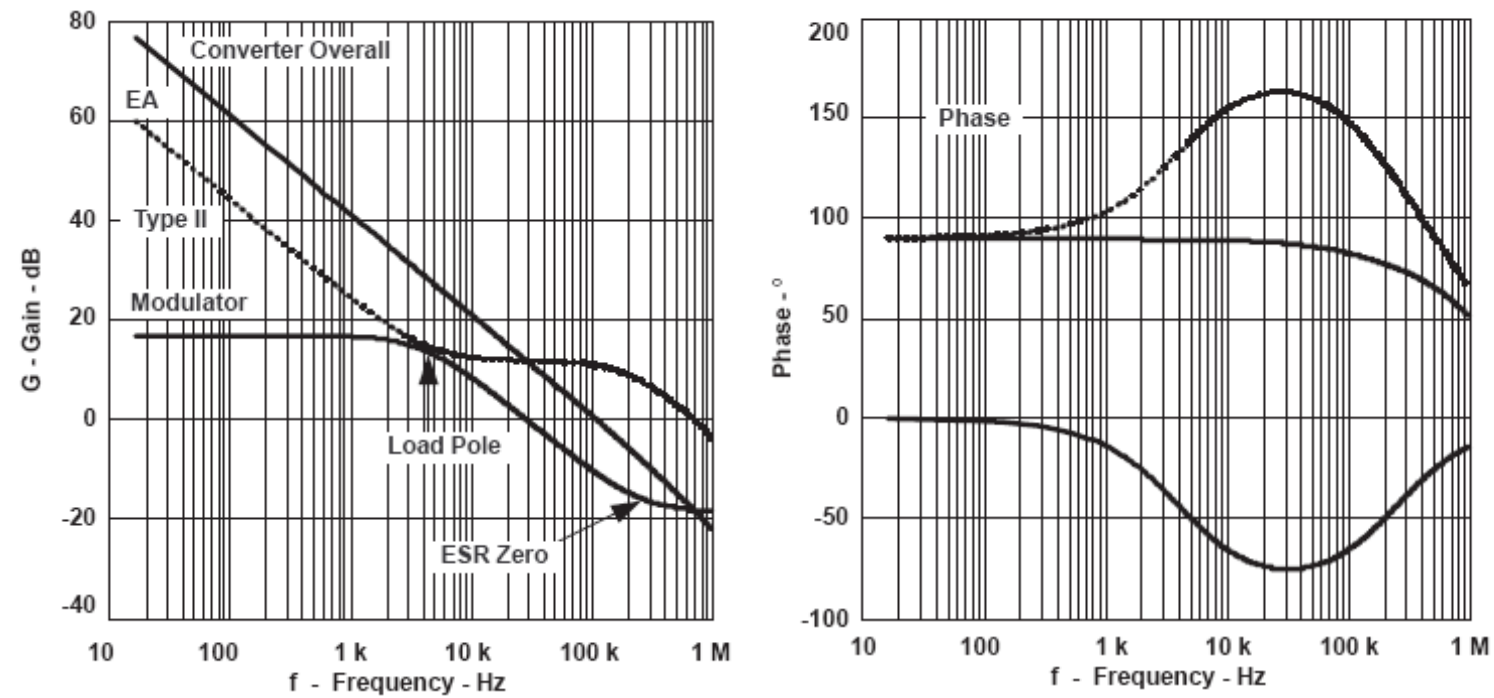

Figure 2-6. Magnitude and phase plots for control stage of converter [22]

The output and control stages work hand-in-hand to ensure proper circuit operation occurs. The first goal of the output stage is to filter the output voltage and reduce its ripple. It can also be used to store energy for the load during times when the switch is not conducting and the input is not connected to the output. The output stage often provides a current sensing element that can be used to find the output current. This signal can then be amplified and fed back to the control stage as feedback. Voltage feedback is also an important role of the output stage and like current sensing it is fed back to the control stage and used to help accurately regulate the converter's output voltage [22].

Neither the control stage nor the output stage will be discussed in any further detail in the background section of the report. Their importance will come later in the hardware section, where the control aspects become very critical. 


\subsection{The Input Stage}

The input current for a single or multiphase buck converter is less than ideal. The input is connected in series with the switch causing the input current to go discontinuous and look similar to a square wave, see Figure 2-7 [9].
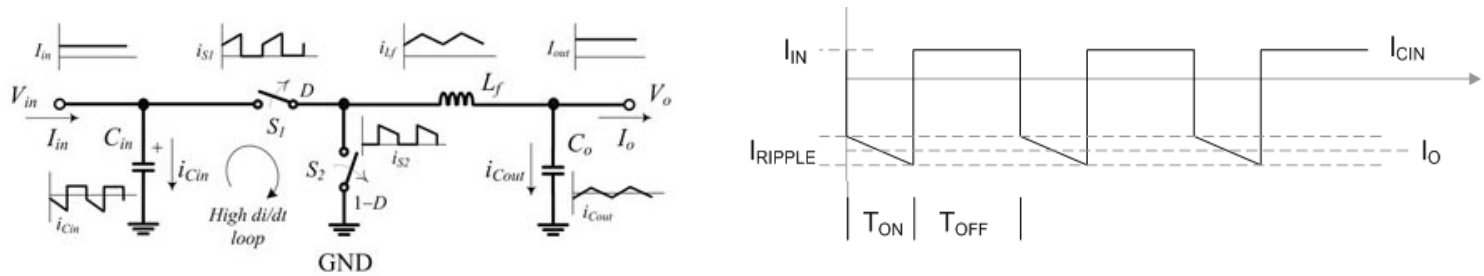

Figure 2-7. Typical input current waveform in a buck converter [9]

The input to the buck converter is a DC voltage, and the discontinuous input current introduces lots of electromagnetic interference (EMI) noise due to the large di/dt noise caused by the switch. The goal of an input filter is to attenuate the AC portion of the input power supply current. Passive filters are ideal for this instance because they have the characteristics of having identical forward and reverse attenuations. For the buck converter, both the noise from the source and the reverse noise from the switch must be attenuated, so a passive filter is optimum. Two types of input filters will be analyzed, the purely capacitive filter, and the LC filter with RC damping [19].

Starting with the purely capacitive filter, we will analyze the current and voltage waveforms of the input capacitor taking note that the total charge into the capacitor must be equal to the total charge leaving the capacitor. The input capacitor ripple voltage and current are shown in Figure 2-8. 


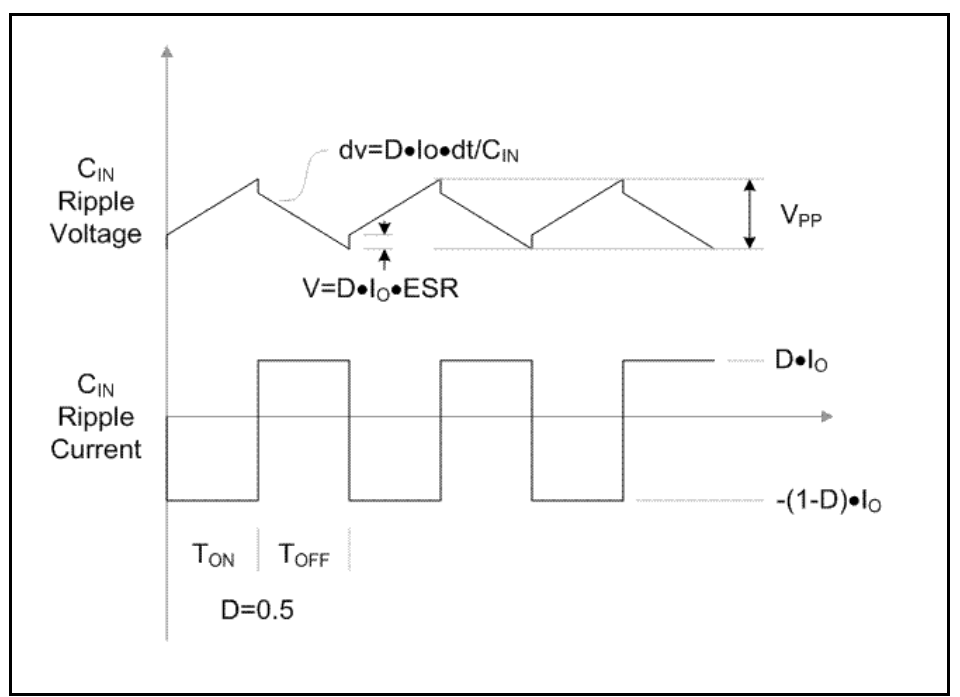

Figure 2-8. Input capacitor voltage and current waveforms [2]

Looking at Figure 2-8 and specifically the ripple voltage waveform, the following relationship can be found:

$$
V_{p p}=D I_{o}\left(E S R+\frac{1-D}{C_{i n} f_{s}}\right)
$$

Since the equivalent series resistance (ESR) will be very low and approximately equal to zero and accounting for the impact of the $\mathrm{N}$ phases, equation (2-7) can be rewritten to the following:

$$
V_{p p}=I_{o} \frac{D(1-D)}{C_{i n} N f_{s}}
$$

By rearranging equation (2-8) the minimum input capacitor size can be solved for:

$$
C_{i n(\min )}=I_{o} \frac{D(1-D)}{V_{p p(\max )} N f_{s}}
$$

Notice that in equation (2-8) the number of phases $(\mathrm{N})$ is in the denominator and results in an inverse relationship between ripple size and 
number of phases [2]. This phenomenon is known as the ripple calculation effect and uses the notation $\mathrm{K}_{\mathrm{CM} \_ \text {in }}$, see Figure 2-9 [23].

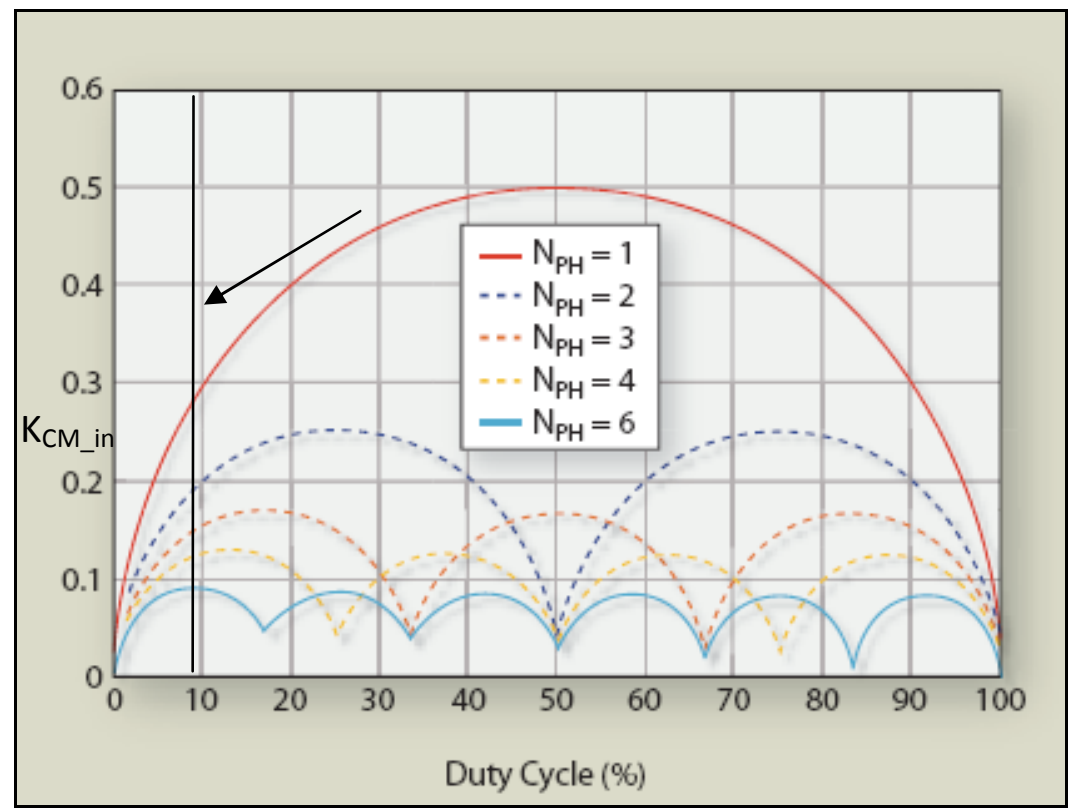

Figure 2-9. Normalized input capacitor current ripple for one to six phases [21]

Figure 2-9 shows the ripple cancellation factor for one to six phases. At higher phases the ripple factor is lower meaning the ripple will be more effectively reduced. Also notice that for each phase there are several locations where the ripple factor goes to zero, meaning that at those duty cycles there is no current ripple. Finally, notice the vertical line that had been added at about $8-9 \%$ duty cycle and the arrow which locates the point where the $\mathrm{N}_{\mathrm{PH}}=4$ portion of the graph crosses this vertical line. This indicates the ripple cancellation effect that is to be expected from our four phase converter, or approximately $\mathrm{K}_{\mathrm{CM} \_ \text {in }}=0.12$, indicating that the ripple should be low.

The other type of passive filter that will be explored is the LC with RC damping filter, which is shown in Figure 2-10. 


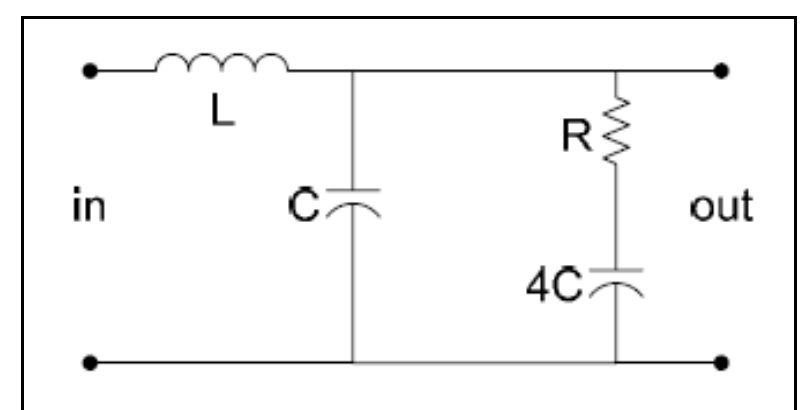

Figure 2-10. LC Filter with RC damping

A series $\mathrm{RC}$ network is placed in parallel with the $\mathrm{LC}$ filter because the $\mathrm{RC}$ network has the effect of reducing the $Q$ of the filter, which reduces peaking and the output impedance. The resistor $(\mathrm{R})$ causes the damping effect while the capacitor (4C) in series blocks the DC portion of the current. One unique aspect of this circuit has to do with the resistor and capacitor being in series. The chosen capacitor can have a high ESR as long as the sum of the ESR and the series resistance equal $R$ [19]. The transfer function of the LC filter with damping is shown:

$$
T(s)=\frac{1+4 R C s}{1+4 R C s+5 L C s^{2}+4 R L C s^{3}} \text { where } R=\sqrt{\frac{L}{C}}
$$


The gain plot of the filter is shown in Figure 2-11.

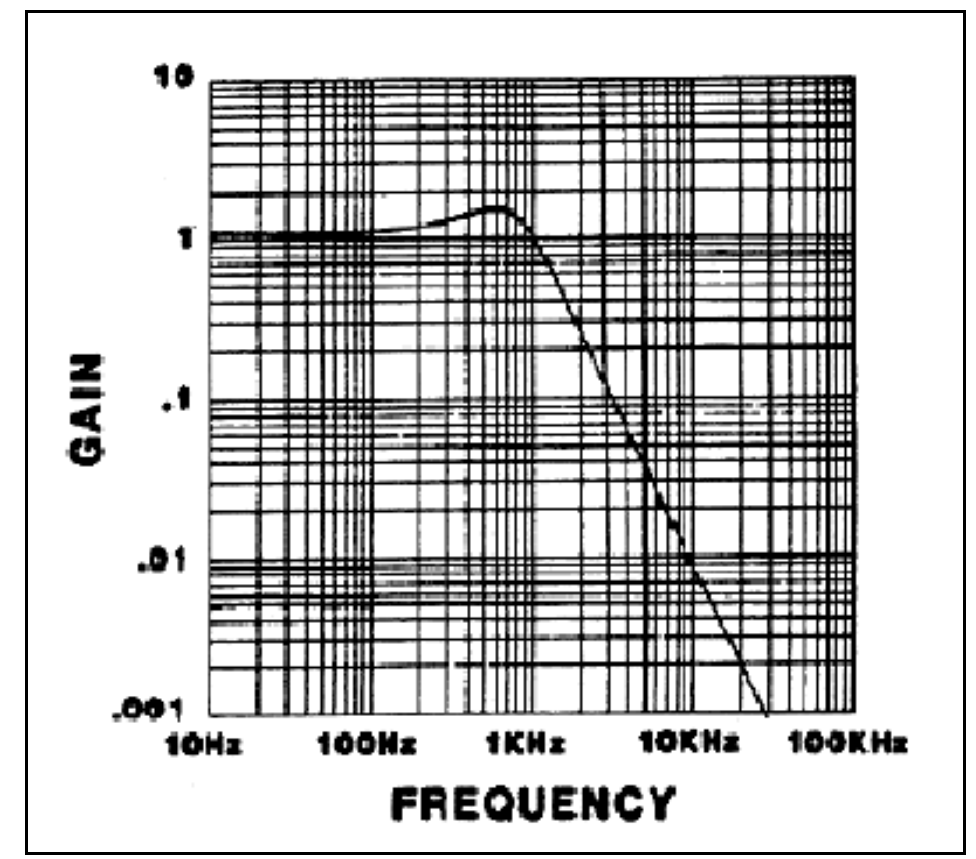

Figure 2-11. Gain plot of LC filter with RC damping [19]

The break frequency is equal to: $f_{o}=\frac{1}{2 \pi \sqrt{L C}}$ and rolls off at $-40 \mathrm{~dB} / \mathrm{dec}$ ade.

Filters are a very nice addition to a buck converter, but their positive contribution does come at a price. They are often large, heavy, and expensive, all of which are typically the opposite of an optimum design [19]. 


\subsection{The Buck Converter}

The most commonly used DC-to-DC converter topology is the buck converter or DC chopper. It is a circuit used to output a voltage that is lower than the input voltage. Figure 2-11 shows an ideal buck topology. It consists of a switch at the input, diode, inductor, output capacitor, and the load resistor.

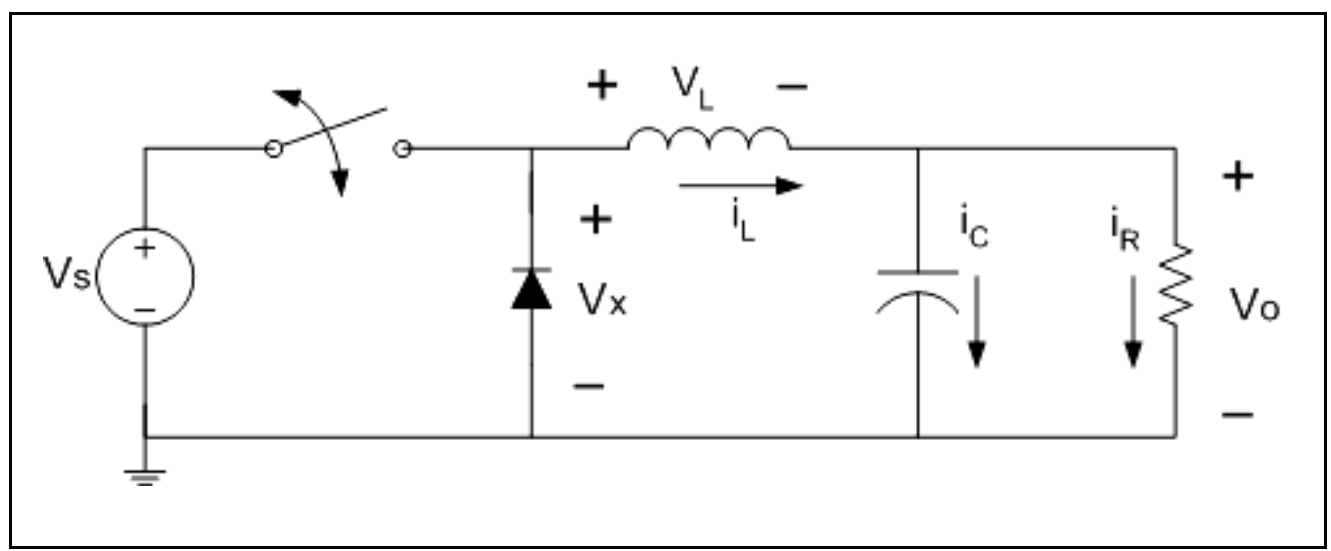

Figure 2-12. Buck converter

The operation of the buck is controlled by the switching period $\left(T_{s}\right)$ of the switch and the time the switch is turned on $\left(t_{o n}\right)$. The relationship between switch on-time and period is defined as the duty cycle (D) and is shown below.

$$
D=\frac{t_{o n}}{T_{s}}
$$

The relationship between input and average output voltage is directly proportional to the duty cycle as shown in the transfer function of the buck converter, equation (2-12).

$$
V_{o}=D V_{i}
$$

The basic operations of the buck converter are as follows. The switch turns on forcing the diode to turn off, this is called the on-time $\left(\mathrm{t}_{\text {on }}\right)$. The inductor is then charged and the inductor current $\left(i_{L}\right)$ increases linearly. Next, the switch 
turns off and the diode turns on, this is called off-time ( $\left.\mathrm{t}_{\text {off }}\right)$. Now the inductor discharges and $i_{L}$ decreases linearly. The inductor current is the same as the output current. The AC or ripple portion of the inductor current travels through the capacitor. From Figure 2-12 it can be seen that the inductor current is the same as the output current, that is to say that $i_{L}=i_{C}+i_{R}$. The average value of the inductor current is equal to the average value of the output current seen by the load. For further details see Figure 2-13 [16].

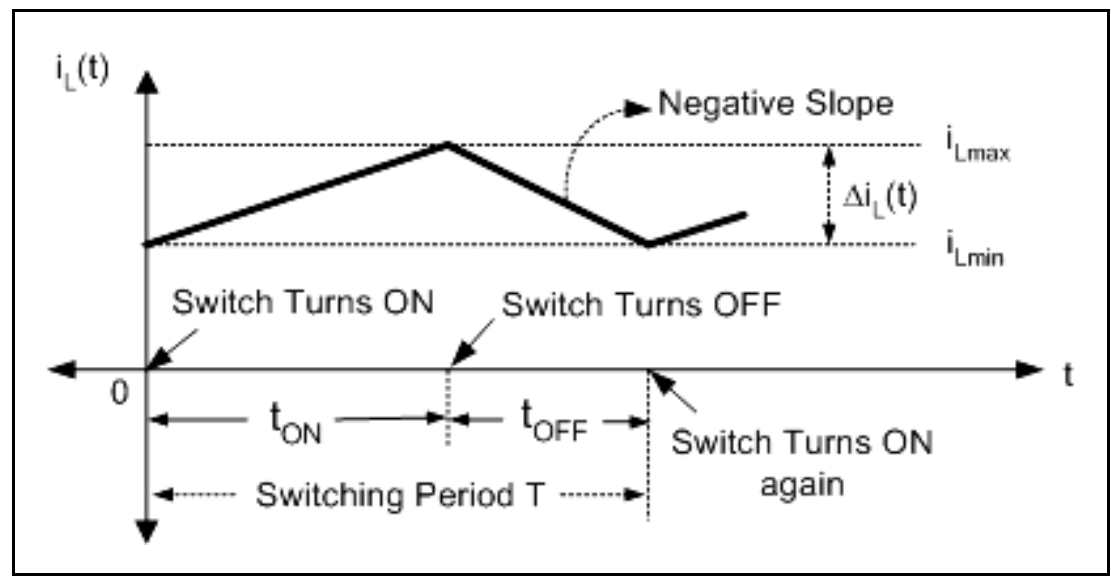

Figure 2-13. Inductor current [20]

\subsection{Synchronous Rectification}

As can be seen in the previous section, the freewheeling path during the energy transfer on the input side is typically through a Schottky diode. The diode turns on automatically when the main switch is turned off, and vice versa. A Schottky diode is typically used due to its very low forward voltage drop (approximately $0.15 \mathrm{~V}$ to $0.7 \mathrm{~V}$ ) and it has a very fast reverse recovery time (approximately 10ns to 100ns). For large output voltage applications the standard non-synchronous buck converter works great, but as power supply voltages continue to decrease, the forward voltage drop of the diode constitutes 
a larger portion of the output voltage. While using an output Schottky at a 2V output voltage, the efficiency is typically between 80 and 85 percent. When the output voltage is reduced to $1 \mathrm{~V}$, the efficiency degrades to less than 75 percent. As chapter 1 illustrates, the trend of future microprocessors is for the output voltage to continue to decrease to less than $1 \mathrm{~V}$. As such, a new method must be used to improve the degrading efficiency with the Schottky diode [18].

The solution to the proposed problem is using what is called synchronous rectification, which involves replacing the Schottky diode with another MOSFET, see Figure 2-14.

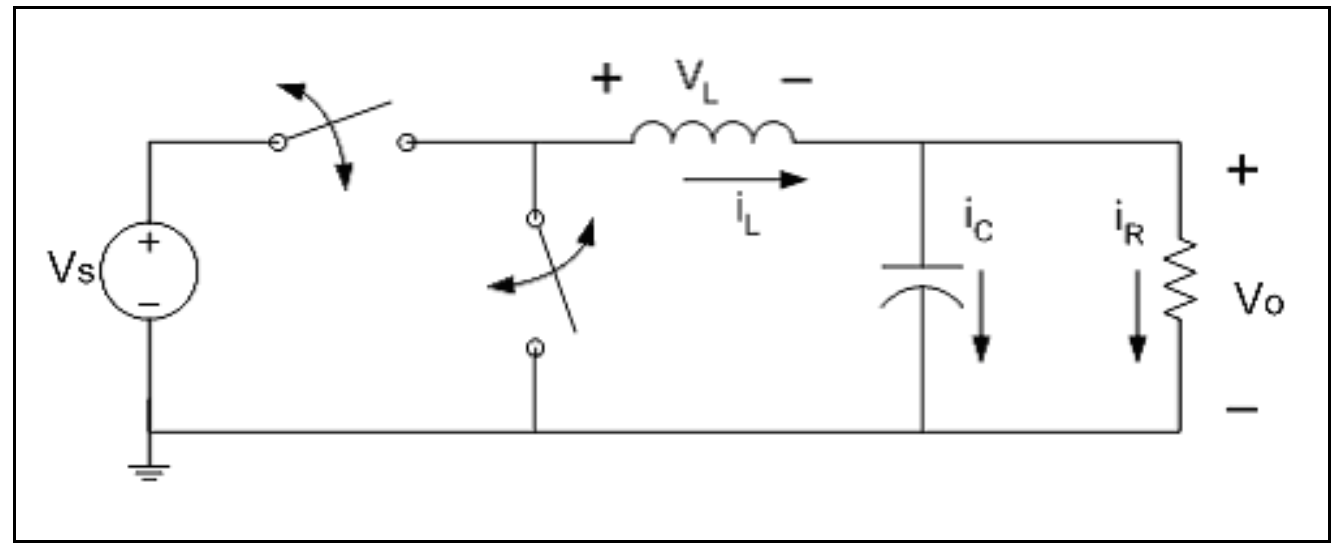

Figure 2-14. Synchronous Buck Converter

Current semiconductor fabrication improvements allow for MOSFETs that have very small on-resistances $\left(R_{d s-o n}\right)$ and are very efficient at dissipating heat. $A$ small on-resistance implies a small voltage drop while the switch is on, due to Ohm's law. The main tradeoff between synchronous and non-synchronous rectification is the extra control and power requirements that the second MOSFET requires. For low voltage applications, the benefits of a second MOSFET outweigh the drawbacks. For synchronous rectification, the controller needs to prevent the high and low side switches from overlapping and creating a 
short to ground condition. For this reason most switching regulators include a dead-time delay. However, most commercial MOSFETs also include a parasitic body diode which allows current to continue to freewheel during this dead time. The diode will automatically be turned off when the main switch fully turns on. The current is very small but can still add 1-2 percent in efficiency [18].

\subsection{Real Capacitors}

Throughout much of this thesis report, values of components are a key focus. Though this is a very important aspect of a design, optimizing and effectively dealing with the challenges of the real world is another important aspect of a design that will be touched on in this section regarding the challenge of using real capacitors. The equivalent circuit of a real capacitor is shown in Figure 2-15.



Figure 2-15. Equivalent circuit of a real capacitor

As Figure 2-15 shows, the model for a real capacitors is made of four characteristics. The first is the equivalent series inductance (ESL) and it is a sum of all the inductive components within the capacitor. It is expressed as:

$$
E S L=2 \pi f L
$$

where $f$ is the frequency and $L$ is the inductance. Next is the equivalent series resistance (ESR) and it is a sum of all the resistive components within a capacitor. It is expressed as: 


$$
E S R=\frac{D F}{2 \pi f C}=D F X_{C}
$$

where DF is the dissipation factor that depends on the dielectric used, $\mathrm{C}$ is the capacitance, and $X_{C}$ is the capacitive reactance. Next is the impedance $(Z)$ of the capacitor and it is expressed as:

$$
Z=\sqrt{E S R^{2}+\left(E S L-X_{C}\right)^{2}}
$$

Finally we have the parallel resistance $\left(R_{p}\right)$ across the capacitance. Note from equations (2-13), (2-14), and (2-15) that ESL, ESR, and Z are frequency dependant, while $R_{p}$ is DC dependant [19].

Of these four, the critical and most talked about component is the equivalent series resistance. ESR is electrically the same as having an additional resistor in series with the capacitor. ESR is undesirable, but all real capacitors exhibit ESR to some degree. It is an important characteristic, because the power dissipated by the capacitor as well as the ability of the capacitor to suppress noise is directly related to the ESR. Different types of capacitors have different ESR values [19]. Also ESR can be reduced by placing capacitors in parallel and this technique is often used. Dealing with the losses of real components can be very challenging and will be one of the big tests for this thesis. 


\subsection{Thermal Analysis}

Thermal management becomes increasingly important as high current and high power applications are analyzed. Power loss and performance suffers as components reach higher and higher temperatures. Components that operate outside of their recommended thermal range reduce their lifetime and in extreme conditions can burn up and be destroyed. The on-resistance of the MOSFET increases with increasing temperature and hence efficiency will degrade significantly if a MOSFET is not adequately cooled (due to $\mathrm{I}^{2} \mathrm{R}_{\mathrm{ds}-\text { on }}$ losses). Multiphase topologies have the advantage of splitting the total power seen by each buck cell by $1 / \mathrm{N}$, where $\mathrm{N}$ is the number of phases, meaning that both the switches and inductors will be both less expensive and smaller because their requirements will be reduced by multiphasing [8].

In some cases, simply using a multiphase topology is not enough to guarantee proper thermal operation of the circuit. A thermal analysis of the MOSFETs is required in order to determine whether a heatsink is required. The basics of heat flow and the development of a heat flow model are shown below. Heat Flow:

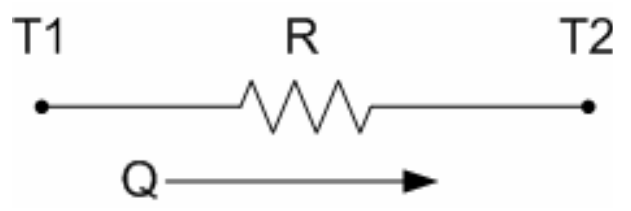

Heat flow equation: $Q=\frac{T_{1}-T_{2}}{R}$ 
Where:

- $Q$ is the heat flow in Watts

- $\mathrm{R}$ is the thermal resistance in ${ }^{\mathrm{C}} \mathrm{C} \mathrm{W}$

- $\mathrm{T}_{1}$ and $\mathrm{T}_{2}$ is the junction temperature (usually $\mathrm{T}_{\mathrm{j}}$ ) in ${ }^{\circ} \mathrm{C}$ or $\mathrm{K}$

For proper device operation, the junction temperature $T_{j}$ needs to be kept below a specified maximum, determined by the manufacturer of the part.

In transistors, the die is the switching area and it gets extremely hot if not adequately cooled. The device creates the heat which flows: to the case, an interface, a potential heatsink, and finally to the ambient air. A model for the heat flow of a typical power MOSFET is shown in Figure 2-16 [19].



$\mathrm{Ta}$

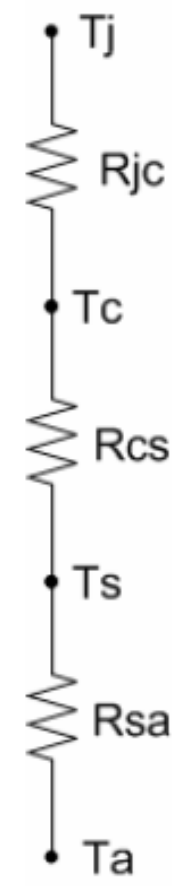

Figure 2-16. Model for the heat flow of a typical power MOSFET 
Where:

- $\mathrm{T}_{\mathrm{j}}$ is the Junction Temperature

- $\mathrm{T}_{\mathrm{c}}$ is the Case Temperature

- $\mathrm{T}_{\mathrm{s}}$ is the Surface Temperature of the heatsink

- $\mathrm{T}_{\mathrm{a}}$ is the Ambient Temperature

- $\mathrm{R}_{\mathrm{jc}}$ is the Junction to Case thermal resistance in ${ }^{\mathrm{C}} \mathrm{C} / \mathrm{W}$

- $\mathrm{R}_{\mathrm{cs}}$ is the Case to sink thermal resistance in ${ }^{\circ} \mathrm{C} / \mathrm{W}$

- $\mathrm{R}_{\mathrm{sa}}$ is the Thermal resistance of the heatsink to ambient

In natural convection, a dark colored heatsink will perform between 3 and 8 percent better than a naturally silver color aluminum heatsink because dark colors radiate heat more efficiently [19].

Again looking at the model in Figure 2-16, when a source is added it will be equal to the power dissipated in the power package $\left(P_{D}\right)$, as the model shows:



Applying the power flow equation:

$$
T_{j(\max )}=P_{D}\left(R_{j c}+R_{c s}+R_{s a}\right)+T_{A}
$$


There is a dilemma with using such an equation to solve for the value of the heatsink needed. Designing for the minimum heatsink needed for the part to still operate means that it is still exposed to an unnecessarily large amount of heat. A good rule of thumb is that for every $10^{\circ} \mathrm{C}$ rise in temperature that the junction must withstand, the estimated life of the component is halved. Hence it is advantageous to use a larger safety margin for the heatsink than the above equation would indicate [19]. 


\subsection{The Multiphase Buck Converter}

Several limitations exist with the single phase buck converter concerning efficiency and the switching frequency $\left(\mathrm{f}_{\mathrm{s}}\right)$. High switching frequency improves the output ripple and transient (dynamic) response of the converter as well as reducing the physical size and value of the filter capacitors and inductors. The tradeoff is that switching losses are proportional to the switching frequency and hence there is a limit that must be determined, a compromise between efficiency and switching frequency.

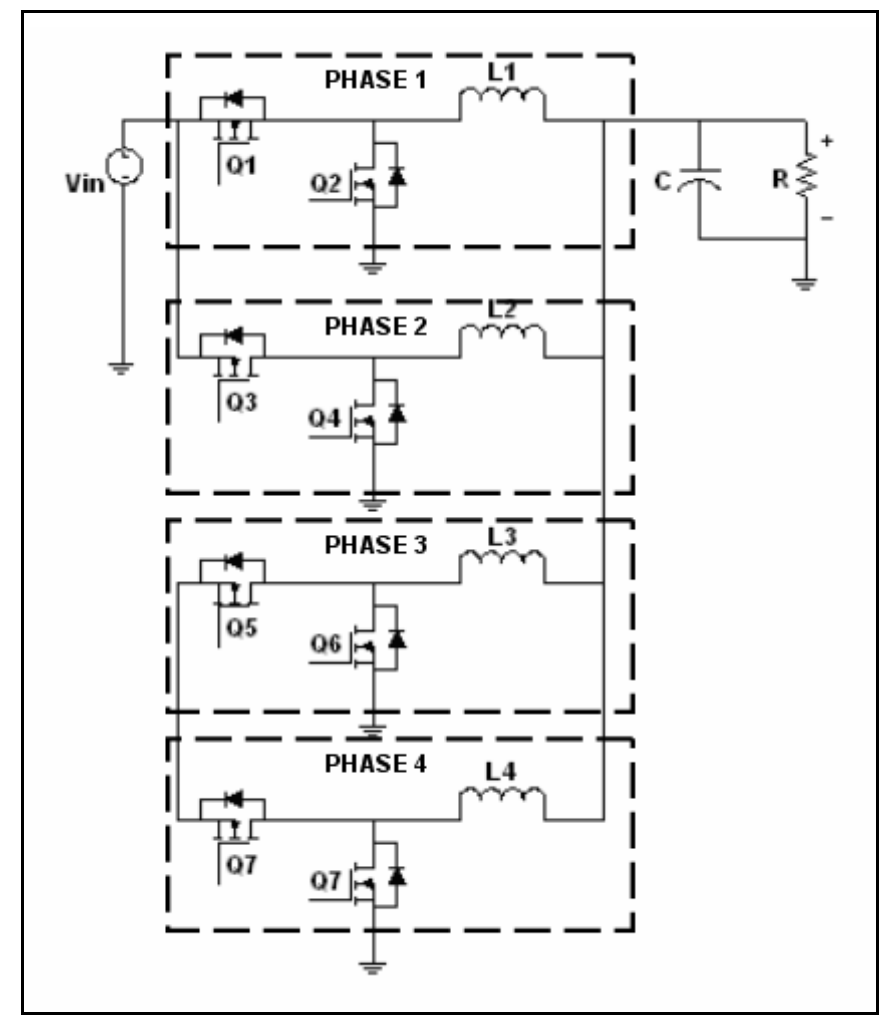

Figure 2-17. Multiphase Buck converter

The multiphase buck converter shown in Figure 2-17 offers a simple solution to the problem. The fundamental frequency is multiplied by the number of phases $(\mathrm{N})$ or in other words, the filter capacitors and inductors see $\mathrm{Nf}_{\mathrm{s}}$. This is good because higher frequencies can be filtered with smaller value 
components. The switch and switching losses are found using just the switching frequency. Also the transient response is very fast because the bandwidth is extended to $\mathrm{Nf}_{\mathrm{s}}$ [7].

For multiphase operation, the phases are shifted by $360 \%$ N. For example, a six phase converter would be driven by gate signals at $0^{\circ}, 60^{\circ}, 120^{\circ}, 180^{\circ}$, 240 and $300^{\circ}$, see Figure 2-18. Because each buck cell is in parallel with one another, the ripple frequency seen by the input and output is $\mathrm{Nf}_{\mathrm{s}}$, while the frequency seen by the switch remains at the switching frequency [7].

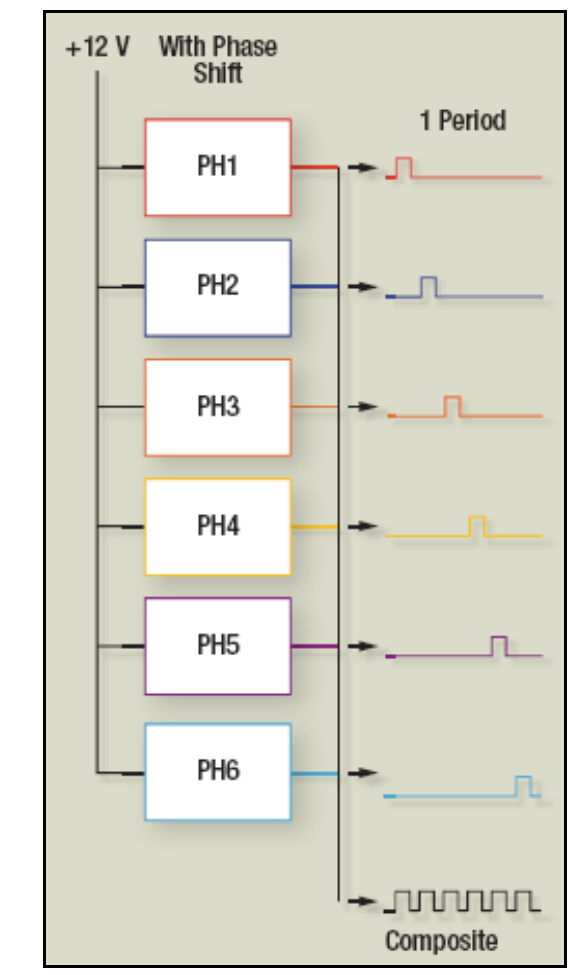

Figure 2-18. Phase pulse waveforms and composite

Figure 2-19 shows a generic representation of a N-phase multiphase buck converter, where $V_{\text {in, }}, l_{\text {in }}$, and $C_{\text {in }}$ is the input voltage, input current, and input filter capacitor respectively, and $\mathrm{V}_{0}, \mathrm{I}_{0}$, and $\mathrm{C}_{0}$ is the average output voltage, average output current, and output filter capacitor respectively. Figure 2-19 also has all 
ideal components, items such as inductor DC series resistance (DCR) and capacitor equivalent series resistance (ESR) and equivalent series inductance (ESL) are not represented. The switch (MOSFET) on-resistance and output (miller) capacitance losses are not shown or represented [7].

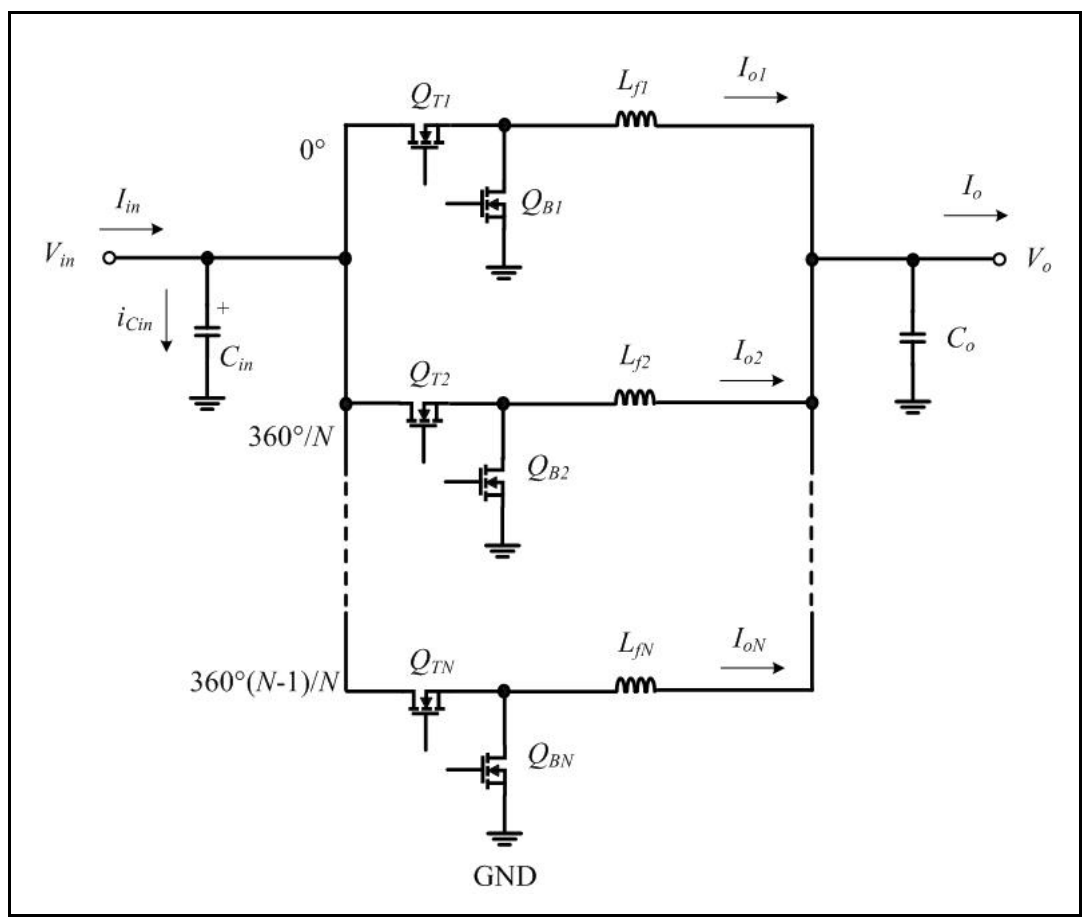

Figure 2-19. N-phase multiphase buck converter

Looking at Figure 2-19 and applying simple $\mathrm{KCL}$, currents $\mathrm{I}_{\mathrm{o} 1}, \mathrm{I}_{\mathrm{o} 2}$, and $\mathrm{I}_{\mathrm{ON}}$ sum to produce the total output current $I_{0}$. The relationship between the single phase duty cycle of each buck cell and the output current of each buck cell is shown in equation (2-18) and (2-19) respectfully.

$$
\begin{aligned}
& D_{1}=D_{2}=\ldots=D_{N}=D=\frac{V_{o}}{V_{i n}} \\
& I_{o 1}=I_{o 2}=\ldots=I_{o N}=\frac{I_{o}}{N}
\end{aligned}
$$


As equation (2-18) and (2-19) imply, the currents and duty cycle of each phase are shared equally [7]. For example in a four phase buck converter with:

$$
\begin{aligned}
& V_{\text {in }}=12 \mathrm{~V} \\
& V_{o}=1 \mathrm{~V} \\
& \mathrm{I}_{\mathrm{o}}=40 \mathrm{~A}
\end{aligned}
$$

the duty cycles and average output currents are:

$$
\begin{aligned}
& D_{1}=D_{2}=D_{3}=D_{4}=D=\frac{V_{o}}{V_{i n}}=\frac{1 \mathrm{~V}}{12 \mathrm{~V}}=8.33 \% \\
& I_{o 1}=I_{o 2}=I_{o 3}=I_{o 4}=\frac{I_{o}}{N}=\frac{40 \mathrm{~A}}{4}=10 \mathrm{~A}
\end{aligned}
$$

The input and output ripple amplitude and frequency are also improved by multiphasing. The following example will show these benefits. Take a three phase buck converter running at $500 \mathrm{kHz}$, so $360 \% 3$ means that each phase is shifted by $120^{\circ}$ from its adjacent phase. Each phase will have an average DC output current of $1 A$ with the total output current equaling $1 A^{*} 3=3 A$. Each phase also operates at 50\% duty cycle, see Figure 2-20 [7].

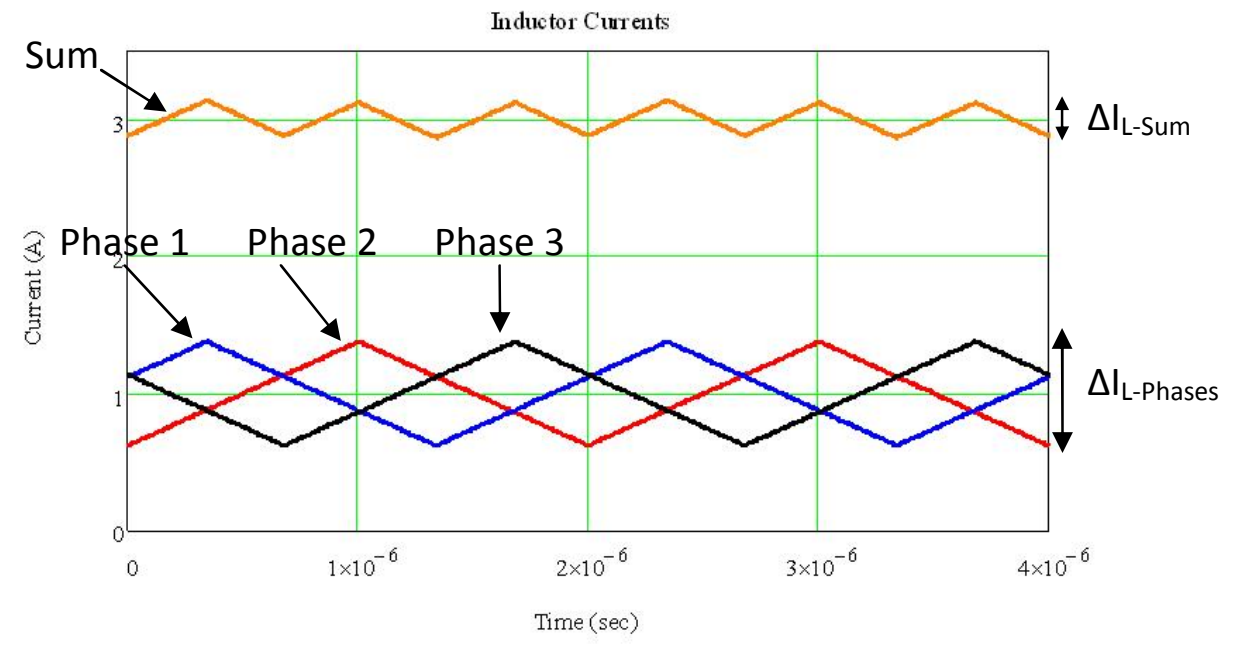

Figure 2-20. Inductor current of individual phases and their sum 
Figure 2-20 shows the three individual phase currents along with their sum which is the total output current. The average output current is three times the average DC current and frequency of the individual phase currents. The total output peak-to-peak current ripple $\left(\Delta \mathrm{I}_{\mathrm{L}-\mathrm{Sum}}\right)$ has been decreased by a third as compared to the individual phase peak-to-peak current ripples ( $\left.\Delta \mathrm{I}_{\mathrm{L}-\mathrm{Phases}}\right)$ [7].

On a per phase inductor basis the inductor currents are equal, the total output current is split evenly over its $\mathrm{N}$ phases. The value of the inductor is shown in equation (2-22) where $\Delta \mathrm{i}_{L 1-p h a s e}$ is the current ripple of a single phase in amperes, $I_{\llcorner\max }$ and $I_{\llcorner\min }$ are the maximum and minimum inductor currents in amperes, and $L_{f}$ is the inductor value in henrys.

$$
\Delta i_{L 1-\text { phase }}=I_{L \max }-I_{L \min }=\frac{V(1-D)}{L_{f} f_{s}}
$$

Recalling that multiphasing increases the frequency seen by the inductor by a multiple of $\mathrm{N}$, the total output current ripple is

$$
\Delta i_{L N-\text { phase }}=\frac{V(1-D)}{L_{f} N f_{s}}
$$

Again notice that the number of phases is in the denominator and results in an inverse relationship between ripple size and number of phases. This phenomenon is known as the ripple calculation effect and uses the notation $\mathrm{K}_{\mathrm{CM}}$, see Figure 2-21 [23]. 


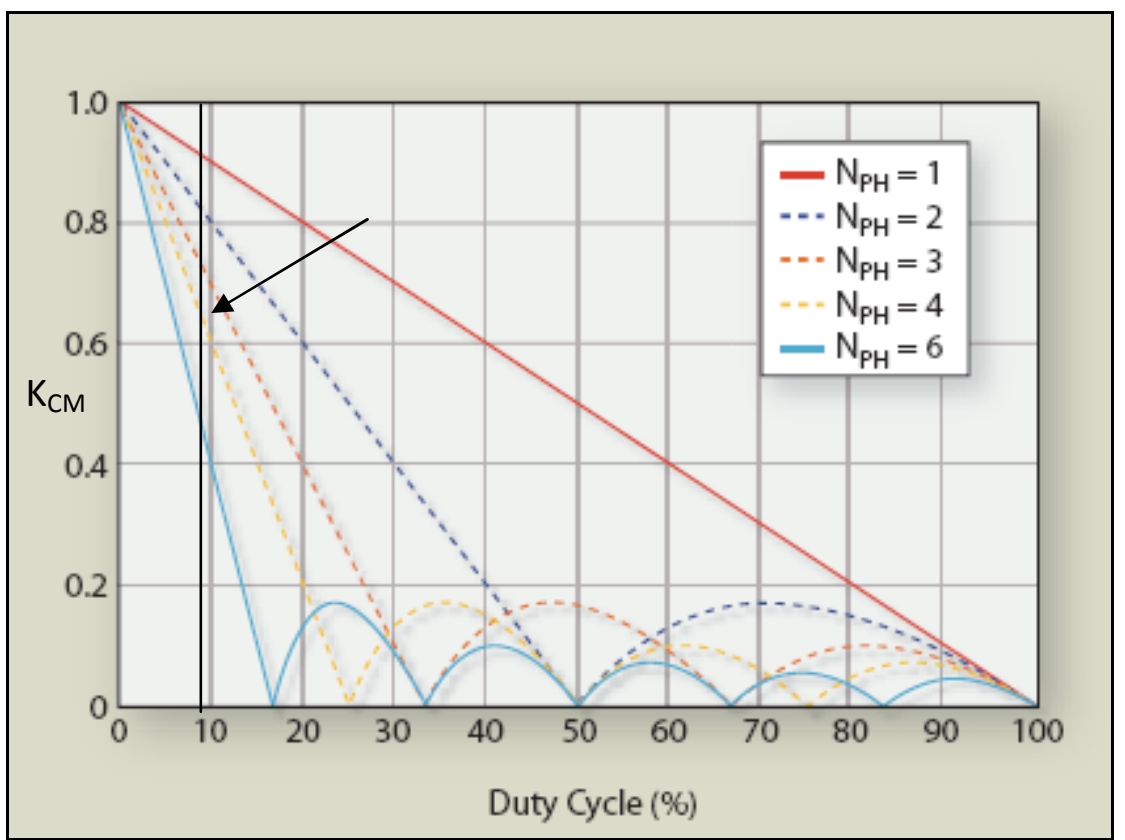

Figure 2-21. Normalized current ripple factor for one to six phases [21]

Figure 2-21 shows the ripple cancellation factor for one to six phases with the vertical axis being the ripple cancellation factor and the horizontal axis being the duty cycle. Notice that at higher phases the ripple factor is reduced quicker, meaning that there will be less current ripple. Also notice that for each phase there are several locations where the ripple factor goes to zero, meaning that at those duty cycles there is no current ripple. Finally, notice the vertical line that had been added at about 8-9\% duty cycle and the arrow which locates the point where the $\mathrm{N}_{\mathrm{PH}}=4$ crosses this vertical line. This indicates the ripple cancellation effect from a four phase converter, approximately $\mathrm{K}_{\mathrm{CM}}=0.65$.

For output capacitor considerations it is assumed that we are using ideal components. This means that we can assume that the entire $A C$ component of the output current (which is the same as the inductor current) flows through the capacitor, while the entire DC component of the output current flows through the 
output load resistor. In order to size the output capacitor, the ripple portion of the inductor current will be analyzed, taking note that the total charge into the capacitor has to be equal to the total charge leaving the capacitor. The output capacitance can be found by using the capacitor charge equation, see equation (2-16). The output capacitance value can be found by finding the area under the ic waveform, shown in Figure 2-22 [20].

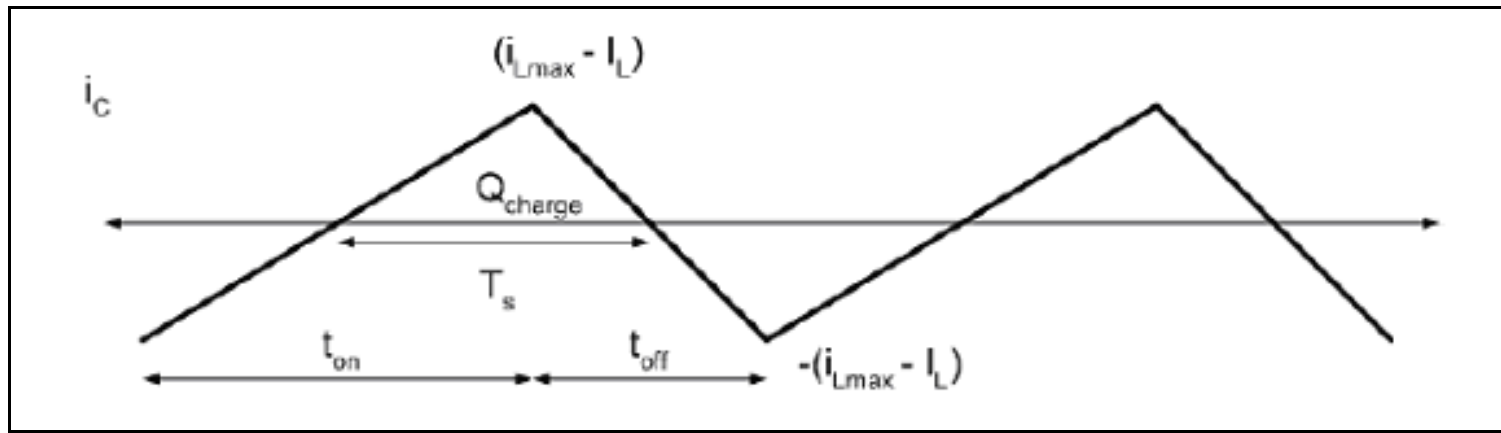

Figure 2-22. Output capacitor current waveform [20]

Start with the capacitor charge equation.

$$
Q=C V \quad Q_{\text {charge }}=C_{\text {out }} \Delta V_{o}
$$

Finding the area of the $\mathrm{i}_{\mathrm{C}}$ curve yields $\mathrm{Q}_{\text {charge }}$ (area of a triangle base $\mathrm{x}$ height) while the other parameters are typically known.

$$
C_{\text {out }}=\frac{Q_{\text {charge }}}{\Delta V_{o}}=\frac{\frac{1}{2}\left(\frac{\Delta i_{L}}{2}\right)\left(\frac{T}{2 N}\right)}{\Delta V_{o}}=\frac{\Delta i_{L}}{8 \Delta V_{o} N f_{s}}
$$

\subsection{Multiphase Literature Review}

Before performing any in-depth study in a new field, it is important to conduct a literary review to determine the current state of development in that field. This helps to place one's findings in context with the rest of the world's conclusions, and to ensure duplication of work that has previously been done 
does not occur. Several literature reviews were performed and summarized in this report, each dealing with a different multiphase topology geared towards improvements in size, efficiency, and eliminating common multiphase problems. Ultimately, the goal of this thesis is to improve upon the efficiency along with other common problems associated with multiphase topologies, so this investigation is quite beneficial.

\subsubsection{A Self-Driven Soft-Switching Topology}

One of the main obstacles for designers of voltage regulators (VR) for future microprocessors deals with the vast discrepancy between the on-times of the main MOSFET and the synchronous MOSFET. In a buck converter with $\mathrm{V}_{\text {in }}$ $=12 \mathrm{~V}$ and $\mathrm{V}_{\mathrm{o}}=1 \mathrm{~V}$, there is a difference of $83.4 \%$ in on-times, with the synchronous switch being on for a majority of the time. This difference leads to many problems and losses in efficiency. Naturally, it is desired to extend the duty cycle and avoid these problems. As can be seen in Figure 2-23, as the duty cycle is extended, the two switches share more of the on-time [26].



Figure 2-23. Peak and average PWM signals with duty cycle extension [26] 
The proposed topology is to extend the duty cycle of a self-driven $12 \mathrm{~V}$ soft-switching VR. The design will be self-driven because for future high current VRs it is advantageous to place multiple MOSFETs in parallel to reduce the overall on-resistance. However, MOSFETs in parallel require more gate driving power and more complicated gate drivers, the self-driven circuitry simplifies the gate driver problem and partially recycles energy, reducing costs and improving efficiency. The proposed circuit is shown in Figure 2-24 [26].

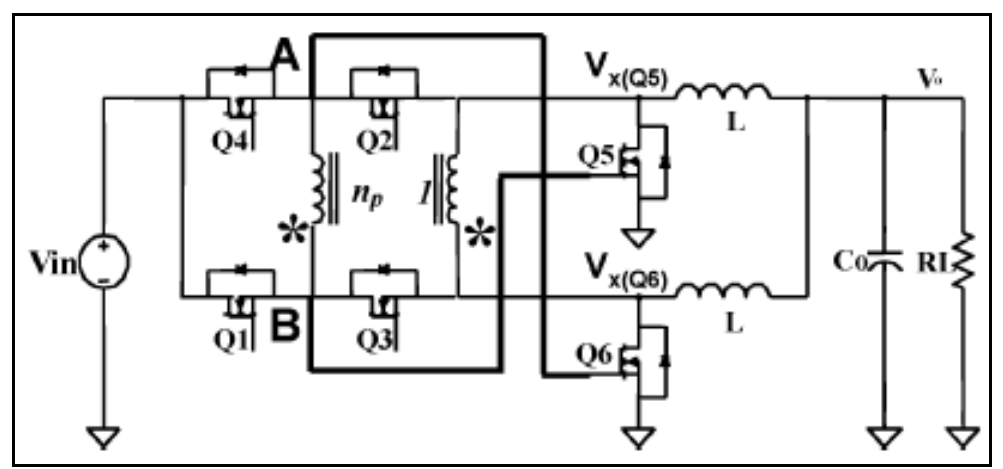

Figure 2-24. Proposed ZVS self-driven 12V VR [26]

Figure 2-24 is essentially a two phase buck interleaving topology with self driven technology that can achieve zero voltage switching. The VR operates at $1 \mathrm{MHz}$, outputs $1.3 \mathrm{~V}$ at $100 \mathrm{~A}$, and has an overall efficiency of $86 \%$. The four modes of operation are broken down and shown in Figure 2-25.

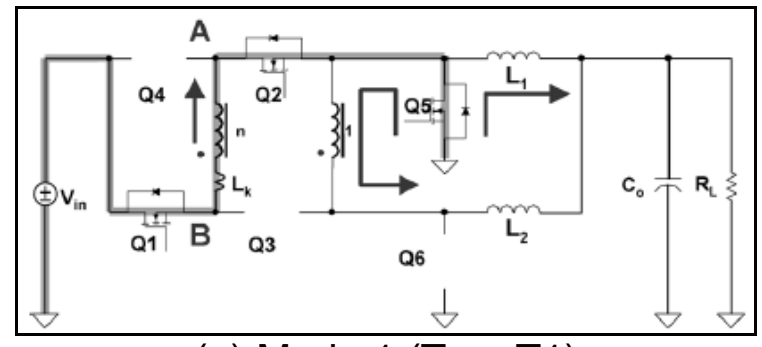

(a) Mode 1 (To - T1)

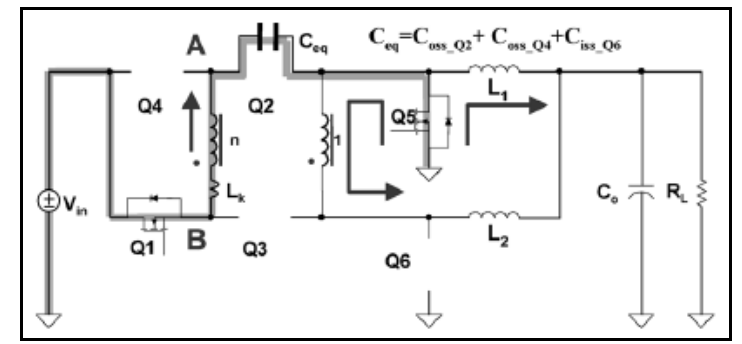

(b) Mode 2 (T1 - T2) 


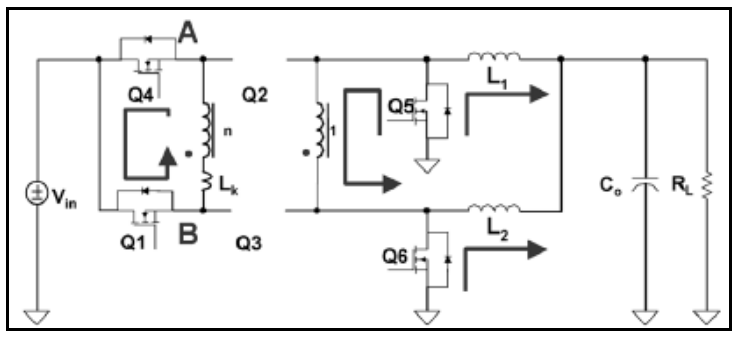

(c) Mode 3 (T2 - T3)

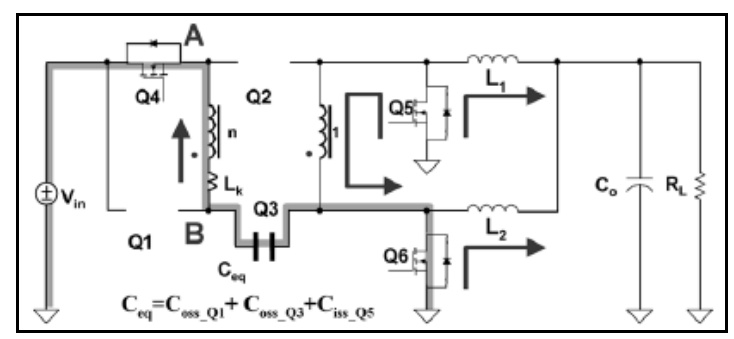

(d) Mode 4 (T3 - T4)

Figure 2-25. Self-driven topology modes of operation, (a) mode 1, (b) mode 2 , (c) mode 3, and (d) mode 4 [26]

Starting with Mode 1 (To-T1), Q1 and Q2 are on. This makes the voltage at node $\mathrm{B}$ equal to the input voltage of $12 \mathrm{~V}$. The self driven characteristics of the circuit makes Q2 and Q5 turn on as well. This in turn means that node A has to be connected to ground which keeps Q6 off. The energy is transferred from the input to the output through the transformer, see Figure 2-25 (a).

Q2 turns off at $\mathrm{T} 1$ and we enter into Mode $2(\mathrm{~T} 1-\mathrm{T} 2)$. Q5 remains on during this time which means that the output capacitors of Q4, Q2, and the gateto-source capacitance of $\mathrm{Q} 6$ are all in parallel and is shown as $\mathrm{C}_{\text {eq }}$, see Figure 225 (b). Given a suitable dead time the drain-to-source voltage of Q4 will drop to zero and zero voltage switching (ZVS) can occur.

During the next mode, Mode 3 (T2 - T3), both Q1 and Q4 are on meaning that both node $A$ and $B$ are connected to the input and Q5 and Q6 are both on as well. The energy stored in the transformer leakage inductor is transferred to the output through these switches, see Figure 2-25 (c).

Q1 turns off at T3 and we enter the final mode, Mode 4 (T3 - T4). The leakage inductor of the transformer resonates with the output capacitor of Q1, 
Q3, and the gate capacitor of Q5. In order for ZVS to be achieved at Q3 there must be first, a dead time of one-fourth of the resonant period and second, enough stored energy in the resonant inductor to charge and discharge the resonant capacitors. This is a two phase example and as such from T4 to T8 the same half-period repeats itself, just with a $180^{\circ}$ polar ity change.

In order to judge the new topology it is necessary to compare it to a standard two phase buck converter. The soft-switching circuit has loss savings by duty cycle extension, switching loss savings due to ZVS of both Q4 and Q1, and the synchronous rectifier driver losses are reduced because of the selfdriven scheme that is implemented. The soft-switching circuit does have an additional loss with the power transformer, but overall there is a $2-3 \%$ increase in efficiency using the self-driven soft-switching topology over the standard buck converter [26].

\subsubsection{Multiphase Coupled-Buck Converter}

For reasons discussed above in section 2.9.1, the extension of the duty cycle provides a very nice benefit to the system, see Figure 2-23. The tappedinductor buck converter topology is one of the simplest methods to accomplish duty cycle extension. Figure 2-26 shows the proposed topology, where the turns ratio $(n)$ of the tapped inductor is defined as the number of the winding in series with the main MOSFET over the number of windings in series with synchronous MOSFET [25]. 


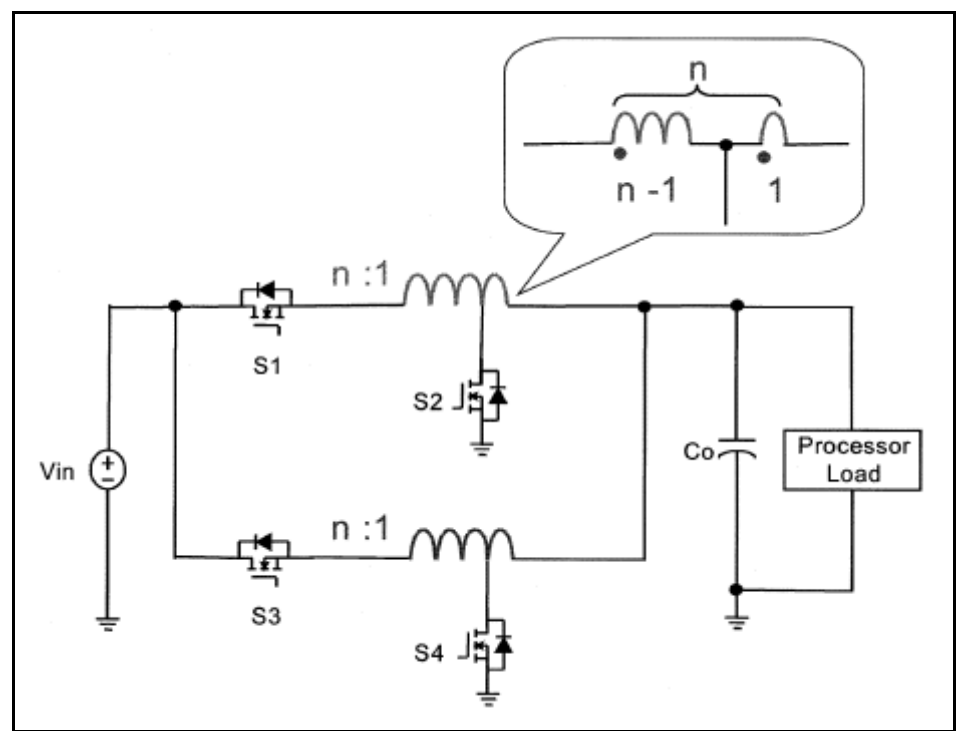

Figure 2-26. Basic coupled-buck converter [25]

With the addition of the tapped-inductor, the transfer function is now a function of both the duty cycle (D) and the turns ratio as shown:

$$
\frac{V_{o}}{V_{\text {in }}}=\frac{D}{D+n \cdot(1-D)}
$$

As can be seen by equation (2-26), a large turns ratio yields a high duty cycle. The desirable turns ratio is related to the transient response of the converter. We will not go into this process in any substantial detail, but the basis behind it involves matching the transient inductor slew rates when the main MOSFET is on and when the synchronous MOSFET is on. For a buck converter with $V_{\text {in }}=12 \mathrm{~V}$ and $V_{o}=1.5 \mathrm{~V}$, the ideal turns ratio is $\mathrm{n}=2: 1$ which results in a duty cycle $\mathrm{D}=$ $22.5 \%$, a vast improvement from the original $12.5 \%$ without the coupled inductor [25].

The new topology, see Figure 2-27, uses the tapped-inductor but also incorporated an active clamping circuit between the interleaving phases to 
eliminate any voltage spikes that may occur due to the resonance between the leakage inductance and output capacitance of the MOSFET.



Figure 2-27. Multiphase tapped-inductor buck with active clamp [25]

The top two switches (S1 and S2) control the current flow for their phase and also serve as the active clamp for the neighboring phases. Active clamping is accomplished by using capacitor $\mathrm{Cc}$ as a constant voltage source, which is equal to the input voltage minus the output voltage, $V_{c c}=V_{i n}-V_{o}$. All the leakage energy will be stored in the capacitor and can be recovered to the load at a later time. The four modes of operation are broken down and discussed in Figure 2-28 [25].

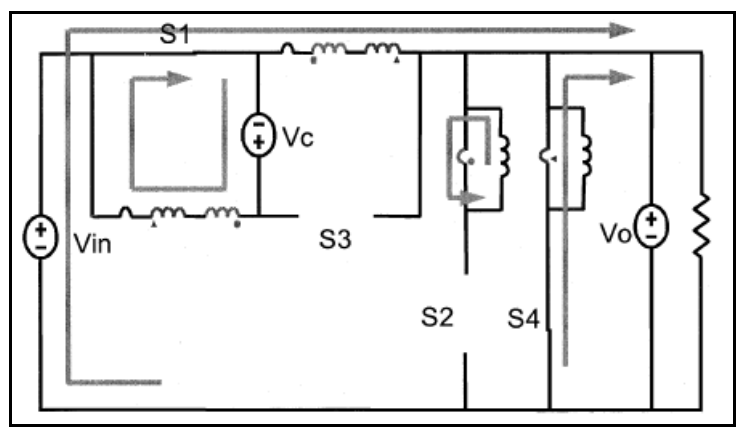

(a) The buck mode

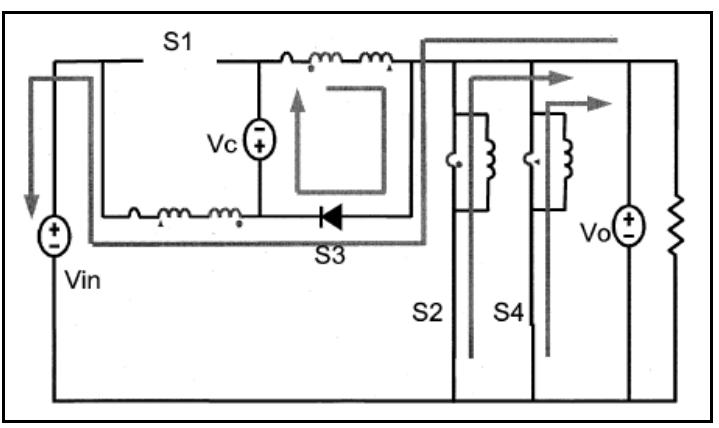

(b) The leakage energy recovery mode 


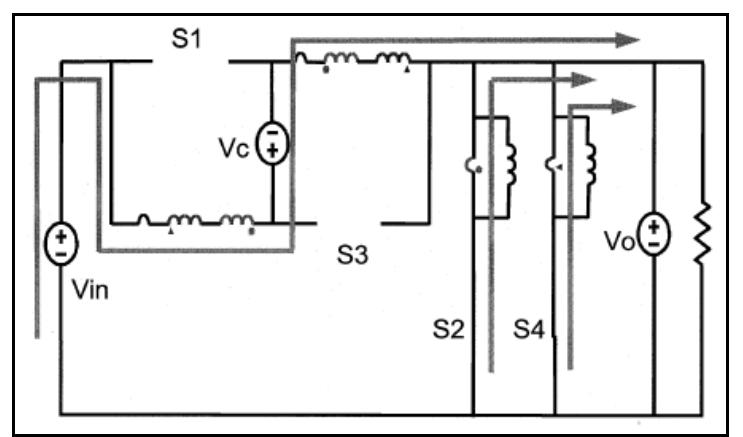

(c) The freewheeling mode

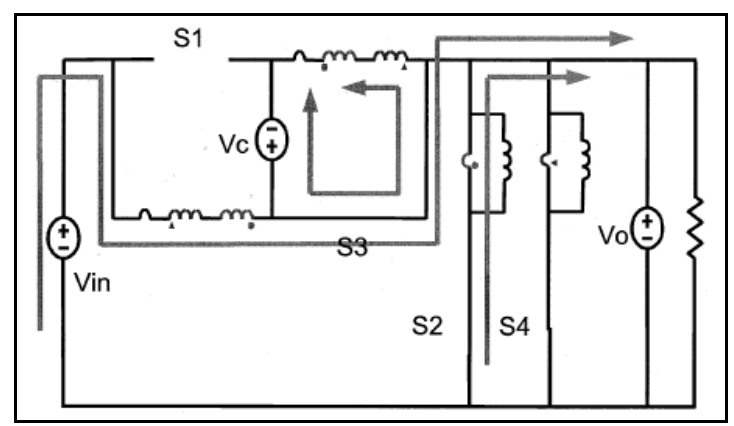

(d) The leakage current reset mode

Figure 2-28. Coupled buck topology modes of operation, (a) mode 1, (b) mode 2, (c) mode 3, and (d) mode 4 [25]

Starting with Mode 1 (To-T1), the buck mode, S1 and S4 are on while S3 and S2 are off. Energy is passed from the input and clamping capacitor to the output through the $L_{K 1}$ inductor. Inductor $L 2$ is freewheeling, see Figure 2-28 (a) for more details.

S1 turns off and S2 turns on at T1 and we enter into Mode 2 (T1 - T2), the leakage energy recovery mode. Along with $\mathrm{S} 1$ being off and $\mathrm{S} 2$ being on, the body diode of S3 is on and S4 is on. The voltage across S1, which was turned off, is clamped to the sum of the input voltage and the clamping capacitor voltage $\left(V_{c}\right)$. L1 and L2 are both freewheeling and delivering energy to the load, see Figure 2-28 (b).

The body diode of S3 turns off at T3 and we enter Mode 3 (T2 - T3), the freewheeling mode. Here, S1 and S3 are off while S2 and S4 are on. Both L1 and L2 continue to freewheel, from mode 2 . The voltage of the clamping capacitor that was depleted during mode 2 is replenished by the input voltage. The flow of energy for this mode is shown in Figure 2-28 (c). 
S3 turns on at T3 and we enter the final mode, Mode $4(\mathrm{~T} 3-\mathrm{T} 4)$ the leakage current reset mode. As shown in Figure 2-28 (d), S1 is off while S2, S3, and S4 are all on. Energy is passed from the input and clamping capacitor to the output through the $L_{k 2}$ inductor, inductor $L 1$ is freewheeling. The current through S3 will begin to increase and mode 4 ends when the current through S3 equals the current through $L_{k 1}$. The circuit operation then repeats starting with Mode 1 once again.

In order to judge the effectiveness of the new topology it is necessary to compare the duty cycles of a standard buck converter and the coupled-buck converter. Based on experimental data taken during testing of the coupled-buck topology, the duty cycle of the circuit is:

$$
\frac{V_{o}}{V_{i n}}=\frac{D}{D+n}
$$

Like the example shown before, for a buck converter with $V_{\text {in }}=12 \mathrm{~V}$ and $V_{0}$ $=1.5 \mathrm{~V}$, the ideal turns ratio is $\mathrm{n}=2: 1$ which results in a duty cycle $\mathrm{D}=28.6 \%$, a vast improvement from the original $12.5 \%$ without the coupled inductor. Again, the extension of the duty cycle leads to fewer losses and a higher efficiency, which is the ultimate goal. In an experiment comparing a traditional four-phase buck converter with a four-phase coupled-buck converter converting a $12 \mathrm{~V}$ input to a $1.5 \mathrm{~V}$ output at $50 \mathrm{~A}$, the coupled-buck had an overall power loss reduction of 4W which corresponds to a $4 \%$ improvement in efficiency at full load [25]. 


\subsubsection{The Two-Stage Solution}

The two-stage solution is again designed to optimize the duty cycle. The method presented here is the simplest of the three and involves first converting $12 \mathrm{~V}$ to $5 \mathrm{~V}$ and then converting the $5 \mathrm{~V}$ to $1 \mathrm{~V}$, see Figure $2-29$.

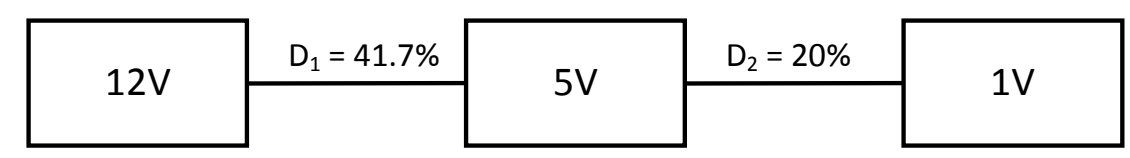

Figure 2-29. Block diagram of two-stage operation

The benefit here is that duty cycle is never less than $20 \%$ so the main and synchronous MOSFETs are used much more evenly. In order for proper operation using a two stage design, each stage must be running at a different frequency, see Figure 2-30.

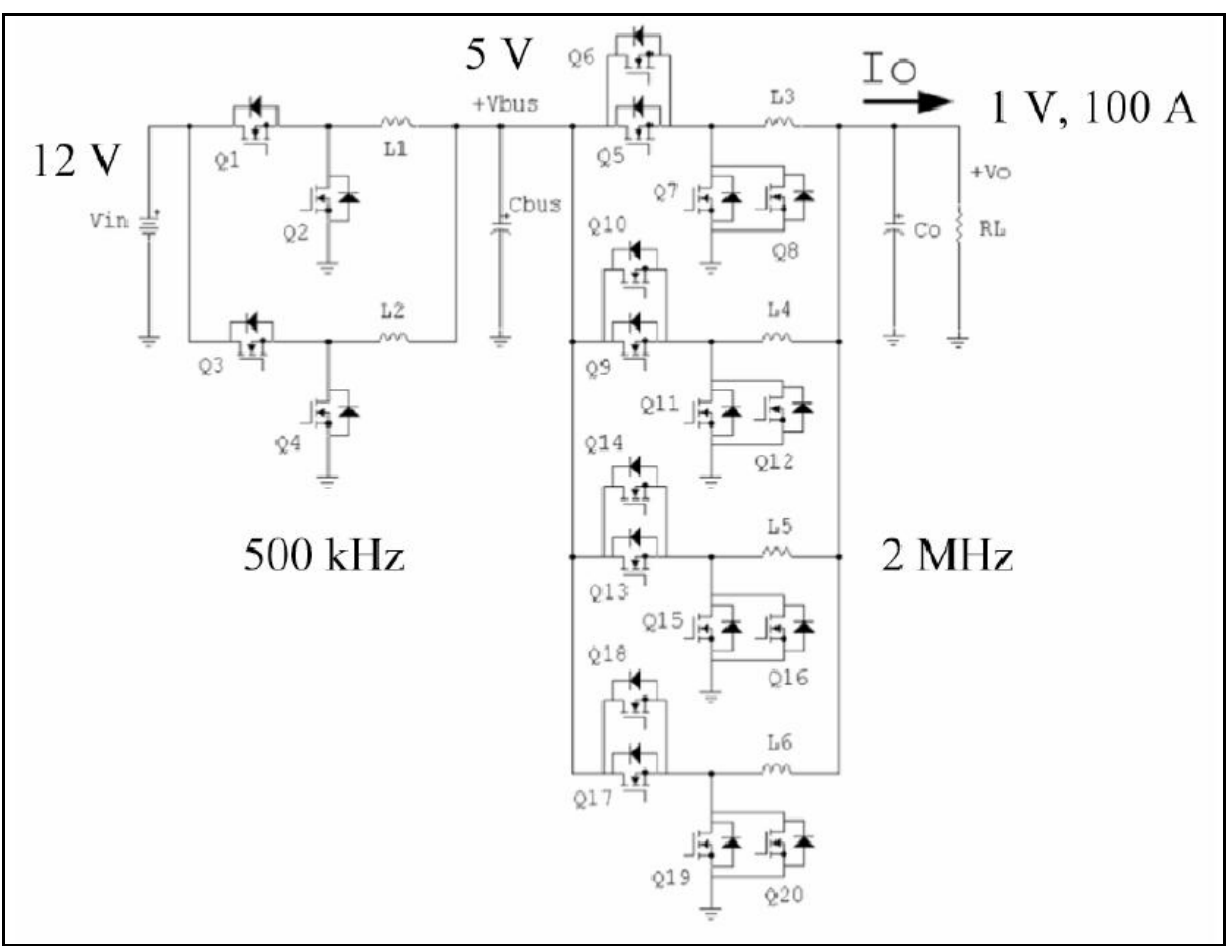

Figure 2-30. Two stage multiphase converter [6] 
The overall transfer function of the two-stage converter is:

$$
\frac{V_{o}}{V_{\text {in }}}=D_{1} D_{2}
$$

The main drawback to using a multi-stage topology as opposed to a single stage is the additional losses associated with first converting the $12 \mathrm{~V}$ down to $5 \mathrm{~V}$. Careful analysis must be taken to ensure that the benefits received from only needing to convert $5 \mathrm{~V}$ down to $1 \mathrm{~V}$ in the second stage is not offset by the losses in the first stage. Also, the two-stage converter uses several more MOSFETs and inductors which add additional costs to the design [6].

\subsubsection{Looking Ahead}

When looking back on the background section of the report, it should become obvious that multiphase is the wave of the future for powering microprocessors. It is a relatively simple concept that must be improved in order to meet the ever increasing demands that CPUs are placing on the voltage regulators that power them. Section 2.9 and the subsequent subsections give a feel for the current state of affairs in the business of multiphase voltage regulators. The remainder of this report is concerned with a new topology that attempts to use phase interleaving, specific component selection, and an LC input filter to solve some of the problems associated with the current multiphase buck topology. 


\section{Chapter 3. Interleaving Multiphase DC-DC Converter with Input LC Filter}

\subsection{Proposed Multiphase Topology}

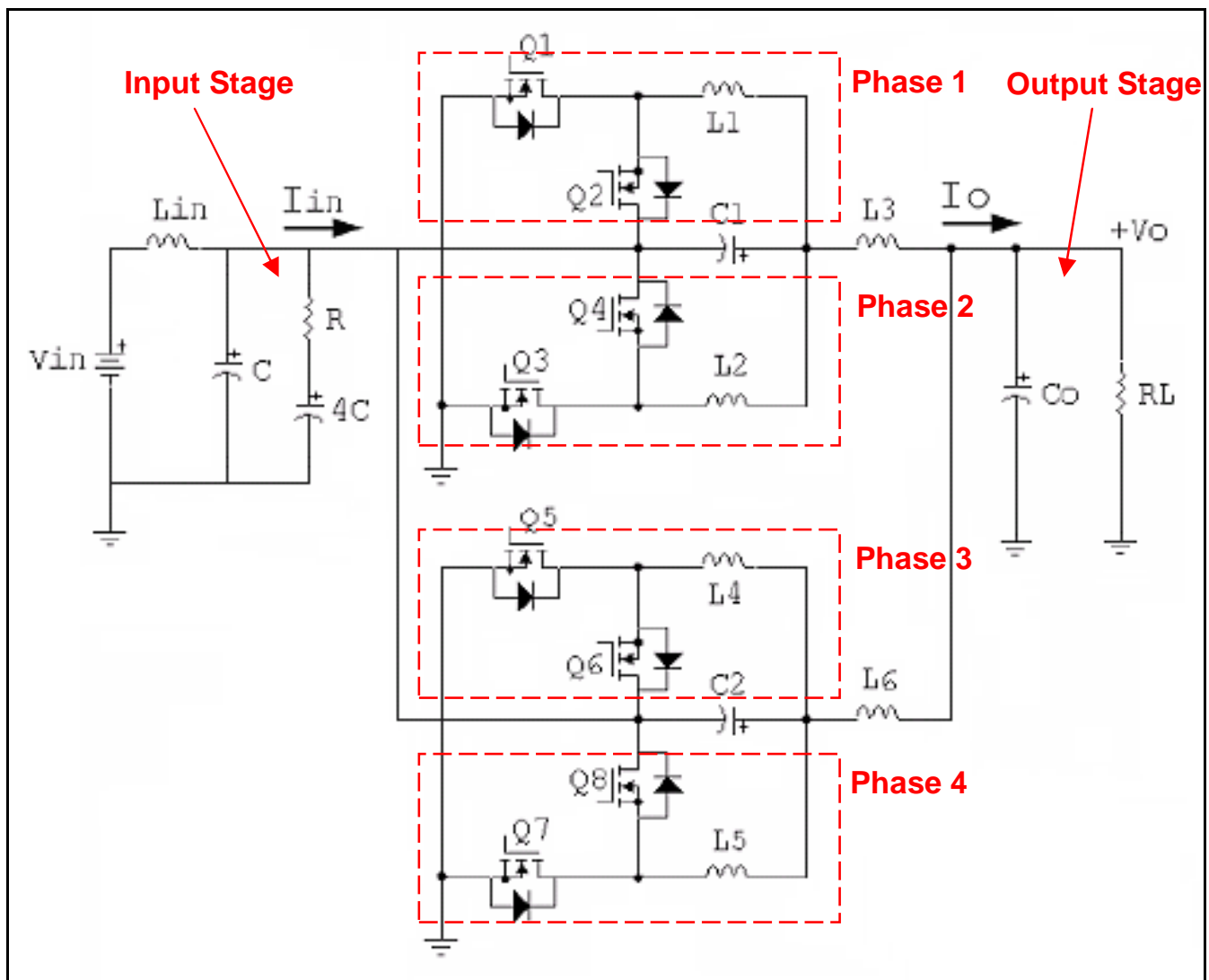

Figure 3-1. Interleaving multiphase DC-DC converter with input LC filter

Figure 3-1 depicts the proposed interleaving multiphase converter with input LC filter. The converter consists of two modules, each of which contains two individual buck phases in parallel. The modules in turn are connected in parallel. Figure 3-1 shows a total of four phases, with phases 1 and 2 being the top module and phases 3 and 4 being the bottom module. The easiest method to understand and analyze the proposed multiphase buck converter topology is to look at each of the key components of the design individually, as the block diagram shown in Figure 3-2 illustrates. 


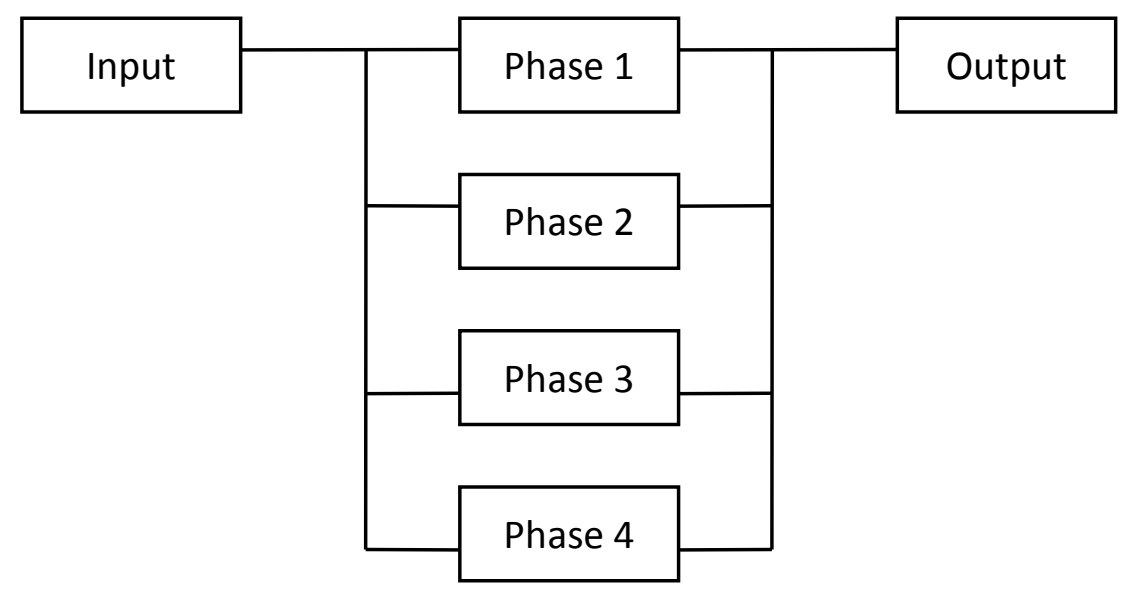

Figure 3-2. Block diagram of four phase operation

We will start with the power stage (phases 1 through 4) and disregard the input and output blocks for the moment. It is clear that phases 1 through 4 are in parallel, but they are offset by a phase angle of $360 \% 4=90^{\circ}$. In a regular multiphase buck topology the control signals operate in sequential order, with the order of energy flow through each phase being 1, 2, 3, 4. An interleaved multiphase buck's control signals operate slightly different, changing the order of energy flow through each phase to $1,3,2,4$. This subtle difference can be explained by looking at Figure 3-1. Although all of the phases look to be in parallel, phases 1 and 2 share the same output inductor (L3), just as phases 3 and 4 share the same output inductor (L6). By using an interleaving control scheme, output current alternates between the two output inductors and it is used for this reason.

Referring to Figure 3-2, each phase has the same input and output voltage, and therefore would equally share the output current. For the proposed topology, the input of each phase is $12 \mathrm{~V}$, the output is $1 \mathrm{~V}$, and the total output current for the converter is $40 \mathrm{~A}$. With equal current sharing, each phase is 
required to provide $10 \mathrm{~A}$ of current. The phases in essence are independent and hence each phase and the components required by each phase can be analyzed as a single buck converter.

\subsection{Design Equations and Loss Analysis}

The component and loss analysis will be conducted using a non-ideal, single phase synchronous buck converter shown in Figure 3-3, which is the basic foundation of each phase in the multiphase buck converter.

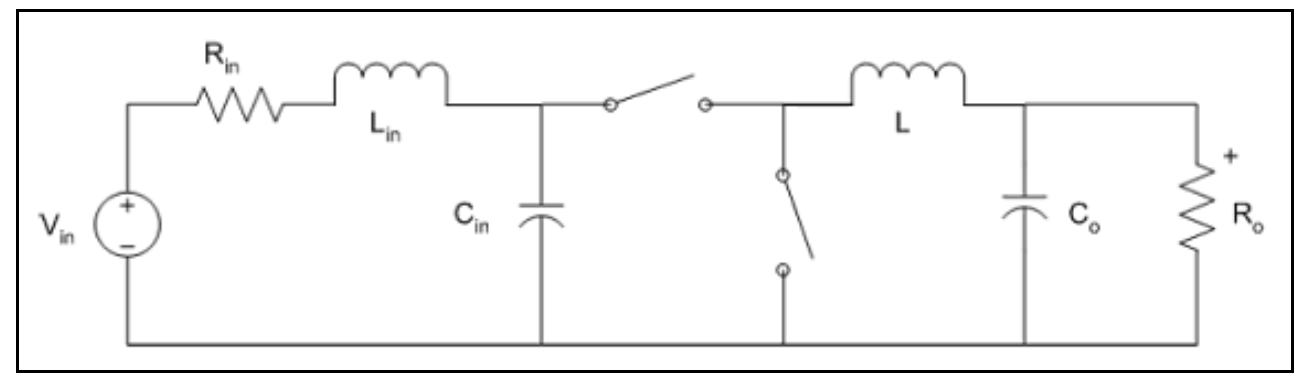

Figure 3-3. Non-Ideal Buck Converter

In the circuit shown in Figure $3-3, V_{\text {in }}$ is the input voltage, $V_{o}$ is the average output voltage, $P_{o}$ is the average output power, $R_{\text {in }}$ is the line resistance, $L_{\text {in }}$ is the line inductance, $\Delta \mathrm{V}_{\mathrm{o}}$ is the output voltage ripple at full load, $\Delta \mathrm{V}_{\mathrm{Cin}}$ is the input capacitor voltage ripple at full load, $\mathrm{R}_{\mathrm{SW} 1-\mathrm{ON}}$ is the main switch on-resistance, and $R_{S W 2-O N}$ is the synchronous switch on-resistance. For simplicity reasons we will assume that $\mathrm{R}_{\mathrm{SW} 1-\mathrm{ON}}=\mathrm{R}_{\mathrm{SW} 2-\mathrm{ON}}=\mathrm{R}_{\mathrm{ON}}$.

\subsubsection{Deriving the Transfer Function (output current/input current)}

Due to the small values of $\Delta \mathrm{V}_{\text {Cin }}$ and $\Delta \mathrm{V}_{\mathrm{o}}$, we can assume that $\mathrm{V}_{\text {Cin }}$ and $\mathrm{V}_{\mathrm{o}}$ are constant and hence $I_{\text {in }}$ and $I_{0}$ are constant. Taking into account the specifications given in section $2-4$, the current transfer function can be derived as follows. 
The duty cycle is found by dividing the on-time of the main switch by the switching period:

$$
D=\frac{t_{o n}}{T} \quad[\%]
$$

The output current is first found by dividing the average output power by the average output voltage:

$$
I_{o}=\frac{P_{o}}{V_{o}} \quad[\mathrm{~A}]
$$

The load resistance is also found by dividing the average output voltage by the average output current:

$$
R_{L}=\frac{V_{o}}{I_{o}}[\Omega]
$$

Using Figure 3-3 and KCL the following relationship between inductor current, main switch current (SW1), and synchronous switch current (SW2) can be found:

$$
I_{L}=I_{S W 1}+I_{S W 2}
$$

Where $I_{L}$ is the average value of the inductor current, $I_{S W_{1}}$ is the average value of the main switch current, and $I_{s w 2}$ is the average value of the synchronous switch current. In steady state the average input current $I_{\text {in }}$ is the same as the average main switch current $I_{\mathrm{SW} 1}$ because they are in series. The average inductor current $I_{L}$ is the same as the average output current $I_{0}$ again because they are in series. The following relationship illustrates this point:

$$
I_{S W 1}=I_{i} \quad I_{L}=I_{o}
$$

Referring to Figure 3-4, when the main switch is on its current is the same as the inductor current and referring to Figure 3-5 when the main switch is off the 
synchronous switch current is the same as the inductor current. This leads to the following relationship:

$$
I_{S W 1}=D I_{L} \quad I_{S W 2}=(1-D) I_{L}=(1-D) I_{o}
$$

Substitution equations (3-5) and (3-6) into equation (3-4) yields the following relationship:

$$
I_{o}=I_{\text {in }}+(1-D) I_{L}=I_{\text {in }}+I_{o}-D I_{o}
$$

And simplifying gives the current transfer function:

$$
D I_{o}=I_{\text {in }} \Rightarrow \frac{I_{o}}{I_{\text {in }}}=\frac{1}{D}
$$

\subsubsection{Finding the Non-Ideal Duty Cycle}

In order to find the non-ideal duty cycle, we need to find the voltage across the inductor when the main switch is both on and off. We will start with the condition when the main switch in on and is replaced by its on-resistance $\left(R_{o n}\right)$ and the inductor voltage being equal to $V_{+}$, see Figure 3-4.

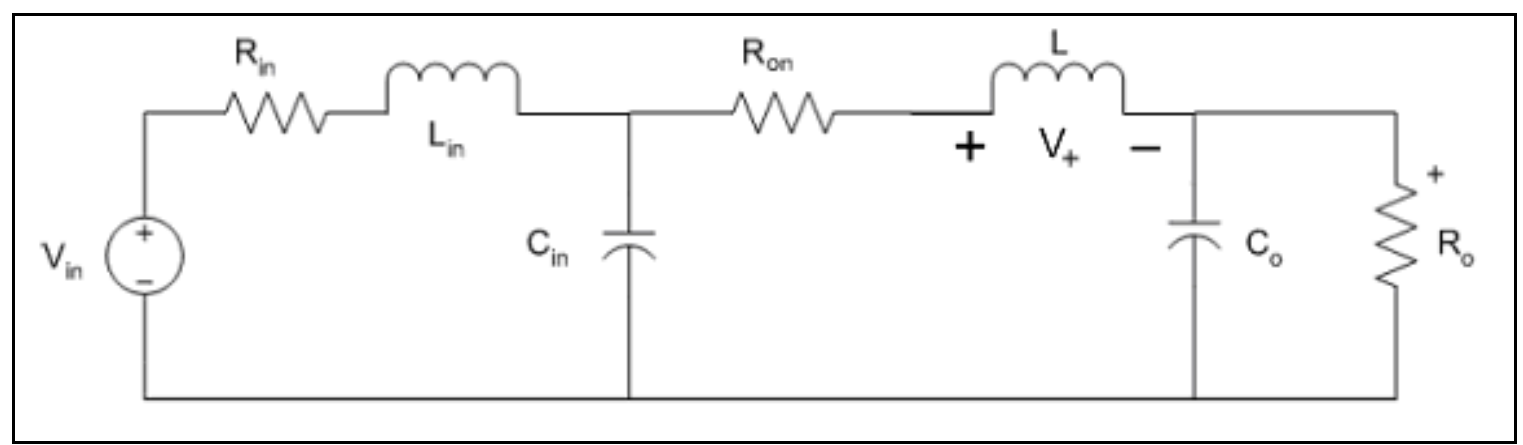

Figure 3-4. Main Switch is on and replaced by $R_{o n}$

The voltage across the inductor when the main switch is on using KVL in Figure 3-4 is:

$$
V_{+} \approx V_{\text {in }}-R_{\text {in }} I_{\text {in }}-L_{\text {in }} \frac{d i_{\text {in }}}{d t}-R_{O N} I_{L}-V_{o}
$$


Since $L_{\text {in }} \frac{d i_{\text {in }}}{d t} \approx 0$, equation (3-9) becomes:

$$
V_{+} \approx V_{\text {in }}-R_{\text {in }} I_{\text {in }}-R_{O N} I_{L}-V_{o}
$$

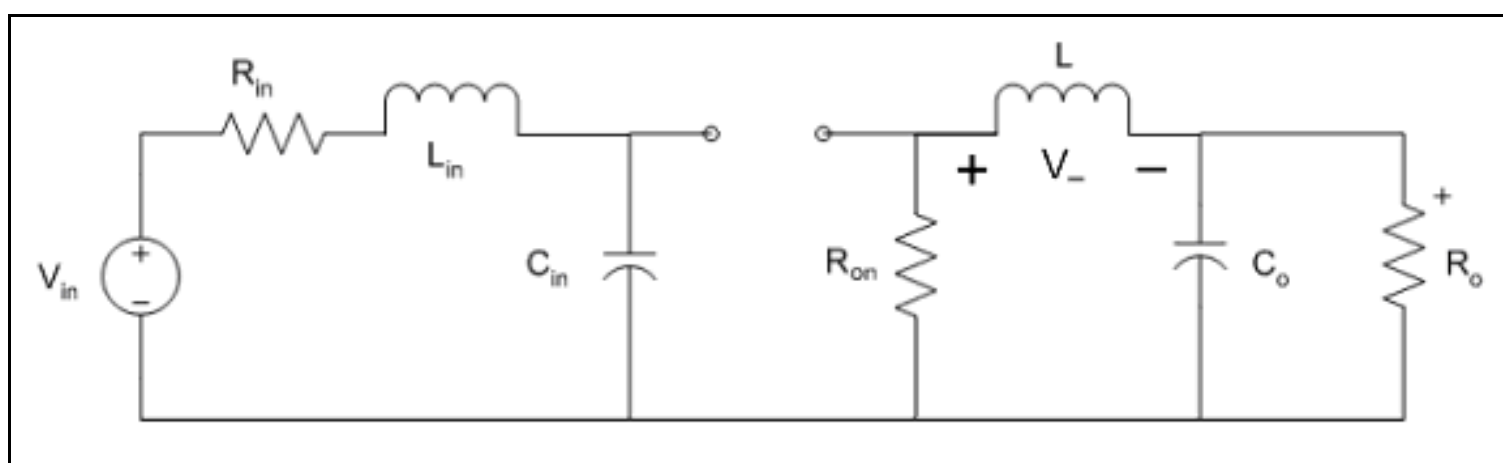

Figure 3-5. Main switch is off, synchronous switch is on and replaced by $R_{o n}$

Referring to Figure 3-5, the voltage across the inductor $\left(\mathrm{V}_{-}\right)$when the main switch is off and the synchronous switch is on and replaced by $R_{o n}$ using $K V L$ is:

$$
V_{-} \approx-R_{O N} I_{S W 2}-V_{o}=-\left(R_{O N} I_{S W 2}+V_{o}\right)
$$

The average steady state voltage across an inductor according to volt-second balance is zero. Because of this $\mathrm{V}_{+}=\mathrm{V}_{\text {. }}$ and setting equations (3-10) and (3-11) equal to each other we have:

$$
D\left(V_{\text {in }}-R_{\text {in }} I_{\text {in }}-R_{O N} I_{L}-V_{o}\right)=(1-D)\left(R_{O N} I_{S W 2}+V_{o}\right)
$$

Substituting equation (3-6) and the current transfer function from equation (3-8) into equation (3-12) yields:

$$
D\left(V_{\text {in }}-R_{\text {in }} D I_{o}-R_{O N} I_{o}-V_{o}\right)=(1-D)\left(R_{O N}(1-D) I_{o}+V_{o}\right)
$$

And simplifying:

$$
\begin{gathered}
D V_{\text {in }}-D^{2} R_{\text {in }} I_{o}-D R_{O N} I_{o}-D V_{o}=R_{O N} I_{o}-D R_{O N} I_{o}+V_{o}-D R_{O N} I_{o}-D^{2} R_{O N} I_{o}-D V_{o} \\
D^{2}\left(R_{i n} I_{o}-R_{O N} I_{o}\right)+D\left(-R_{O N} I_{o}-V_{i n}\right)+\left(R_{O N} I_{o}+V_{o}\right)=0
\end{gathered}
$$


Solving the quadratic equation will give the non-ideal duty cycle taking into account losses in the converter given that the other variables in the equation are known.

\subsubsection{Output Inductor Value}

First, the relationship for inductor voltage as it relates to its current is:

$$
V_{L}=L \frac{d i}{d t} \quad V_{i}-V_{o} \approx L \frac{\Delta i_{L}}{\Delta t}
$$

Because $\frac{d i}{d t} \approx \frac{\Delta i_{L}}{\Delta t}$ due to the high frequency of operation.

Solving for the inductor current ripple we have:

$$
\Delta i_{L}=\frac{V_{i}-V_{o}}{L} D T
$$

Where

$$
T=\frac{1}{f_{s}}
$$

Solving for the inductor value in equation (3-16) yields:

$$
L=\frac{V_{i}-V_{o}}{\Delta i_{L}} D T[\mathrm{H}]
$$

\subsubsection{Input Capacitor}

First, the relationship for capacitor current as it related to its voltage is:

$$
I_{C}=C \frac{d V_{C}}{d t} \approx C \frac{\Delta V_{C}}{\Delta t} \Rightarrow C \approx I_{C} \frac{\Delta t}{\Delta V_{C}}
$$

Because $\frac{d V_{C}}{d t} \approx \frac{\Delta V_{C}}{\Delta t}$ is a fair assumption due to the high operating frequency.

The specification calls for the input capacitor voltage ripple $\Delta \mathrm{V}_{\text {Cin. }}$. To do this, we 
can use the condition when the main switch is open so that the input current is equal to the capacitor current:

$$
I_{c}=I_{i n}=I_{S W 1}=D I_{o}
$$

Substituting equation (3-20) and parameter values into equation (3-19), the input capacitance is found:

$$
C_{i n}=D I_{o} \frac{(1-D) T}{\Delta V_{\text {Cin }}}[\mathrm{F}]
$$

\subsubsection{Main Switch Peak Voltage and Conduction Loss}

Referring to Figure 3-6, we can see that the peak switch voltage occurs when the main switch is open.

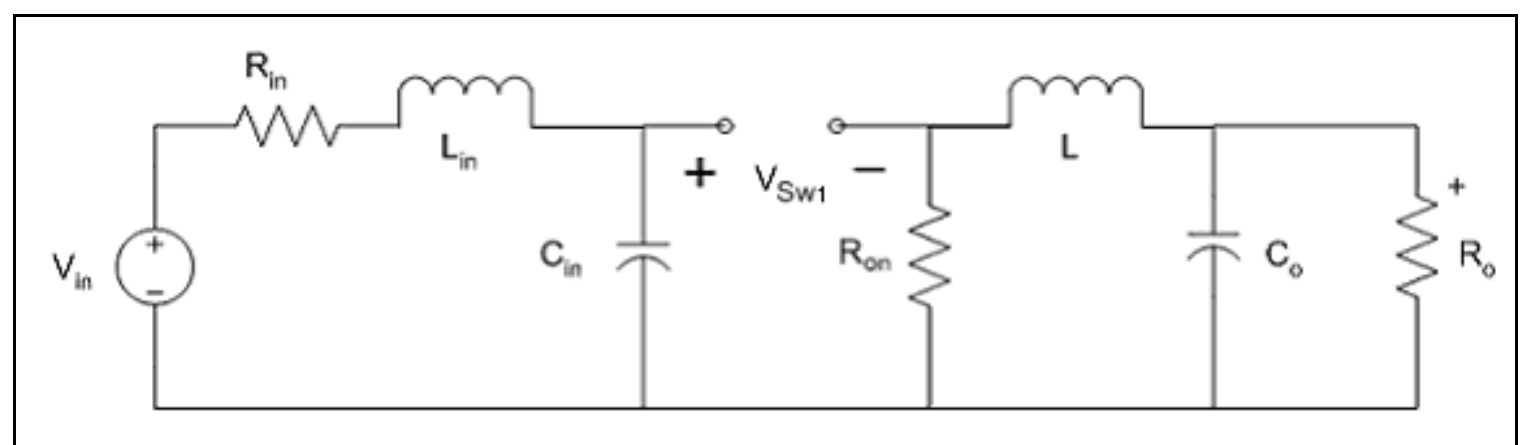

Figure 3-6. Buck converter then the main switch is off

Looking at Figure 3-6 and using KVL:

$$
V_{\text {in }}-R_{\text {in }} I_{\text {in }}-V_{\text {SW1-peak }}-R_{O N}(1-D) I_{o}=0
$$

where $V_{\text {SW1-peak }}$ is the main switch peak voltage.

Rearranging and simplifying gives:

$$
V_{S W 1-\text { peak }}=V_{\text {in }}-R_{O N} I_{o}+D\left(R_{O N} I_{o}-R_{i n} I_{o}\right)
$$


The conduction loss in the main switch is found by first calculating its rms current:

$$
\begin{aligned}
I_{S W 1-r m s} & =\sqrt{\frac{1}{T} \int_{0}^{T} i_{s w 1}^{2}(t) \cdot d t}=\sqrt{\frac{1}{T} \int_{0}^{D T} i_{L}^{2}(t) \cdot d t}=\sqrt{\frac{1}{T} \int_{0}^{D T}\left[I_{L}+\left(i_{L}-I_{L}\right)\right]^{2} \cdot d t} \\
I_{S W 1-r m s} & =\sqrt{\frac{1}{T}\left[I_{L}^{2} \int_{0}^{D T} d t+2 I_{L} \int_{0}^{D T} \Delta i_{L}\left(\frac{t}{D T}-\frac{1}{2}\right) d t+\Delta i_{L}^{2} \int_{0}^{D T}\left(\frac{t}{D T}-\frac{1}{2}\right)^{2} d t\right]}
\end{aligned}
$$

The second and third integrals are approximately zero so equation (3-24) simplifies to:

$$
I_{S W 1-r m s}=I_{L} \sqrt{D}=I_{o} \sqrt{D}
$$

The conduction loss for the main switch at full load is therefore:

$$
P_{S W 1}=I_{S W 1-r m s}^{2} R_{O N}=I_{o}^{2} R_{S O N} D \quad[\mathrm{~W}]
$$

\subsubsection{Synchronous Switch Peak Voltage and Conduction Loss}

Referring to Figure 3.7, the diode peak reverse voltage occurs when the main switch is on, or alternately when the synchronous switch is off.

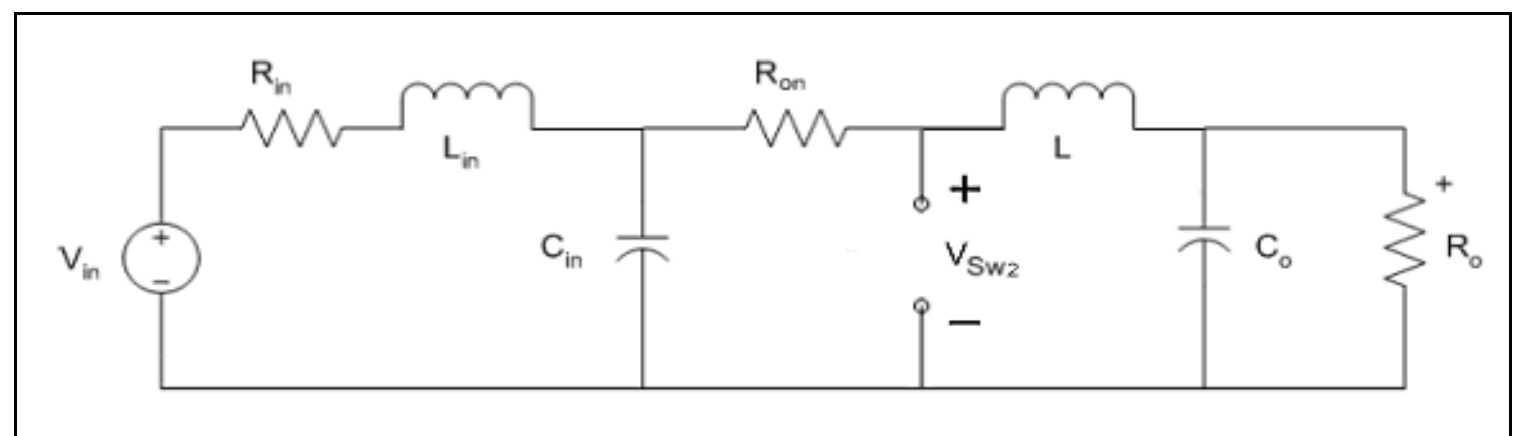

Figure 3-7. Buck converter then the main switch is on

Looking at Figure 3-7 and using KVL:

$$
V_{\text {in }}-R_{\text {in }} I_{\text {in }}-R_{\text {SON }} I_{\text {in }}-V_{S W 2-p e a k}=0
$$

where $V_{\text {Sw2-peak }}$ is the synchronous switch peak voltage. 
Rearranging and simplifying gives:

$$
V_{S W 2-p e a k}=-V_{\text {in }}+I_{o} D\left(R_{\text {in }}+R_{S O N}\right)
$$

As shown in equation (3-24), the conduction loss in the synchronous switch is found by first calculating its rms current, the second and third integrals are approximately zero, so the integral simplifies to:

$$
I_{S W 2-r m s}=\sqrt{\frac{1}{T}\left[I_{L}^{2} \int_{D T}^{(1-D) T} d t\right]}=I_{L} \sqrt{1-2 D}=I_{o} \sqrt{1-2 D}
$$

We can now derive the equation for the conduction loss of the main switch:

$$
P_{S W 2}=I_{S W 2-r m s}^{2} R_{O N}=I_{o}^{2} R_{S O N}(1-2 D)[\mathrm{W}]
$$

\subsection{Design Requirements}

\begin{tabular}{|l|c|}
\hline Parameters & Specification \\
\hline Test Input Voltage Range & $10.8 \mathrm{~V}$ to $13.2 \mathrm{~V}$ \\
\hline Nominal Test Input Voltage & $12 \mathrm{~V}$ \\
\hline Nominal Output Voltage & $1 \mathrm{~V}$ \\
\hline Maximum Output Current & $40 \mathrm{~A}$ \\
\hline Output Voltage Ripple & $<50 \mathrm{mV}_{\mathrm{pp}}(<5 \%)$ \\
\hline Percent Line Regulation & $<2 \%$ \\
\hline Percent Load Regulation & $<5 \%$ \\
\hline Full Load Efficiency & $>80 \%$ @ Full Load \\
\hline Measured Switching Frequency & $500 \mathrm{kHz}$ per phase (2MHz overall) \\
\hline Equal Current Sharing & $10 \mathrm{~A} \mathrm{each} \mathrm{phase} \mathrm{@} \mathrm{Full} \mathrm{Load}$ \\
\hline Circuit Board Area & $35 \mathrm{in}^{2}(50 \%$ of previous board) \\
\hline
\end{tabular}

Table 3-1. Design Requirements

Table 3-1 lists the design requirements for the project described in this thesis. These design requirements were chosen from the previous work described in the theses by Kay Ohn [15] and lan Waters [24]. These requirements were mainly derived from Intel's VRM specifications. The standard input voltage for computer power supplies is $12 V_{D C}$ and this value should be 
allowed to fluctuate by $\pm 10 \%$, therefore the input ranges from $10.8 \mathrm{~V}$ to $13.2 \mathrm{~V}$. Additions to the previous design requirements are for equal current sharing and for circuit board area. Successful current sharing would mean that each phase provides an equal amount of output current or $10 \mathrm{~A}$ in the case of full load current. The circuit board requirement is a board with double the current density of the previous board, or a board that is half the area. The previous boards were 70 square inches meaning that this board should be 35 square inches or less [15][24].

\subsection{Design Calculations}

The design calculations in this report were performed using the equations derived in sections 3.1 and 3.2, along with the specifications given in section 3.3. Those equations were used in conjunction with MathCAD 14 software in order to perform the calculations shown in this section. The parameters that are needed and used for calculation purposes throughout this section are:




Items to note are as follows: $N$ represents the number of phases, $f_{\text {osc }}$ is the oscillating frequency which is the frequency that is seen by the input and output, $I_{o}$ are the individual phase currents ranging from $10 \%$ to $100 \%$ load, and $n$ is the matrix index for $I_{0}$ which ranges from 0 to 9 . $I_{\text {omax }}$ represents the total output maximum load current or $40 \mathrm{~A}$ for this thesis.

We will start by finding the size of the output inductor and use that to find the theoretical output current ripple. First the on-time of the phase 1 main switch was found. The on-time of the other three phases will be the same length. Next the output current ripple per phase was found. Assuming that equal current sharing is occurring, all the phases would have this value as their current ripple. A value around 10 to 12 percent current ripple was chosen because this range leads to a nice tradeoff between the amount of ripple and the size of the inductor needed to obtain it. The higher the inductance value the lower the ripple and vice versa. Large inductances lead to smaller ripple, fewer conductor losses, and higher efficiencies, however they are large, bulky, and expensive so a tradeoff must be made between the two [23]. With the output current or each phase ranging from $10 \%$ to $12 \%$ ripple the output inductor values range from approximately $1.55 \mu \mathrm{H}$ to $1.85 \mu \mathrm{H}$. Choosing a convenient inductor size of $1.75 \mu \mathrm{H}$ leads to an inductor ripple of $1.047 \mathrm{~A}$ per phase which corresponds to a percent ripple of $10.47 \%$. With the inductor value now chosen, we can find the net output current ripple, which will be smaller than the per phase current ripple due to the 4 phases. See calculations below for specifics. 


\section{Finding Output Current Ripple and Output Inductor Value}

The ideal on-time of the phase 1 main switch

ton $:=\frac{V_{0}}{V i n} \cdot \frac{1}{\text { fosc }}$ ton $=4.167 \times 10^{-8} \mathrm{~s}$

Output current ripple per phase

I $\phi$ ripple $:=0.10475 \mathrm{Io}_{9} \quad$ I $\phi r i p p l e=1.047 \mathrm{~A}$

Inductor value

$\mathrm{L}_{\mathrm{M}}:=\frac{(\text { Vin }- \text { Vo }) \cdot \text { Vo }}{\text { Vin. fs } \cdot \text { I } \phi \text { ripple }} \quad \mathrm{L}=1.75 \times 10^{-6} \mathrm{H}$

Net output current ripple

Iripple $:=\frac{\mathrm{N} \cdot \text { Vo } \cdot\left(\text { Vin }-\mathrm{N} \cdot \mathrm{Vo}_{\mathrm{o}}\right)}{\mathrm{Vin} \cdot \mathrm{L} \cdot \mathrm{fosc}} \quad$ Iripple $=0.762 \mathrm{~A}$

Now that the net output inductor current ripple has been found we can use this information to find the output capacitance value and output capacitor ripple. For the output capacitance, five output capacitors will be used in parallel in order to both reduce the ESR and increase the capacitance value. Assume a modest ESR capacitor has $E S R=50 \mathrm{~m} \Omega$, five in parallel would have a fifth of the series resistance or $E S R=10 \mathrm{~m} \Omega$. The capacitor value can then be found as shown, which takes into account duty cycle, output voltage, inductor, switching frequency, and output voltage ripple limit. The total capacitor ripple is due to both the charging and discharging of the capacitor as well as the ESR of the capacitor. The total capacitor ripple value is found as shown. 


\section{Finding Output Capacitor Value}

ESR Value

ESR $:=0.01 \Omega$

Finding capacitor value

$$
\mathrm{Co}:=\frac{(1-\mathrm{D}) \cdot \mathrm{Vo}}{8 \cdot \mathrm{L} \cdot \mathrm{fs}^{2} \cdot \Delta \mathrm{Vo}_{\mathrm{o}}} \quad \mathrm{Co}=5.237 \times 10^{-6} \mathrm{~F}
$$

Ripple due to capacitor charge and discharge

$$
\Delta \mathrm{Vc}:=\frac{\text { Iripple } \cdot \mathrm{Ts}}{8 \mathrm{Co}} \quad \Delta \mathrm{Vc}=0.036 \mathrm{~V}
$$

Ripple due to capacitor ESR

$$
\begin{array}{ll}
\Delta \text { Vesr }:=\text { Iripple } \cdot \text { ESR } & \Delta \text { Vesr }=7.618 \times 10^{-3} \mathrm{~V} \\
\Delta \text { Vtot }:=\Delta \mathrm{Vc}+\Delta \text { Vesr } & \Delta \text { Vtot }=0.044 \mathrm{~V}
\end{array}
$$

These calculations are for the ideal case and yield a capacitor ripple voltage of $44 \mathrm{mV}$. In reality, the capacitance was increased to $1100 \mu \mathrm{F}$ in order to meet the hardware specifications. For this reason, the above calculations were performed again using $\mathrm{C}_{\text {out }}=1100 \mu \mathrm{F}$. As expected, this increase in the capacitance yields a decrease in the ripple voltage for the capacitor as shown.

$$
\text { Actual capacitor value used } \quad \text { Cout }:=1.1 \cdot 10^{-3} \mathrm{~F}
$$

Ripple due to capacitor charge and discharge

$$
\Delta \mathrm{Vc}_{\mathrm{c}}:=\frac{\text { Iripple } \mathrm{Ts}}{8 \text { Cout }} \quad \Delta \mathrm{Vc}=1.731 \times 10^{-4} \mathrm{~V}
$$

Ripple due to capacitor ESR

$$
\begin{array}{ll}
\Delta \mathrm{Vesr}_{\mathrm{N}}:=\text { Iripple.ESR } & \Delta \mathrm{Vesr}=7.618 \times 10^{-3} \mathrm{~V} \\
\Delta \mathrm{Vtot}:=\Delta \mathrm{Vc}+\Delta \mathrm{Vesr} & \Delta \mathrm{Vtot}=7.791 \times 10^{-3} \mathrm{~V}
\end{array}
$$


Now that the critical components have been selected it is time to find the real power losses that exist with each component. The first step towards finding the power loss of the output capacitor involves finding the RMS current that travels through it, as the calculation shows.

\section{RMS capacitor current}

Equation of IL during ON time

$\operatorname{IL1}(\mathrm{t}):=$ Iomax - Iripple $+\frac{\text { Iripple }}{\text { ton }} \cdot \mathrm{t}$

Equation of IL during OFF time

$$
\operatorname{IL2}(\mathrm{t}):=\text { Iomax }+ \text { Iripple }+\frac{- \text { Iripple }}{\text { Ts }- \text { ton }} \cdot \mathrm{t}
$$

$$
\text { Icrms }:=\sqrt{\frac{1}{\mathrm{Ts}} \cdot\left[\int_{0 \mathrm{~s}}^{\mathrm{ton}}(\operatorname{IL} 1(\mathrm{t})-\operatorname{Iomax})^{2} \mathrm{dt}+\int_{\text {ton }}^{\mathrm{Ts}}(\operatorname{IL2}(\mathrm{t})-\operatorname{Iomax})^{2} \mathrm{dt}\right.}
$$

Icrms $=0.426 \mathrm{~A}$

Having found the RMS current traveling through the output capacitor, we can now find the power loss associated with the capacitor. As stated before, there will be five output capacitors that are each $220 \mu \mathrm{F}$ and have an ESR of $50 \mathrm{~m} \Omega$. With this the power losses can be found as shown.

\section{Critical Component Losses:}

Output capacitor (each)

Capacitance:

$$
\begin{aligned}
& \mathrm{Co}:=220 \cdot 10^{-6} \mathrm{~F} \\
& \text { ESRCo }:=50 \cdot 10^{-3} \Omega
\end{aligned}
$$

ESR:

Output capacitor (total - 5 in parallel)

Capacitance:

ESR:

Losses on the output capacitor:
Cotot $:=110010^{-6} \mathrm{~F}$

ESRCotot $:=10 \cdot 10^{-3} \Omega$

$$
\text { Pocap }:=(\text { Icrms })^{2} \cdot \text { ESRCotot } \quad \text { Pocap }=1.816 \times 10^{-3} \mathrm{~W}
$$


The other major components that will contribute significant power losses are the main and synchronous switches, but each one will contribute losses in a different manner. The main MOSFET (part number IPP14N03LA) will be off for a majority of the time and switching losses will be dominant. In this case we want a MOSFET with a low total gate charge, $Q_{g}$. For this analysis for the main MOSFET and the power losses associated with it, the following parameters are key and were taken from the manufacturer's datasheet: the total gate charge $\left(Q_{g}\right)$, output capacitance $\left(C_{o s s}\right)$, rise time $\left(t_{r}\right)$, fall time $\left(t_{f}\right)$, gate source voltage $\left(V_{g}\right)$, and on-resistance $\left(R_{d s o n}\right)$. These key parameters are used to find the switching losses $\left(P_{s w}\right)$, conduction losses $\left(P_{\text {cond }}\right)$, and the total losses on the main MOSFET $\left(P_{\operatorname{mos}}\right)$ as shown [11]. 


\section{Main MOSFET}

These values are all obtained from the datasheet of the MOSFET

$$
\begin{aligned}
& \operatorname{Qg} 1:=6.3 \times 10^{-9} \mathrm{C} \\
& \operatorname{Coss} 1:=303 \times 10^{-12} \mathrm{~F} \\
& \operatorname{Tr} 1:=33 \times 10^{-9} \mathrm{~s} \\
& \operatorname{Tf} 1:=2.6 \times 10^{-9} \mathrm{~s}
\end{aligned}
$$

Gate Drive Voltage: $\quad \operatorname{Vg} 1:=20 \mathrm{~V} \quad \operatorname{Rdson} 1:=0.0139 \Omega$

$\operatorname{Pgd} 1:=\mathrm{Qg} 1 \cdot \operatorname{Vg} 1 \cdot \mathrm{fs} \quad \operatorname{Pgd} 1=0.063 \mathrm{~W}$

$\operatorname{Psw}_{\mathrm{n}}:=\frac{1}{4} \cdot \mathrm{Io}_{\mathrm{n}} \cdot \operatorname{Vin} \cdot(\mathrm{Tf} 1+\operatorname{Tr} 1) \cdot \mathrm{fs}+\frac{1}{2} \cdot \operatorname{Coss} 1 \cdot \mathrm{Vin}^{2} \cdot \mathrm{fs}$

Pcond $1_{\mathrm{n}}:=\left(\mathrm{Io}_{\mathrm{n}}\right)^{2} \cdot \mathrm{Rdson} 1 \cdot \mathrm{D}$

$\operatorname{Pmos} 1_{n}:=\left(\operatorname{Pgd} 1+\operatorname{Psw} 1_{n}+\operatorname{Pcond} 1_{n}\right)$

$$
\text { Pcond } 1=\begin{array}{|r|r|}
\hline & \multicolumn{1}{|c|}{0} \\
\hline 0 & 1.158 \cdot 10^{-3} \\
\hline 1 & 4.633 \cdot 10^{-3} \\
\hline 2 & 0.01 \\
\hline 3 & 0.019 \\
\hline 4 & 0.029 \\
\hline 5 & 0.042 \\
\hline 5 & 0.057 \\
\hline 6 & 0.074 \\
\hline 7 & 0.094 \\
\hline 8 & 0.116 \\
\hline 9 & \\
\hline
\end{array}
$$

\begin{tabular}{|c|c|}
\hline & 0 \\
\hline 0 & 0.064 \\
\hline 1 & 0.118 \\
\hline 2 & 0.171 \\
\hline 3 & 0.225 \\
\hline 4 & 0.278 \\
\hline 5 & 0.331 \\
\hline 6 & 0.385 \\
\hline 7 & 0.438 \\
\hline 8 & 0.492 \\
\hline 9 & 0.545 \\
\hline
\end{tabular}

The synchronous MOSFET (part number IPP06N03LA) will be on for a majority of the time and conduction losses will be dominant. In this case we want a MOSFET with a low $R_{\text {dson. }}$ For this analysis for the synchronous MOSFET and the power losses associated with it, the following parameters are key and were taken from the manufacturer's datasheet: the gate charge total $\left(Q_{g}\right)$, output capacitance $\left(\mathrm{C}_{\mathrm{oss}}\right)$, rise time $\left(\mathrm{t}_{\mathrm{r}}\right)$, fall time $\left(\mathrm{t}_{\mathrm{f}}\right)$, gate source voltage $\left(\mathrm{V}_{\mathrm{g}}\right)$, and on- 
resistance $\left(R_{d s o n}\right)$. These key parameters are used to find the switching losses $\left(P_{s w}\right)$, conduction losses $\left(P_{\text {cond }}\right)$, and the total losses on the main MOSFET ( $\left.P_{\text {mos }}\right)$ as shown [10].

\section{Synchronous MOSFET}

These values are all obtained from the datasheet of the MOSFET

$$
\begin{aligned}
& \operatorname{Qg} 2:=17 \times 10^{-9} \mathrm{C} \\
& \operatorname{Coss} 2:=800 \times 10^{-12} \mathrm{~F} \\
& \operatorname{Tr} 2:=30 \times 10^{-9} \mathrm{~s} \\
& \operatorname{Tf} 2:=4.4 \times 10^{-9} \mathrm{~s}
\end{aligned}
$$

Gate Drive Voltage: $\quad \operatorname{Vg} 2:=20 \mathrm{~V} \quad \operatorname{Rdson} 2:=0.006 \Omega$

$$
\operatorname{Pgd} 2:=\mathrm{Qg} 2 \cdot \operatorname{Vg} 2 \cdot \mathrm{fs} \quad \operatorname{Pgd} 2=0.17 \mathrm{~W}
$$$$
\operatorname{Psw}_{\mathrm{n}}:=\frac{1}{4} \cdot \mathrm{Io}_{\mathrm{n}} \cdot \operatorname{Vin} \cdot(\mathrm{Tf} 2+\operatorname{Tr} 2) \cdot \mathrm{fs}+\frac{1}{2} \cdot \operatorname{Coss}_{2} \cdot \mathrm{Vin}^{2} \cdot \mathrm{fs}
$$$$
\text { Pcond } 2_{\mathrm{n}}:=\left(\frac{\mathrm{Io}_{\mathrm{n}}}{2}\right)^{2} \cdot \operatorname{Rdson} 2 \cdot(1-\mathrm{D})
$$$$
\operatorname{Pmos} 2_{n}:=\left(\operatorname{Pgd} 2+\operatorname{Psw} 2_{n}+\operatorname{Pcond} 2_{n}\right)
$$

$\operatorname{Pmos} 2=$\begin{tabular}{|r|r|}
\hline & 0 \\
\hline 0 & 0.252 \\
\hline 1 & 0.308 \\
\hline 2 & 0.366 \\
\hline 3 & 0.428 \\
\hline 4 & 0.492 \\
\hline 5 & 0.56 \\
\hline 6 & 0.63 \\
\hline 7 & 0.703 \\
\hline 8 & 0.778 \\
\hline 9 & 0.857 \\
\hline
\end{tabular}

Pcond $2=$\begin{tabular}{|r|r|}
\hline & \multicolumn{1}{|c|}{0} \\
\hline 0 & $1.421 \cdot 10^{-3}$ \\
\hline 1 & $5.683 \cdot 10^{-3}$ \\
\hline 2 & 0.013 \\
\hline 3 & 0.023 \\
\hline 4 & 0.036 \\
\hline 5 & 0.051 \\
\hline 6 & 0.07 \\
\hline 7 & 0.091 \\
\hline 8 & 0.115 \\
\hline 9 & 0.142 \\
\hline
\end{tabular}

\begin{tabular}{|r|r|}
\hline & \multicolumn{1}{|c|}{0} \\
\hline 0 & 0.08 \\
\hline 1 & 0.132 \\
\hline 2 & 0.184 \\
\hline 3 & 0.235 \\
\hline 4 & 0.287 \\
\hline 5 & 0.338 \\
\hline 6 & 0.39 \\
\hline 7 & 0.442 \\
\hline 8 & 0.493 \\
\hline 9 & 0.545 \\
\hline
\end{tabular}

The total power loss $\left(\mathrm{P}_{\text {tot }}\right)$, taking into account the capacitor, main MOSFET, and synchronous MOSFET, for the converter can now be found. The output power $\left(\mathrm{P}_{\text {out }}\right)$ and input power $\left(\mathrm{P}_{\text {in }}\right)$ can also be found, with the input power 
being equal to the output power plus the power losses. Finally the efficiency can be found with $\eta=P_{\text {out }} / P_{\text {in }}$, as is shown.

\begin{tabular}{|c|c|c|c|c|c|c|c|}
\hline \multirow{11}{*}{ Ptot $:=$ Pmos $1 \cdot 4+$ Pmos $2 \cdot 4+$ Pocap } & & 0 & \multirow{11}{*}{ W } & & & 0 & \multirow{22}{*}{ W } \\
\hline & 0 & 1.523 & & & & 4 & \\
\hline & 1 & 1.974 & & & & 8 & \\
\hline & 2 & 2.445 & & & & 12 & \\
\hline & 3 & 2.938 & & & & 16 & \\
\hline & 4 & 3.451 & & Pout $:=4 \cdot \mathrm{Vo} \cdot \mathrm{Io}$ Pou & & 20 & \\
\hline & 5 & 3.984 & & & & 24 & \\
\hline & 6 & 4.538 & & & & 28 & \\
\hline & 7 & 5.113 & & & & 32 & \\
\hline & 8 & 5.708 & & & & 36 & \\
\hline & 9 & 6.324 & & & & 40 & \\
\hline \multirow{11}{*}{ Pin $:=$ Pout + Ptot $=$} & & 0 & \multirow{11}{*}{\multicolumn{2}{|c|}{$\frac{\text { Pout }}{\text { Pin }}=$}} & & 0 & \\
\hline & 0 & 5.523 & & & 0 & 0.724 & \\
\hline & 1 & 9.974 & & & 1 & 0.802 & \\
\hline & 2 & 14.445 & & & 2 & 0.831 & \\
\hline & 3 & 18.938 & & & 3 & 0.845 & \\
\hline & 4 & 23.451 & & & 4 & 0.853 & \\
\hline & 5 & 27.984 & & & 5 & 0.858 & \\
\hline & 6 & 32.538 & & & 6 & 0.861 & \\
\hline & 7 & 37.113 & & & 7 & 0.862 & \\
\hline & 8 & 41.708 & & & 8 & 0.863 & \\
\hline & 9 & 46.324 & & & 9 & 0.863 & \\
\hline
\end{tabular}

Using the input power, output power, and power loss that were calculated, a theoretical efficiency and power loss versus load current was created. Figure 3-8 shows the theoretical efficiency plot for the proposed converter. The converter efficiency reaches a maximum value of $86.3 \%$ from $36 \mathrm{~A}$ to $40 \mathrm{~A}$. The converter also remains more than $85 \%$ efficient down to a $20 \mathrm{~A}$ load. With the efficiency above $85 \%$, it is a good indication the hardware design will also be 
highly efficient. The calculated results meet the system requirements for overall efficiency.

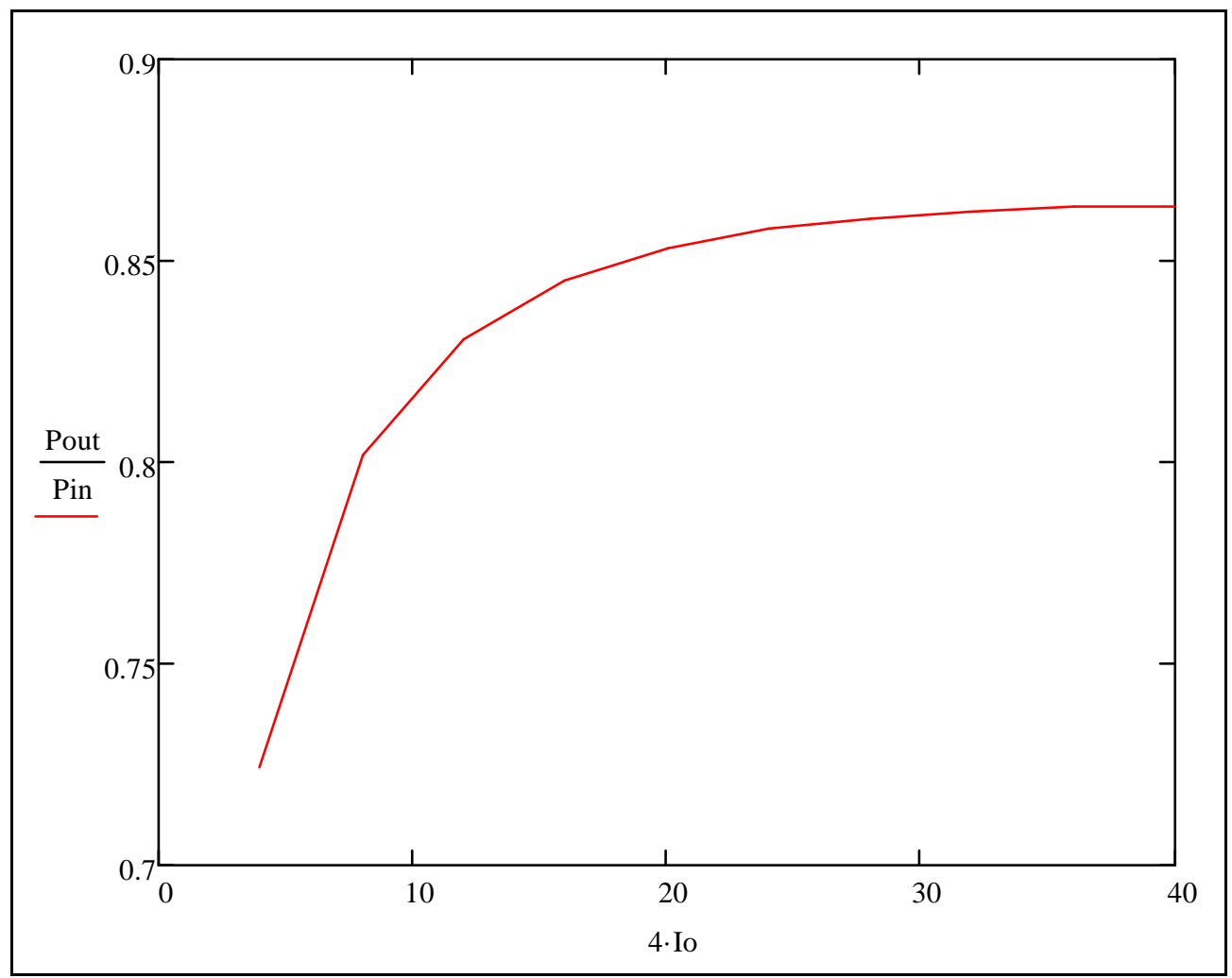

Figure 3-8. Theoretical Efficiency plot versus load current

Figure 3-9 shows the theoretical power loss plot for the proposed

converter. The plot shows a relatively linear relationship between power loss and load current. This is good because it means even as the output power the converter reaches a maximum value, the power losses stay consistence with the losses at smaller loads. The highest losses occur at a 40A load and were equal to $6.324 \mathrm{~W}$. 




Figure 3-9. Theoretical power loss plot versus load current

\subsection{MOSFET Selection}

To reduce losses due to the MOSFETs, the following strategy will be implemented. For the main switch, a MOSFET with a low $Q_{g}$ will be used because switching loss will be dominant. For the synchronous switch, a MOSFET with a low $R_{d s o n}$ will be used because here the conduction losses will be dominant. Also for the synchronous MOSFET, the gate to source charge $\left(Q_{g s}\right)$ should be greater than the gate to drain charge $\left(Q_{g d}\right)$. This is because when the switch node is falling, the $Q_{g d}$ can pull the gate of the lower MOSFET below ground which upsets the driver. In other words, having $Q_{g s}>Q_{g d}$ prevents the synchronous switch from turning on when the main switch starts to turn on [23]. 


\subsection{Controller Selection}

For this thesis, the TPS40090 controller from Texas Instruments was chosen because it has the ability to handle up to 4 phases and can handle a switching frequency of $500 \mathrm{kHz}$ [22]. The four TPS2832 MOSFET gate drivers were selected because of their speed and current capacity for driving the gates of the selected MOSFETs [12]. For comparative study, parts used in the previous work were also implemented in this thesis to better analyze the changes made, resulting in meaningful conclusions regarding how interleaving, carefully selecting switches, LC input filtering, and size reduction effects the overall results. 
The next stage of development for the multiphase interleaving buck converter is a computer simulation to verify the calculated results. Simulation is a convenient method to verify theory and test different designs without using large amounts of time, money, and resources building, designing, and testing an actual circuit board. For this simulation an open loop test was performed. It did not involve feedback and because of this it was not possible to create efficiency or power loss versus percent load plots, find load and line regulation, or measure the transient response of the converter. However, many useful measurements were obtained from the open loop simulation and are shown in section 4.1.

\section{$\underline{4.1 \text { Simulation Results }}$}

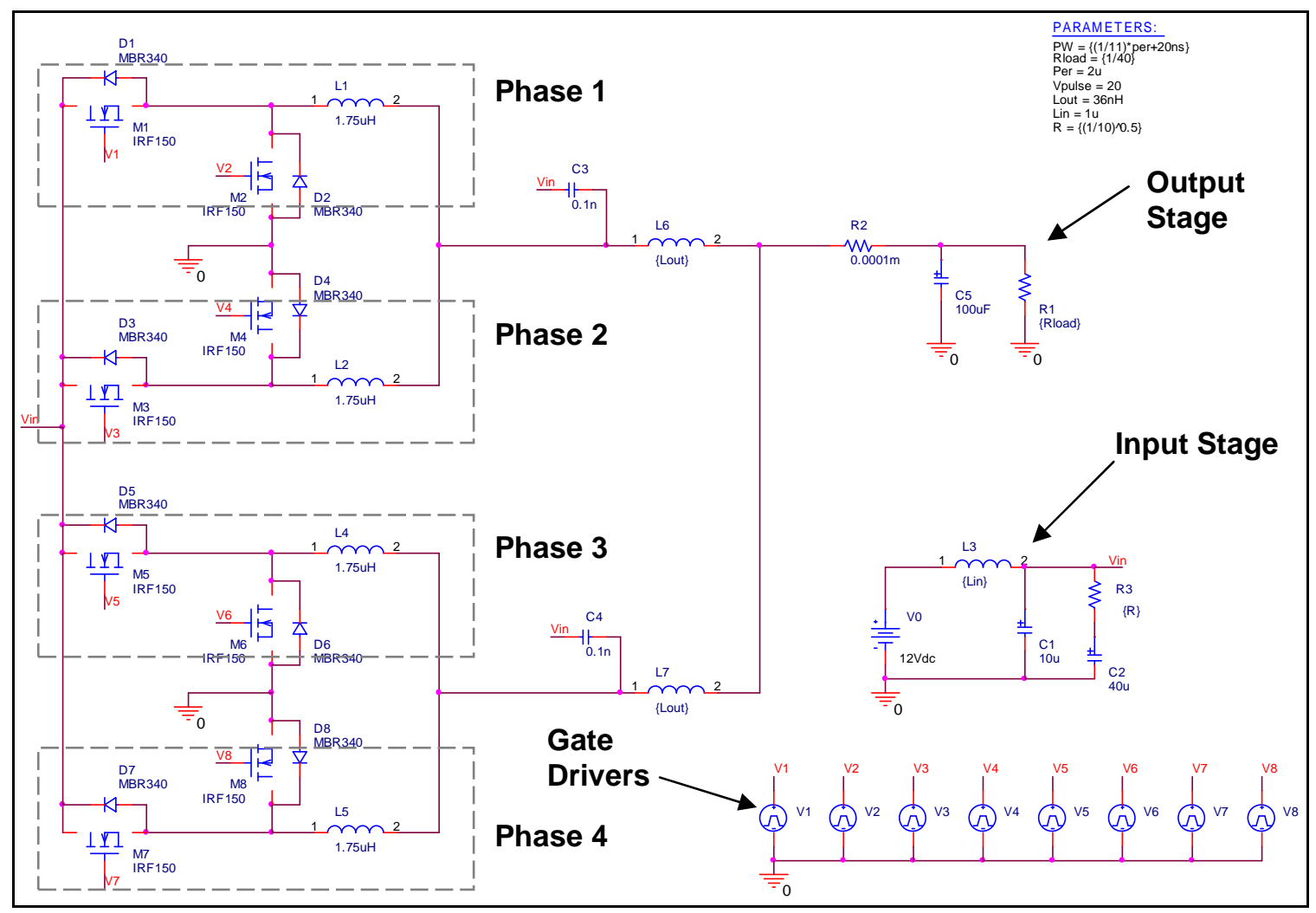

Figure 4-1. Open-Loop schematic of proposed multiphase buck converter 
Figure 4-1 illustrates the schematic created for the proposed topology using OrCAD Capture CIS. The power MOSFETs used for both the main switch and for the synchronous switch is IRF150, while the freewheeling diodes are all Schottky MBR340. The input stage consists of the LC with RC damping filter that was discussed in section 2.6. The gate drivers for each of the main and synchronous switches are generated by pulse voltages from V1 through V8 and are equal to $20 \mathrm{~V}$, which is the required voltage to drive the gates of the MOSFETs. The rise time and fall time of each of the switches is set to $10 \mathrm{~ns}$ to eliminate any short to ground shoot through conditions. The PARAMETERS function was used for simplicity in adjusting circuit parameters. As can be seen in the PARAMETERS list, the duty cycle required to make an output voltage of exactly $1 \mathrm{~V}$ is $1 / 11$ or $9.1 \%$. The period is $2 \mu$ s which is a switching frequency of $500 \mathrm{kHz}$. The load resistor is set to $1 / 40$ or $0.025 \Omega$ to draw the full load current. The values of the inductors and output capacitor used in the simulation were calculated in the design equations section of the report. The results shown below were obtained with simulation time of $2 \mathrm{~ms}$ to ensure the system reached a steady state value. 


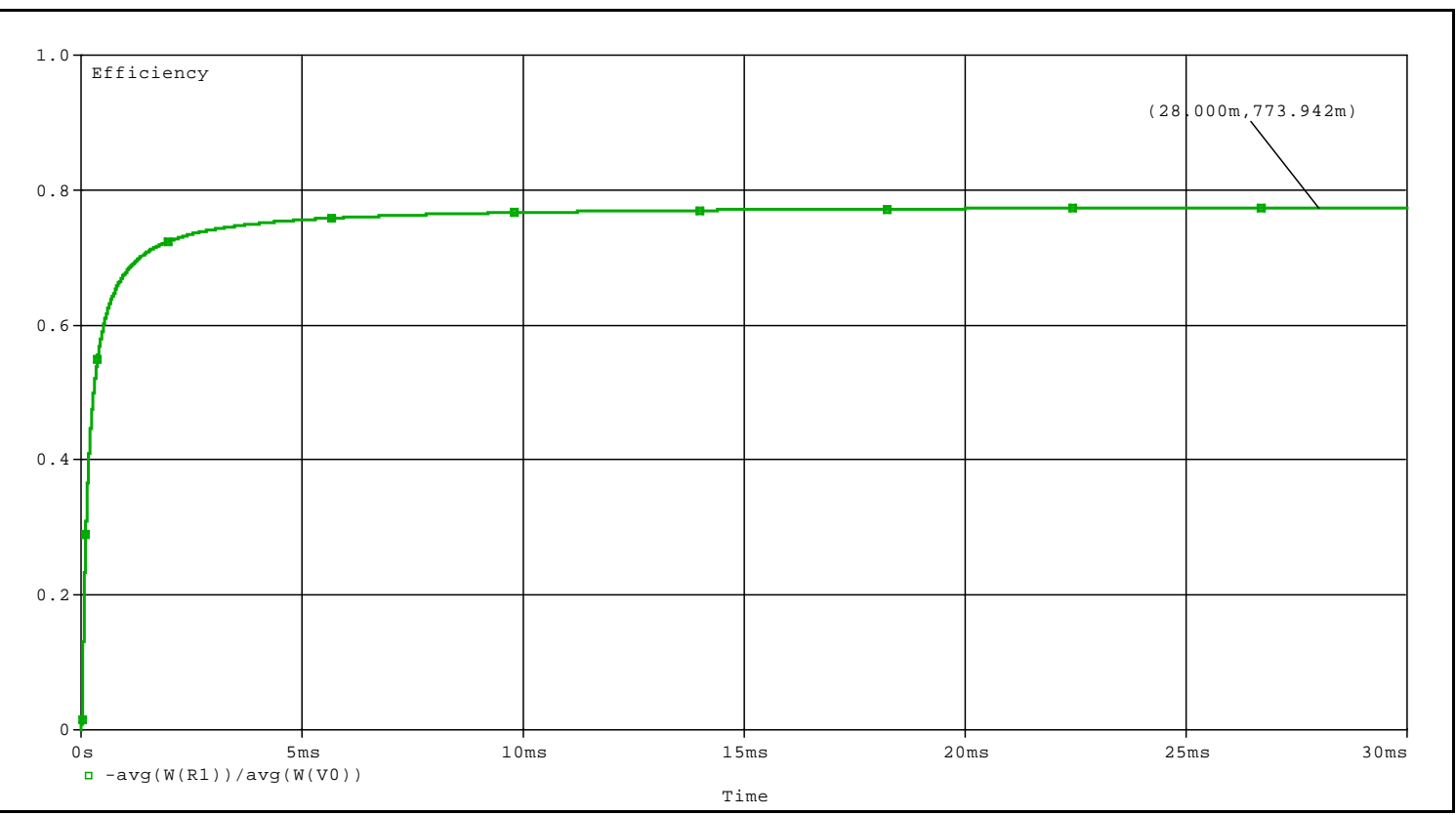

Figure 4-2. Efficiency at full load, $\eta=77.4 \%$

The efficiency plot shown in Figure 4-2 was created by plotting average output power divided by the average input power: $\eta=P_{\text {out }} / P_{\text {in }}$. Due to a large startup current at the input, which is shown in Figure 4-9, it was required to run the simulation for $30 \mathrm{~ms}$ in order for a steady state value to be obtained. The steady state efficiency at full load was $\eta=77.4 \%$. 


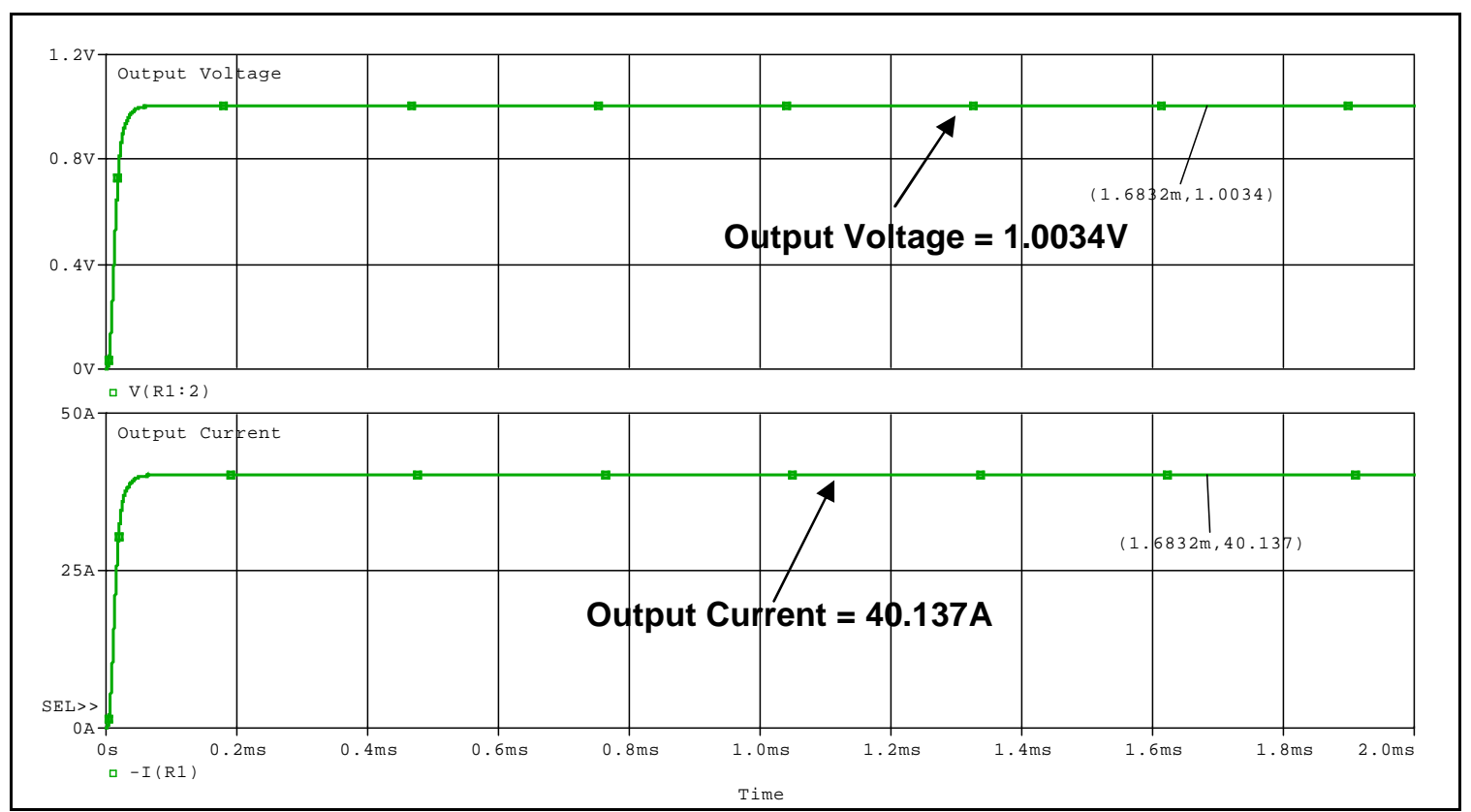

Figure 4-3. Output voltage and current waveforms at full load

The output voltage and current waveforms of Figure 4-3 show the output current reaching a steady state value of $1.0034 \mathrm{~V}$ in approximately $75 \mu$ s while the output current reached a steady state value of $40.137 \mathrm{~A}$ in approximately $75 \mu \mathrm{s}$. The results illustrate a simulation that meets the design specifications for an output voltage of $1 \mathrm{~V}$ and output current of $40 \mathrm{~A}$. The output voltage ripple is shown in Figure 4-4 which shows a close up view of the output voltage waveform shown in Figure 4-3. We can see that the output voltage peak-to-peak ripple is $483.9 \mu \mathrm{V}_{\mathrm{pp}}$. Recall, the specification called for the maximum allowable output voltage peak-to-peak ripple of $50 \mathrm{mV}$ pp , so this ripple specification has easily been met. Another item to note involves the frequency of the output voltage ripple. It has a period of $500.04 \mathrm{~ns}$ which corresponds to a frequency of $1.99 \mathrm{MHz}$. As discussed in section 2.5, the output ripple frequency should be $\mathrm{N}$ times the switching frequency (where $\mathrm{N}$ is the number of phase or 4 in this thesis project). 
The ideal output ripple frequency would then be $2 \mathrm{MHz}$, which is very close to the measured value from the simulation.

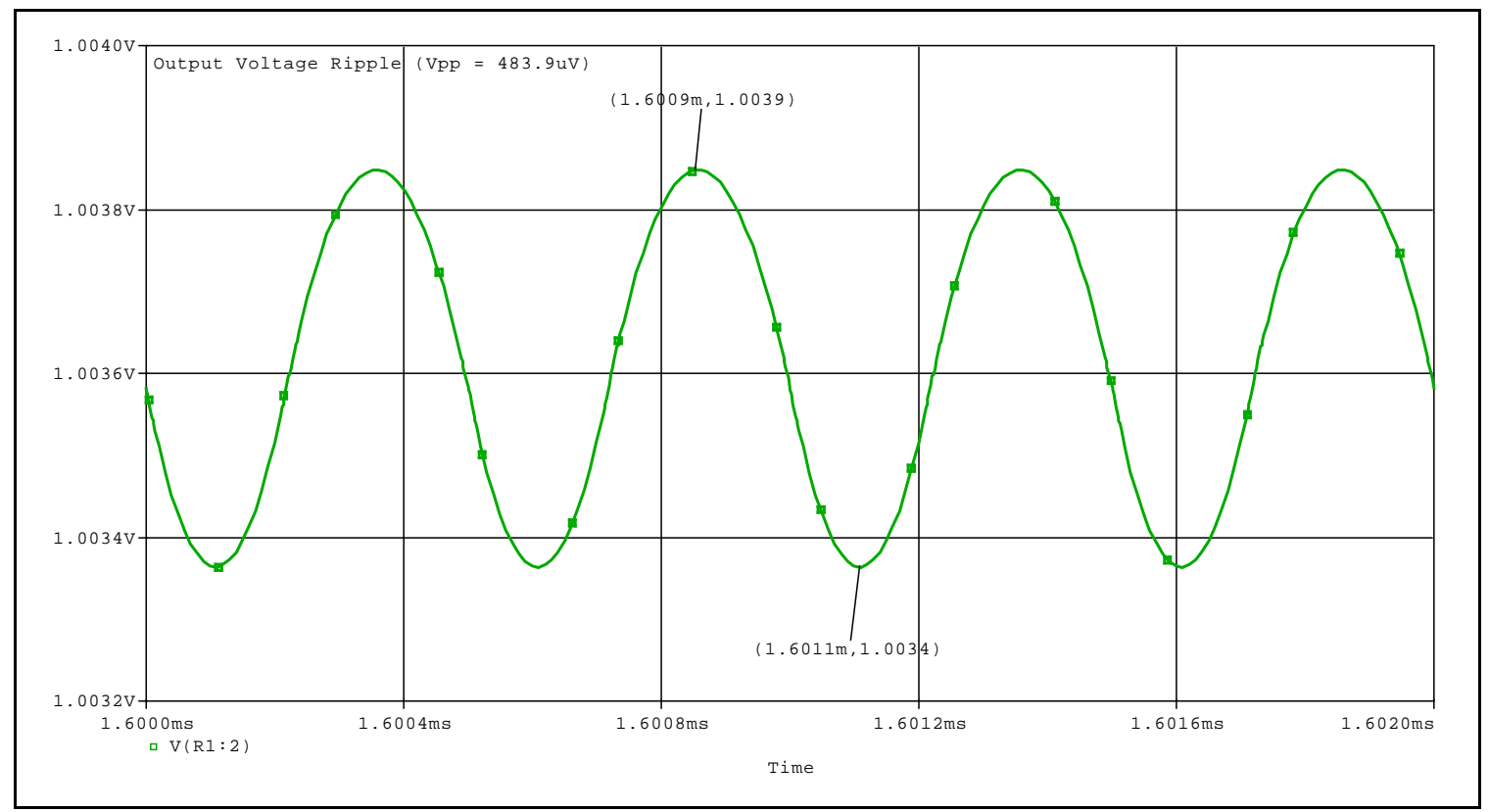

Figure 4-4. Output voltage peak-to-peak ripple at full load, $\mathrm{V}_{\mathrm{pp}}=483.9 \mu \mathrm{V}$

The waveforms in Figure 4-5 shows the inductor current through the phase 1 and phase $21.75 \mu \mathrm{H}$ inductors (L1 and L2) as well as their sum which passes through the $36 \mathrm{nH}$ inductor (L6). Note that the phase 1 and phase 2 currents are $180^{\circ}$ apart, or shifted by half the period $(1 \mu \mathrm{s})$ as expected. The average current, peak-to-peak ripple, and frequency of phases 1 and 2 are identical which indicates proper current sharing between the phases. Their average current is $10.038 \mathrm{~A}$ per phase, with a peak-to-peak ripple of $1.22 \mathrm{~A}$, and a period of $2.0 \mu$ s which corresponds to the actual switching frequency of $500 \mathrm{kHz}$. Independently, phase 1 and 2 look like a single phase buck, so the ripple frequency and the switching frequency should be equal. The current flowing through inductor L6 is the sum of the top two phases: phase 1 and phase 2 . The 
average current through inductor L6 is $20.0745 \mathrm{~A}$, with a peak-to-peak ripple of $1.03 \mathrm{~A}$, and a period of $1.002 \mu \mathrm{s}$ which corresponds to half the output switching frequency of $998 \mathrm{kHz}$. The decrease in peak-to-peak ripple in inductor currents and increase in frequency occur as predicted by theory.

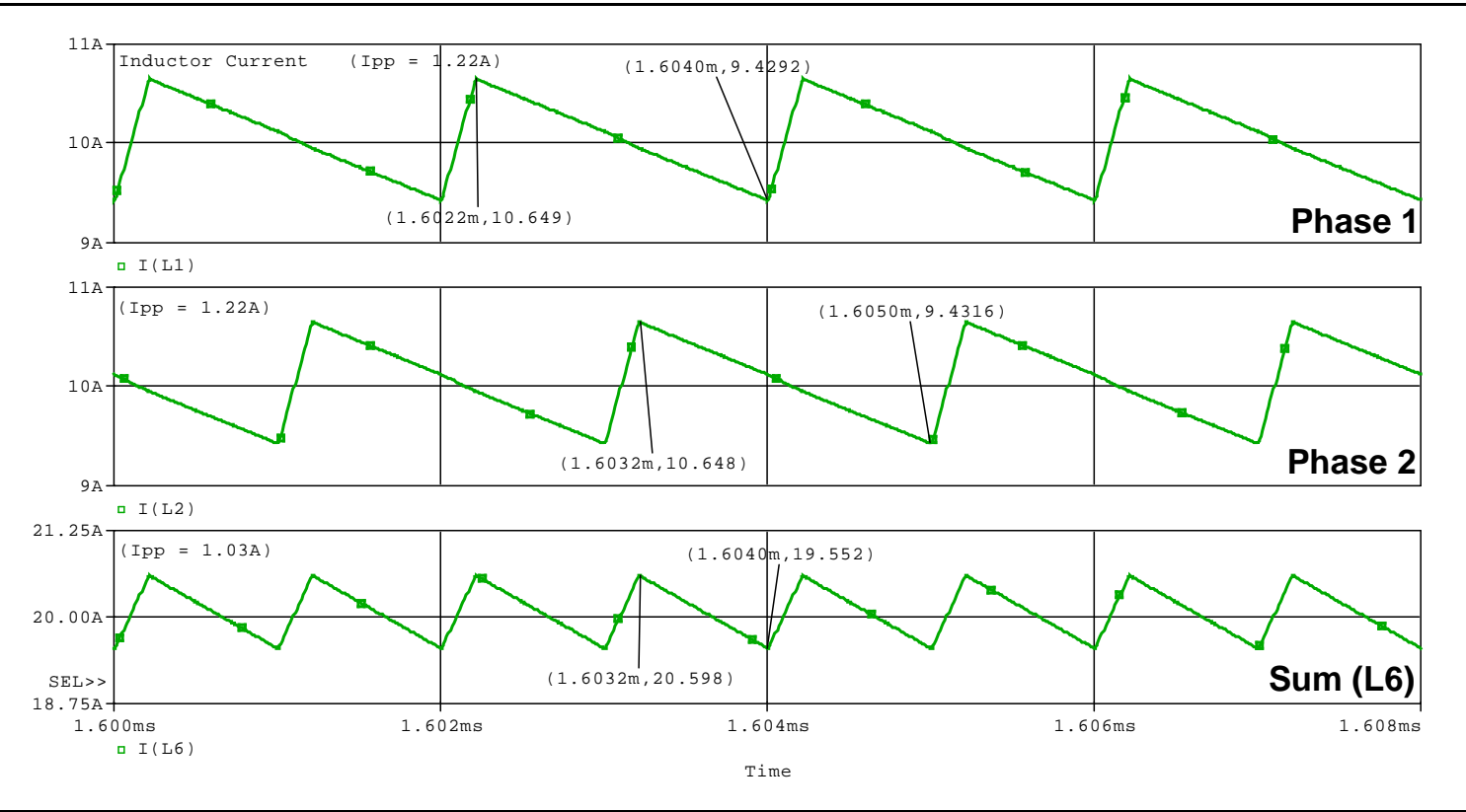

Figure 4-5. Inductor current through phase 1, phase 3, and their sum (L6)

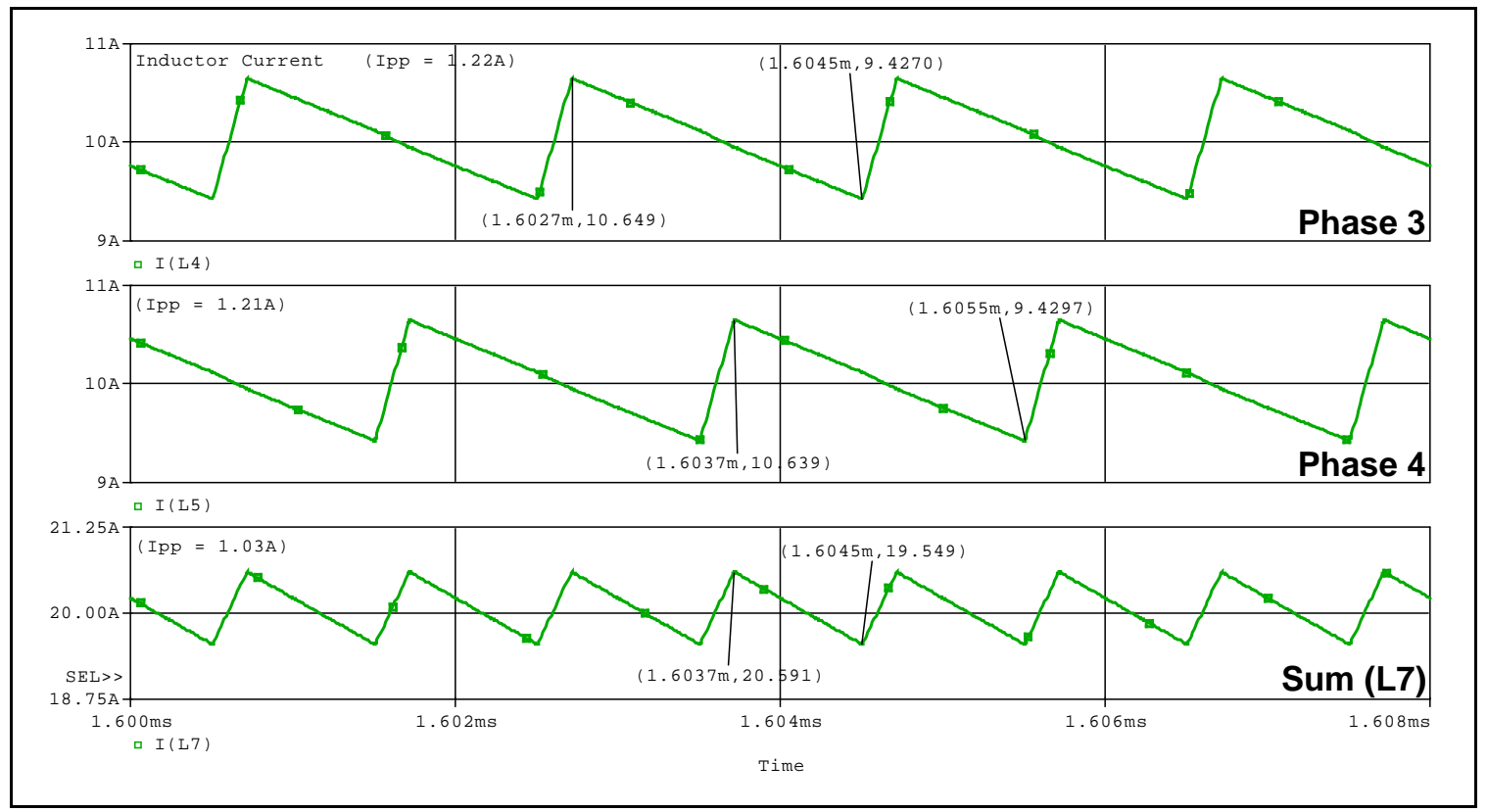

Figure 4-6. Inductor current through phase 2, phase 4, and their sum (L7) 
Figure 4-6 shows a very similar picture to that in Figure 4-5. Phase 3 and 4 are offset by $180^{\circ}$ from each other, and their sum is shown at the bottom of Figure 4-6 as the current through inductor L7. The same results found in Figure 4-5 apply to these waveforms. The individual phase has an average current of $10.038 \mathrm{~A}$, a peak-to-peak ripple of $1.22 \mathrm{~A}$, and a period of $2.0 \mu \mathrm{s}$ which corresponds to the actual switching frequency of $500 \mathrm{kHz}$. The current flowing through inductor $L 7$ has an average current of $20.0745 \mathrm{~A}$, with a peak-to-peak ripple of $1.03 \mathrm{~A}$, and a period of $1.002 \mu$ s which corresponds to half the expected output switching frequency of $998 \mathrm{kHz}$. These results again agree with the predicted results and also show that equal current sharing is taking place in the converter.

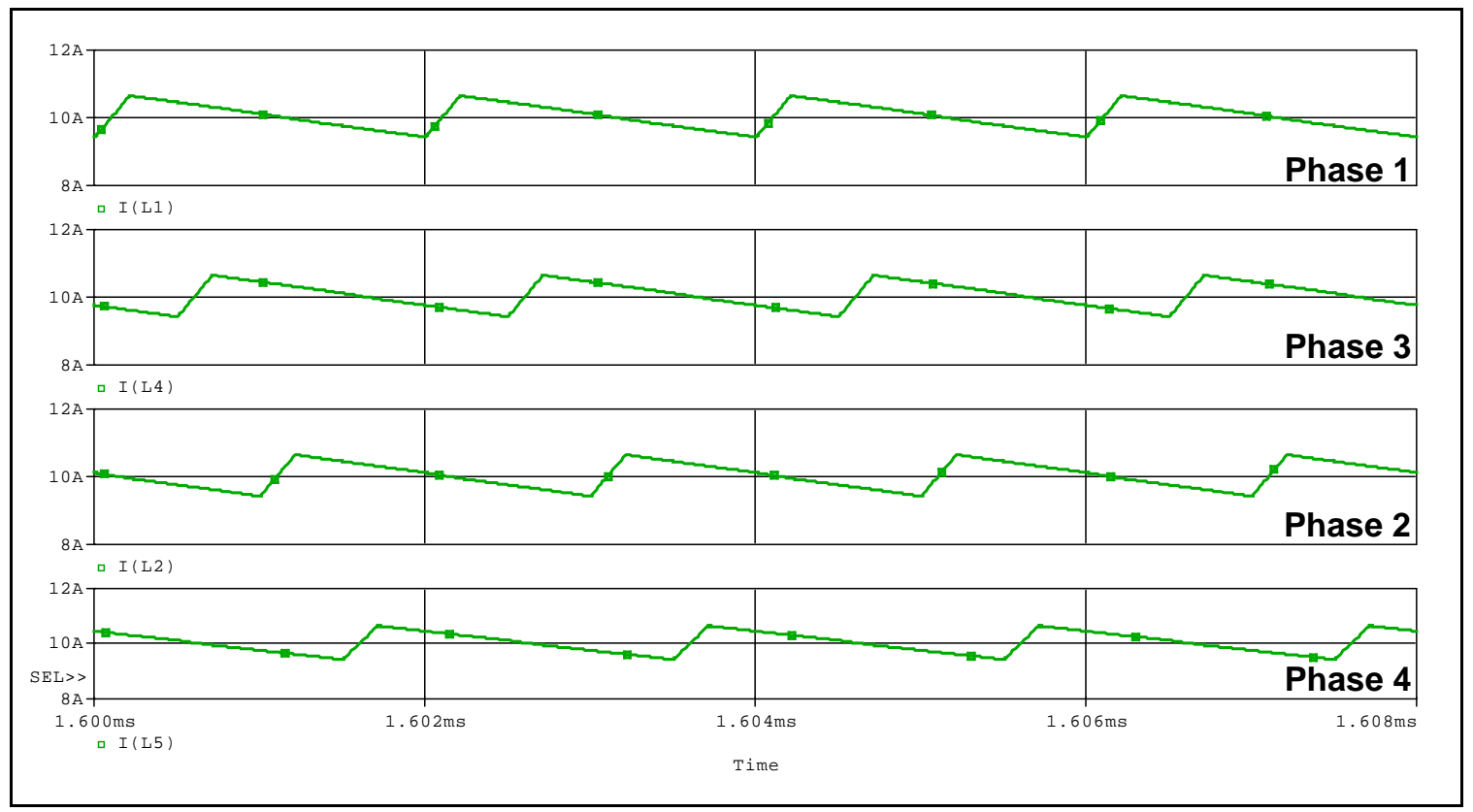

Figure 4-7. Inductor current through phase 1-4, showing interleaving

Figure 4-7 shows a successful interleaved circuit. Looking back at Figure 4-1 for clarification, first current passes through phase 1 which is on the top 
section. Next current passes through phase 3 which is on the bottom section. Then current passes through phase 2 which is again on the top section. Finally current passes through phase 4 which is again on the bottom, and the cycle repeats, returning to phase 1 .

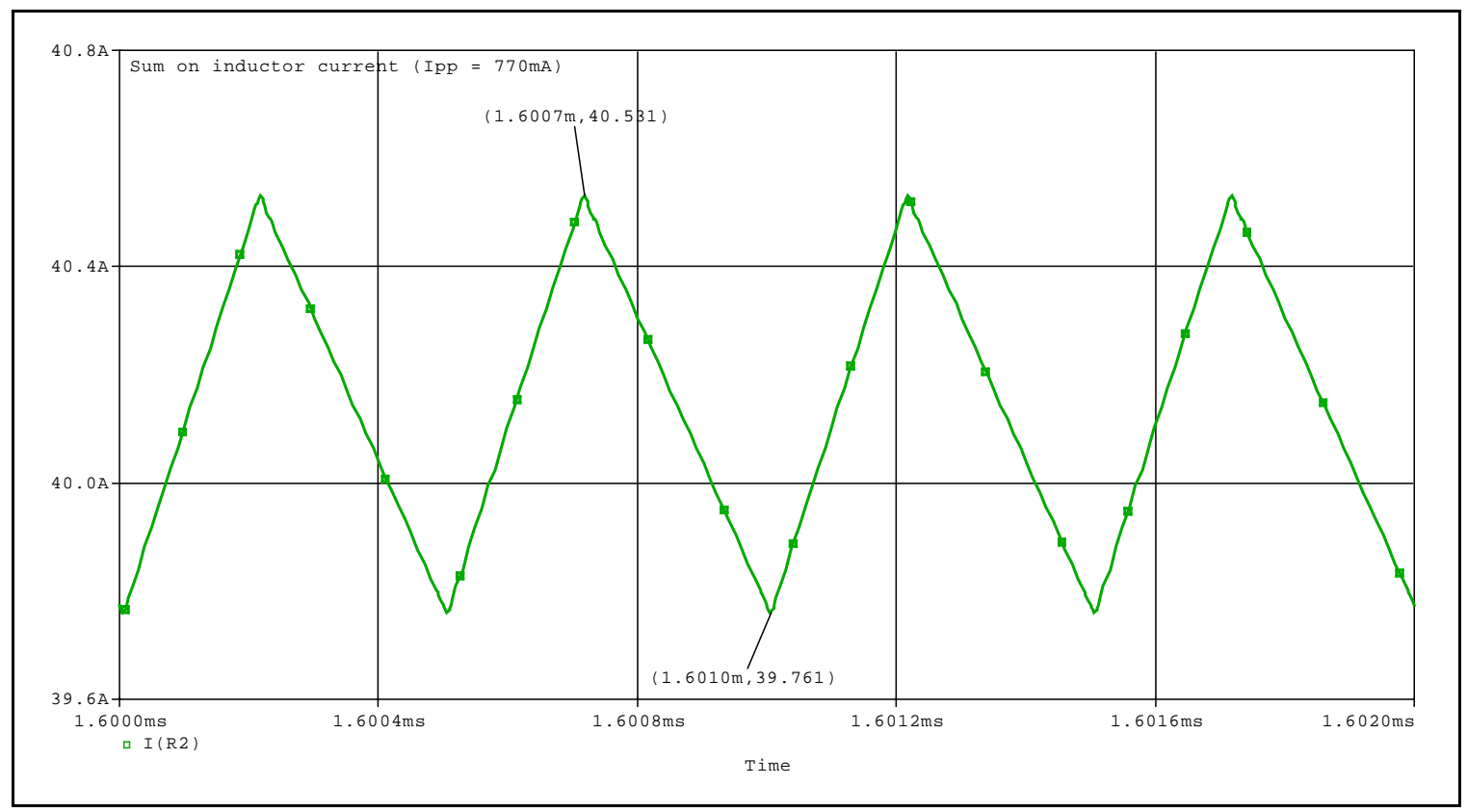

Figure 4-8. Output current showing ripple

Figure 4-8 shows the current flowing to the output stage of the converter. It shows a linear increase and decrease of the current, which is expected. The average current is equal to $40.146 \mathrm{~A}$ which is very close to the specification and the value found in Figure 4-3. The peak-to-peak current ripple has been reduced to only $770 \mathrm{~mA}$, while the output switching frequency has increased to $1 / 500.25 \mathrm{~ns}$ or approximately $2 \mathrm{MHz}$, again as expected. 




Figure 4-9. Input voltage and current waveforms

Figure 4-9 shows the input voltage and current waveforms. The top plot shows the input voltage and as expected it is a flat $\mathrm{DC}$ value of $12 \mathrm{~V}$. The bottom plot shows the input current and the waveform is somewhat unexpected. Recall the typical input current waveform for a standard buck converter, shown in Figure $2-8$, is a discontinuous waveform that looks similar to a square wave and has lots of noise associated with it. Notice the difference between the input current shown in Figure 2-8 and the bottom plot of Figure 4-9, the current is now continuous and a much cleaner looking signal. It is also important to note the large input current spike that occurs before $75 \mu \mathrm{s}$. This large value is one that occurs in the simulation due to the resonance between the inductor and input capacitor. This oscillation is dampened by the $\mathrm{RC}$ damper that was placed in parallel with the LC filter. It is important to note that this behavior was not see later during the hardware portion of the thesis so it is assumed to but isolated to just the simulation. 


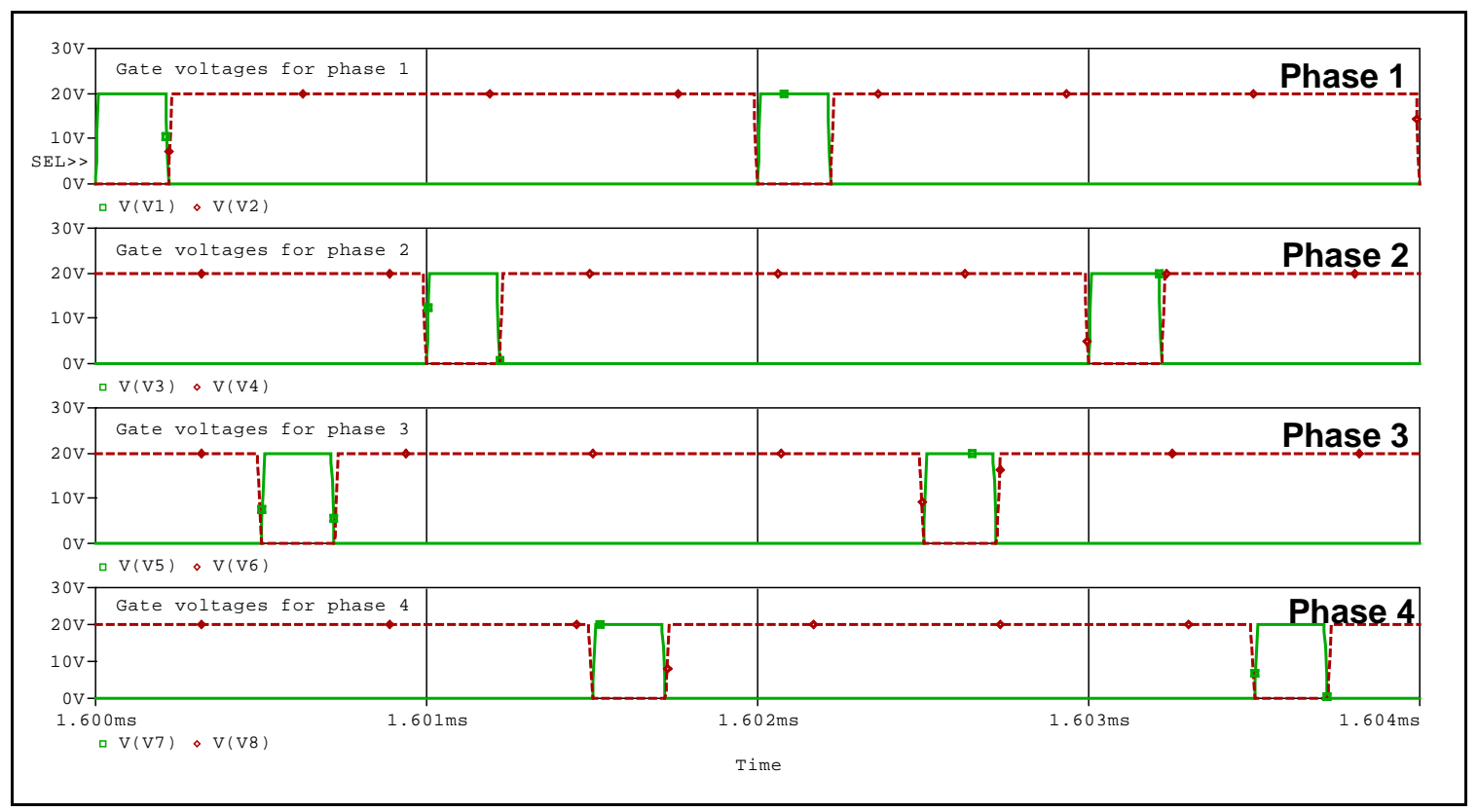

Figure 4-10. Gate voltages of each phase

Figure 4-10 shows the voltage signals that are driving the gates of each MOSFET. You can note from the plot and Figure 4-1 that V1, V3, V5, and V7 are driving the main MOSFETs and are only on for approximately $1 / 11$ or $9.1 \%$ of the switching period. As was stated earlier, a duty cycle of $1 / 11$ was required in order to have an average output voltage of $1 \mathrm{~V}$. On the other hand, V2, V4, V6, and V8 are driving the synchronous MOSFETs and are on for $10 / 11$ or $90.9 \%$ of the switching period. Also note the transition time between when the main MOSFET turns on and the synchronous MOSFET turns off. For example, look at the top plot of $\mathrm{V} 1$ and $\mathrm{V} 2$. At around $1.602 \mathrm{~ms}$ there is a transition between the two signals and there is a small gap in the transition area, meaning that there is not a time when both the main and synchronous MOSFETs are on at the same time. This is one of the most important control aspects to get right, because when done incorrectly it can lead to a short to ground and many current spikes that lead to higher losses and lower efficiencies. From Figure 4-10 we can also 
find the switching frequency. Looking at phase 1 in the top plot, the switching period is $2 \mu$ s which corresponds to a switching frequency of $500 \mathrm{kHz}$, and from the specification in Table 3-1 it proves that the frequency of operation is as expected.

\section{$\underline{4.2 \text { Input Filter Design }}$}

Background and theory for the design of an input LC filter with RC damping is provided in section 2.3. The filter was first designed using the design equations presented in section 2.3. First we will start the equation (4-1) which relates the filter cutoff frequency with the inductor and capacitor values:

$$
f_{o}=\frac{1}{2 \pi \sqrt{L C}}
$$

From equation (4-1) there are three unknowns ( $f_{0}, L$, and $\left.C\right)$ and we are forced to select values for two of these unknowns and then solve for the other. Recalling that the input current is the same as the main switch current, the switching frequency is around $500 \mathrm{kHz}$, and the frequency seen at the input is $\mathrm{Nf}_{\mathrm{s}}$ or $2 \mathrm{MHz}$, a frequency that was several orders or magnitude higher than the frequency of switching was chosen. A cutoff frequency of $f_{0}=50 \mathrm{kHz}$ was used because it should be low enough to block the high frequency switching noise, but still high enough to use small and convenient components. An inductor sized $L=1 \mu \mathrm{H}$ was used because it is a convenient size that is a nice tradeoff between value and size. The value for the capacitor can now be solved for by rearranging equation (4-1):

$$
C=\frac{1}{4 \pi^{2} f_{o}^{2} L}=\frac{1}{4 \pi^{2}\left(50 \times 10^{3}\right)^{2}\left(1 \times 10^{-6}\right)}=10.13 \mu F
$$


From equation (4-2) the value of the capacitor is $10.13 \mu \mathrm{F}$, but since this value was based on two estimates for the values of the cutoff frequency and inductor, we will choose a convenient value for the capacitance and then recalculate to find the adjusted cutoff frequency. The capacitor value $C=10 \mu \mathrm{F}$ will be used. The cutoff frequency for the filter is now, using equation (4-1) once again:

$$
f_{o}=\frac{1}{2 \pi \sqrt{L C}}=\frac{1}{2 \pi \sqrt{\left(1 \times 10^{-6}\right)\left(10 \times 10^{-6}\right)}}=50.33 \mathrm{kHz}
$$

As equation (4-3) shows, the cutoff frequency has been increased ever so slightly from the original $50 \mathrm{kHz}$ in order to accommodate the use of convenient inductor and capacitor values. Finally, we will calculate the value of the damping resistor as shown:

$$
R=\sqrt{\frac{L}{C}}=\sqrt{\frac{\left(1 \times 10^{-6}\right)}{\left(10 \times 10^{-6}\right)}}=0.3162 \Omega
$$

All of the values for the LC filter were used in the simulation that follows, the circuit for which is shown in Figure 4-11.

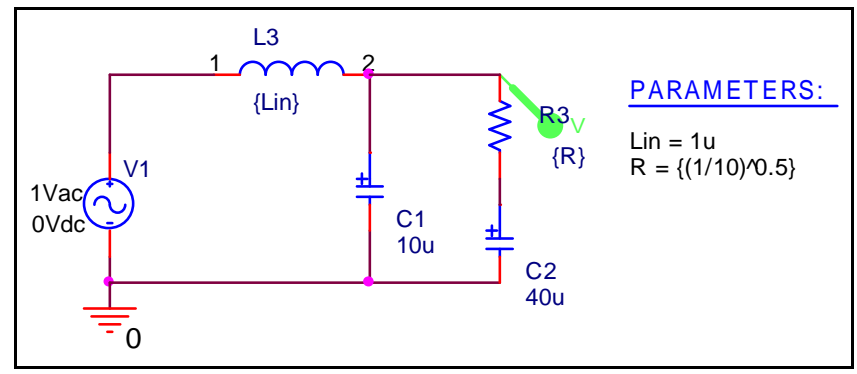

Figure 4-11. Input filter of multiphase buck

A frequency response plot was then simulated again using OrCAD Capture CIS and the magnitude plot was created for the LC filter, see Figure 412. The magnitude plot confirms the design equations and shows the magnitude rolling off right around $50 \mathrm{kHz}$. The simulation shows the magnitude equaling $0 \mathrm{~dB}$ 
at $51.27 \mathrm{kHz}$ and a $-3 \mathrm{~dB}$ frequency of $62.3 \mathrm{kHz}$. Both of these values are very close to the calculated value of $50.33 \mathrm{kHz}$, especially considering it is on a log scale, and proves via simulation that this filter should adequately filter the input high noise interference.

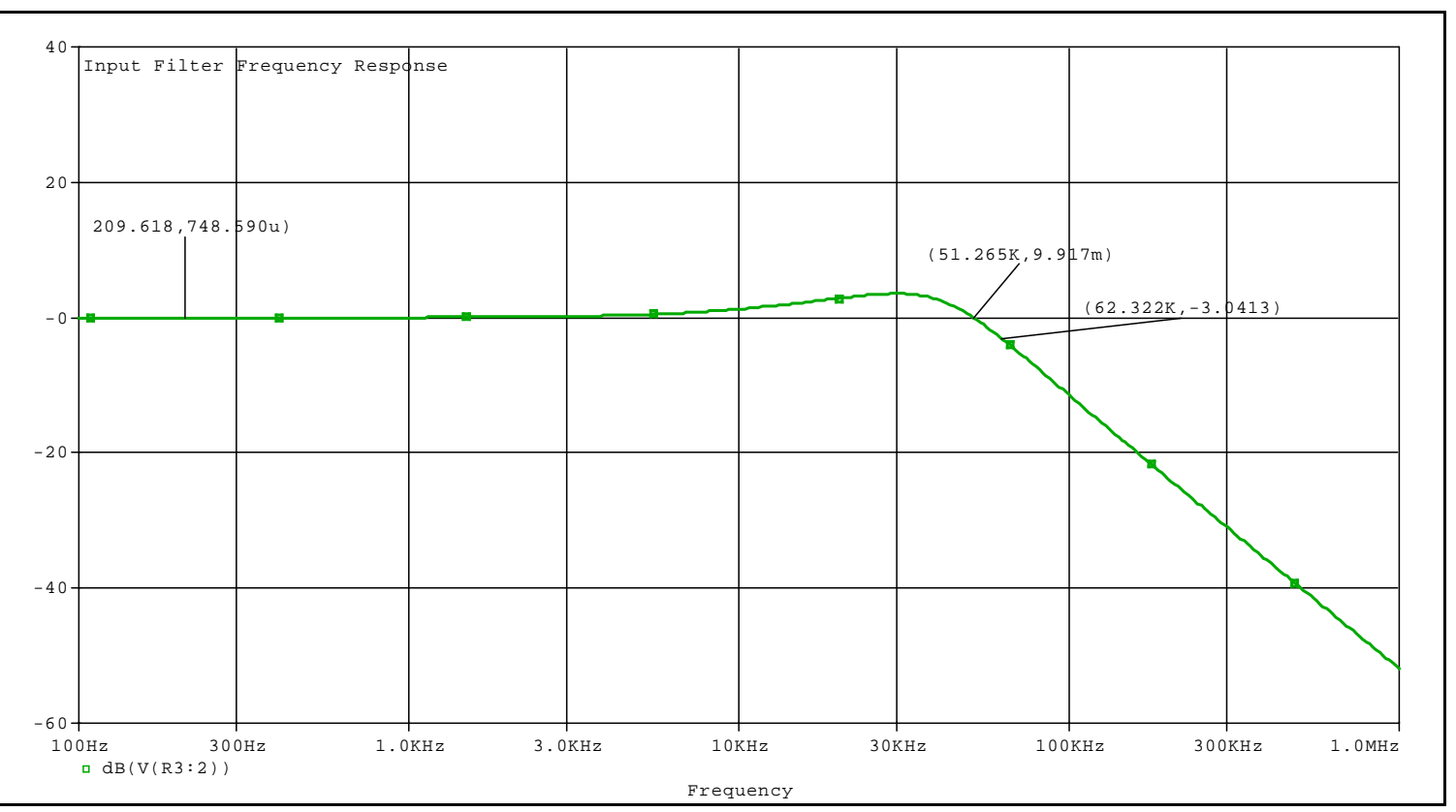

Figure 4-12. Frequency response of input LC filter 


\subsection{Simulation Results Summary}

Table 4-1 shows a summary of the simulation results that are obtained from section 4.1.

\begin{tabular}{|c|c|c|}
\hline Parameters & Specification & Simulation Results \\
\hline Test Input Voltage Range & $10.8 \mathrm{~V}$ to $13.2 \mathrm{~V}$ & $10.8 \mathrm{~V}$ to $13.2 \mathrm{~V}$ \\
\hline $\begin{array}{l}\text { Nominal Test Input } \\
\text { Voltage }\end{array}$ & $12 \mathrm{~V}$ & $12 \mathrm{~V}$ \\
\hline Nominal Output Voltage & $1 \mathrm{~V}$ & $1.0034 \mathrm{~V}$ \\
\hline Maximum Output Current & $40 \mathrm{~A}$ & $40.137 \mathrm{~A}$ \\
\hline Output Voltage Ripple & $<50 \mathrm{mV}_{\mathrm{pp}}(<5 \%)$ & $483.9 \mu \mathrm{V}_{\mathrm{pp}}(0.05 \%)$ \\
\hline Percent Line Regulation & $<2 \%$ & NA \\
\hline Percent Load Regulation & $<5 \%$ & NA \\
\hline Full Load Efficiency & >80\%@ Full Load & $77.40 \%$ \\
\hline $\begin{array}{l}\text { Measured Switching } \\
\text { Frequency }\end{array}$ & $\begin{array}{c}500 \mathrm{kHz} \text { per phase } \\
(2 \mathrm{MHz} \text { overall) }\end{array}$ & $\begin{array}{c}500 \mathrm{kHz} \text { per phase } \\
\text { (2MHz overall) }\end{array}$ \\
\hline Equal Current Sharing & $\begin{array}{c}\text { 10A each phase } \\
\text { @ Full Load }\end{array}$ & $\begin{array}{c}\text { 10.038A each phase } \\
\text { @ Full Load }\end{array}$ \\
\hline Circuit Board Area & $\begin{array}{l}35 \mathrm{in}^{2} \text { (50\% of } \\
\text { previous board) }\end{array}$ & NA \\
\hline
\end{tabular}

Table 4-1. Summary of Simulation Results

For each parameter, the specification was met, except of course in the case of the circuit board area because a circuit board was not created for the simulation. These results are a good indication that the designs is operating properly. We can now proceed to the hardware section of the project and turn the design into a real operating device. 


\section{Chapter 5. Hardware Results}

In order to fully test the proposed multiphase buck topology, it is necessary to demonstrate its functionality using a real life circuit board. All the models, simulations, and equations can give valuable information, but this device is to be used to power present and future microprocessors and as such the results need to be tangible. The circuit board was designed and fabricated, components were selected and soldered to the board, and finally the board was tested for full functionality. The process of these tasks is explained in the following sections.

\subsection{Schematic}

A schematic of the multiphase buck converter was created using Express SCH software from Express PCB [4]. The schematic was broken up into three pages for ease of viewing and organization: the input stage and PWM connections are shown in Figure 5-3, drivers and MOSFET connections are shown in Figure 5-4, and the output stage is shown in Figure 5-5. The printed circuit board (PCB) was created using Express PCB software. A four layer board was created with each of the layers being shown in the appendix of this report: a top signal layer shown in Figure A-1, an inner ground layer shown in Figure A-2, an inner power layer shown in Figure A-3, and a bottom signal layer shown in Figure A-4. There are vias placed throughout the PCB to connect the different layers together when necessary. On the two signal layers there are plus and minus signs, a plus sign indicates the via is attached to the inner power layer, a minus sign indicates the via is attached to the inner ground layer. Trace width for 
the two signal layers is a key. If the trace is too small and cannot handle the required current, the trace will heat up and possibly fail. If traces are made substantially too wide, there will be large inductances associated with that traces and cause problems with circuit operations. For those reasons, creating the correct trace widths is critical. The guidelines shown in Table 5-1 were followed for selecting the appropriate trace width [3].

\begin{tabular}{|c|c|}
\hline $\begin{array}{c}\text { Trace Width } \\
\text { [in] }\end{array}$ & $\begin{array}{c}\text { Current } \\
\text { [A] }\end{array}$ \\
\hline 0.01 & 0.3 \\
\hline 0.015 & 0.4 \\
\hline 0.02 & 0.7 \\
\hline 0.025 & 1 \\
\hline 0.05 & 2 \\
\hline 0.1 & 4 \\
\hline 0.15 & 6 \\
\hline
\end{tabular}

Table 5-1. Guidelines for PCB trace widths for different currents [3]

A four layer board was chosen over a two layer board for a number of reasons. Two layer boards are generally less expensive than four layer boards, but cause the overall system to operate at a lower quality. Ease of component placement and trace running is one obvious reason to use a four layer board. The second and more important reason for using four layers is the noise reduction that is associated with the extra layers. The internal ground and power layers form a large barrier that protects the two outside signal layers from interfering with one another. The large internal ground plane also plays a big role in reducing noise. Another important PCB layout technique that is crucial to reducing noise is creating separate signal and power ground planes. This is because there are some sensitive signals connected to the IC that need to be 
very clean and free of noise. MOSFETs in the circuit that are switching at a very high frequency can cause lots of noise and need to be isolated from the sensitive signal parts of the circuit. For this reason a small signal ground was created on the bottom layer of the board for all of the sensitive signals to connect to. This small signal ground is connected to the power ground through a few small vias. These small vias make it possible for DC signals to easily pass through so that the two grounds remain at the same potential. High frequency noise interference, however, has a tough time getting through these small vias and is kept out of the sensitive areas of the circuit [4].

Most of the resistors and capacitors used in the circuit were ceramic surface mount 0603 components. These were chosen because they are a good balance between component size and ease of use while soldering. They also met all the requirements for current and voltage required by the design [4]. 


\subsection{Design Equations for Real World Circuit}

Much of the hardware design is centered around the IC that is used as the controller. The chosen controller is a TPS40090 from Texas Instruments, and it is capable of handling four phases with a single chip. A pin out of the chip and a functional block diagram showing where all the pins are tied internally is shown as reference in Figure 5-1 [22].

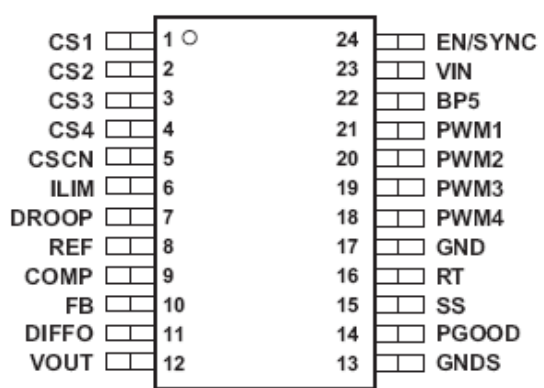

PW package - TPS40090

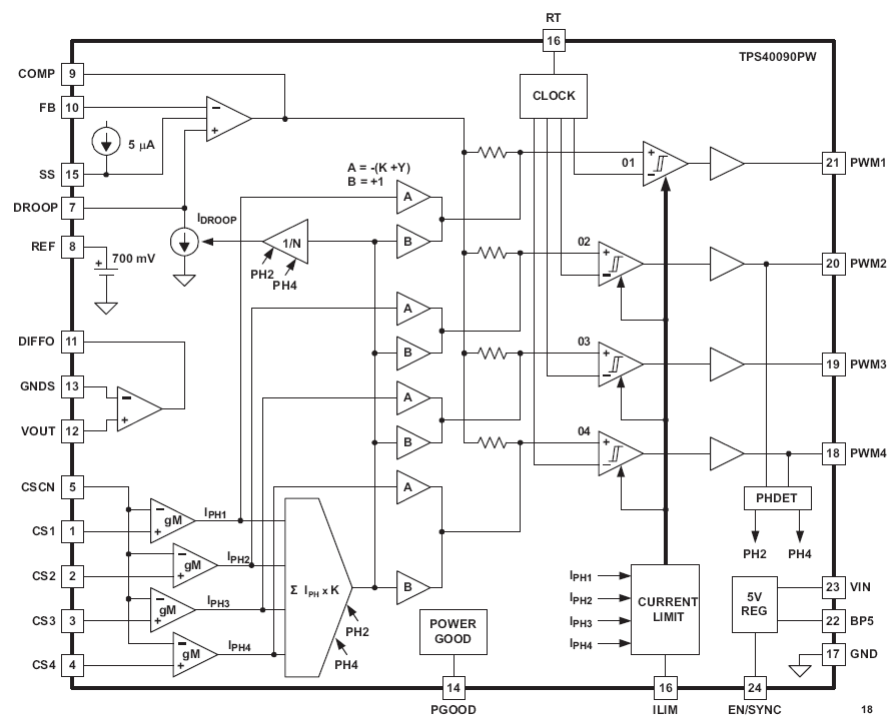

Functional Block Diagram

Figure 5-1. TPS40090 pin out and functional block diagram [22]

Setting up the controller followed the configuration guidelines set forth in the TPS40090 datasheet and application notes. Some of the key points will be touched on here. 


\subsubsection{Setting the Output Voltage}

The output voltage of the converter is set by the ratio of the R4/R5 resistor divider on the outside of the differential amplifier, see Figure 5-3 and the resistors connect to pins 10 and 11 . The output voltage is equal to:

$$
V_{\text {out }}=0.7 \times\left(\frac{R 4}{R 5}+1\right)
$$

For a desired $\mathrm{V}_{\text {out }}=1 \mathrm{~V}$ and choosing $\mathrm{R} 5=10 \mathrm{k} \Omega$ to limit the current through this resistor to a few milliamps, R4 can be found:

$$
1=0.7 \times\left(\frac{R 4}{10 \times 10^{3}}+1\right) \rightarrow R 4=\left(\frac{1}{0.7}-1\right)\left(10 \times 10^{3}\right)=4.29 k \Omega
$$

Choose $\mathrm{R} 4=4.37 \mathrm{k} \Omega$ as it is the nearest $1 \%$ resistor. Notice that there is also an $\mathrm{R} 6$ resistor in series with the $\mathrm{R} 4$ resistor, this resistor was added in series to adjust the feedback resistors slightly so that the average output voltage would be as close as possible to $1 \mathrm{~V}$ [22].

\subsubsection{Setting the Switching Frequency}

The internal clock frequency is set by the value of the resistor connected between the RT pin and ground, see pin 16 on Figure 5-3. The value of the resistor is determined by the following equation:

$$
R_{R T}=K_{P H} \times\left(39.2 \times 10^{3} \times f_{P H}^{-1.041}-7\right)
$$

where $\mathrm{K}_{\mathrm{PH}}$ is a coefficient that depends on the number of active phases, for a four-phase configuration $\mathrm{K}_{\mathrm{PH}}=1$, and $\mathrm{f}_{\mathrm{PH}}$ is the single phase desired switching frequency in $\mathrm{kHz}$. The value of $R_{\mathrm{RT}}$ that is returned is in $\mathrm{k} \Omega$. The desired switching frequency $\left(f_{\mathrm{PH}}\right)$ is $500 \mathrm{kHz}$ which leads to a resistor value of:

$$
R_{R T}=1 \times\left(39.2 \times 10^{3} \times 500^{-1.041}-7\right)=51.3 \mathrm{k} \Omega
$$


In actual practice a resistor $\left(R_{R T}\right)$ of $51.3 \mathrm{k} \Omega$ leads to a switching frequency that is greater than $500 \mathrm{kHz}$, and for this reason the value of the RT resistor was increased to $53.5 \mathrm{k} \Omega[22]$.

\subsubsection{Current Sensing}

There are several widely used methods for performing current sensing. The two most commonly used are either with a sense resistor or by using the DC resistance $(\mathrm{DCR})$ that is in series with the inductance with a real inductor. The inductor DCR current sensing technique is nice because it does not introduce any additional losses as opposed to using the sense resistor method. Looking at Figure 5-2, the following relationships can be found:

$$
\begin{aligned}
& V_{D C R}=\left(V_{I N}-V_{\text {OUT }}\right) \times \frac{D C R}{D C R+\omega L} \\
& V_{C}=\left(V_{I N}-V_{\text {OUT }}\right) \times \frac{1}{\omega C \times\left(R+\frac{1}{\omega C}\right)}
\end{aligned}
$$

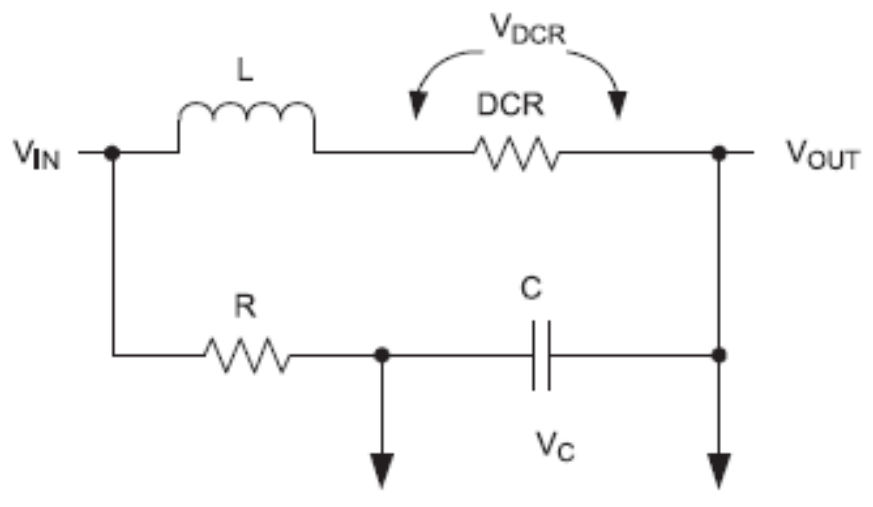

Figure 5-2. Technique used for inductor current sensing 
The voltage drop across the capacitor is equal to the voltage drop across DCR, $V_{C}=V_{D C R}$, when the time constant of the inductor and the $R C$ network are equal, $\mathrm{T}_{\mathrm{DCR}}=\mathrm{T}_{\mathrm{RC}}$. Setting equations (5-5) and (5-6) equal to each other yields:

$$
\left(V_{I N}-V_{\text {OUT }}\right) \times \frac{1}{\omega C \times\left(R+\frac{1}{\omega C}\right)}=\left(V_{I N}-V_{\text {OUT }}\right) \times \frac{D C R}{D C R+\omega L} \Rightarrow \frac{1}{\omega C \times\left(R+\frac{1}{\omega C}\right)}=\frac{D C R}{D C R+\omega L}
$$

And simplifying:

$$
\begin{aligned}
& D C R+\omega L=D C R \times(\omega R C+1) \rightarrow 1+\frac{\omega L}{D C R}=\omega R C+1 \\
& \frac{L}{D C R}=R C \quad \text { when } \tau_{D C R}=\tau_{R C}
\end{aligned}
$$

The main problem with this technique is that $D C R$ is dependent on temperature and as the copper in the inductor heats up the resistance will change. In a practical application the inductor coil can exceed $100{ }^{\circ} \mathrm{C}$ which can lead to problems with the current sensing accuracy. This problem was observed during the testing phase of this project, the results of which are shown later in the report [22]. 


\subsubsection{Thermal Considerations}

Section 2.7 explains the thermal considerations and determines whether or not a heatsink is needed in a circuit. Section 5.2.4 is a follow up to this analysis. The analysis for a heatsink will be performed for both the main and synchronous MOSFETs. Referring back to the model for power dissipation and the datasheet for the main MOSFET [11], the following values can be obtained:

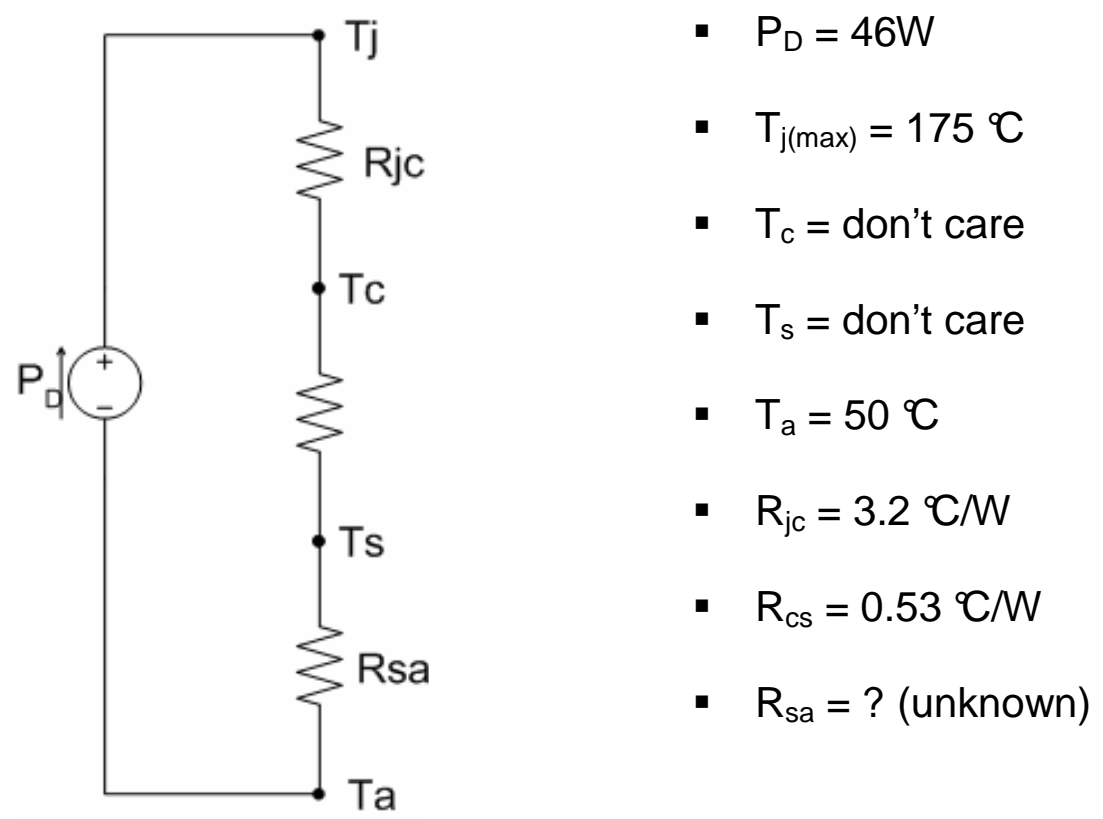

For $T_{c}$ and $T_{s}$ we don't care about these values because they are internal temperatures, we are only concerned the two extremes, which will always be the junction and ambient temperatures. We will now solve for the thermal resistance of the heatsink to the ambient to see if a heatsink is required and if so how big it should be. Applying the thermal equation:

$$
T_{j(\max )}=P_{D}\left(R_{j c}+R_{c s}+R_{s a}\right)+T_{A}
$$

And rewriting to solve for $R_{\text {sa }}$ yields:

$$
R_{s a}=\frac{\left(T_{j(\max )}-T_{A}\right)}{P_{D}}-R_{j c}-R_{c s}=\frac{(175-50)}{46}-3.2-0.53=-1.013^{\circ} \mathrm{C} / \mathrm{W}
$$


The result from equation (5-9) of $R_{s a}=-1.013{ }^{\circ} \mathrm{C} / \mathrm{W}$ tells us that the MOSFET can adequately dissipate all of its heat and a heatsink will not be required for the main MOSFET. Now we will perform the same analysis for the synchronous MOSFET [10].

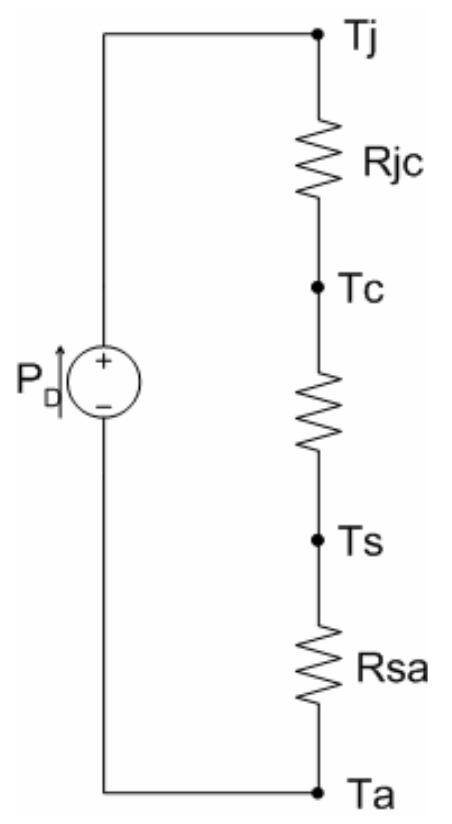

- $P_{D}=83 W$

- $\mathrm{T}_{\mathrm{j}(\max )}=175^{\mathrm{C}}$

- $\mathrm{T}_{\mathrm{c}}=$ don't care

- $\mathrm{T}_{\mathrm{s}}=$ don't care

- $\mathrm{T}_{\mathrm{a}}=50^{\circ} \mathrm{C}$

- $\mathrm{R}_{\mathrm{jc}}=1.8^{\mathrm{C}} \mathrm{C} / \mathrm{W}$

- $\mathrm{R}_{\mathrm{cs}}=0.53^{\circ} \mathrm{C} / \mathrm{W}$

- $\mathrm{R}_{\mathrm{sa}}=?$ (unknown)

Performing the same analysis as we did for the main MOSFET, we rewrite the thermal equation, equation (5-8), to solve for $\mathrm{R}_{\mathrm{sa}}$ and yield:

$$
R_{s a}=\frac{\left(T_{j(\max )}-T_{A}\right)}{P_{D}}-R_{j c}-R_{c s}=\frac{(175-50)}{83}-1.8-0.53=-0.824^{\circ} \mathrm{C} / \mathrm{W}
$$

The result from equation (5-10) of $R_{s a}=-0.824{ }^{\circ} \mathrm{C} / \mathrm{W}$ tells us that the MOSFET can adequately dissipate all of its heat and a heatsink will not be required for the synchronous MOSFET. 


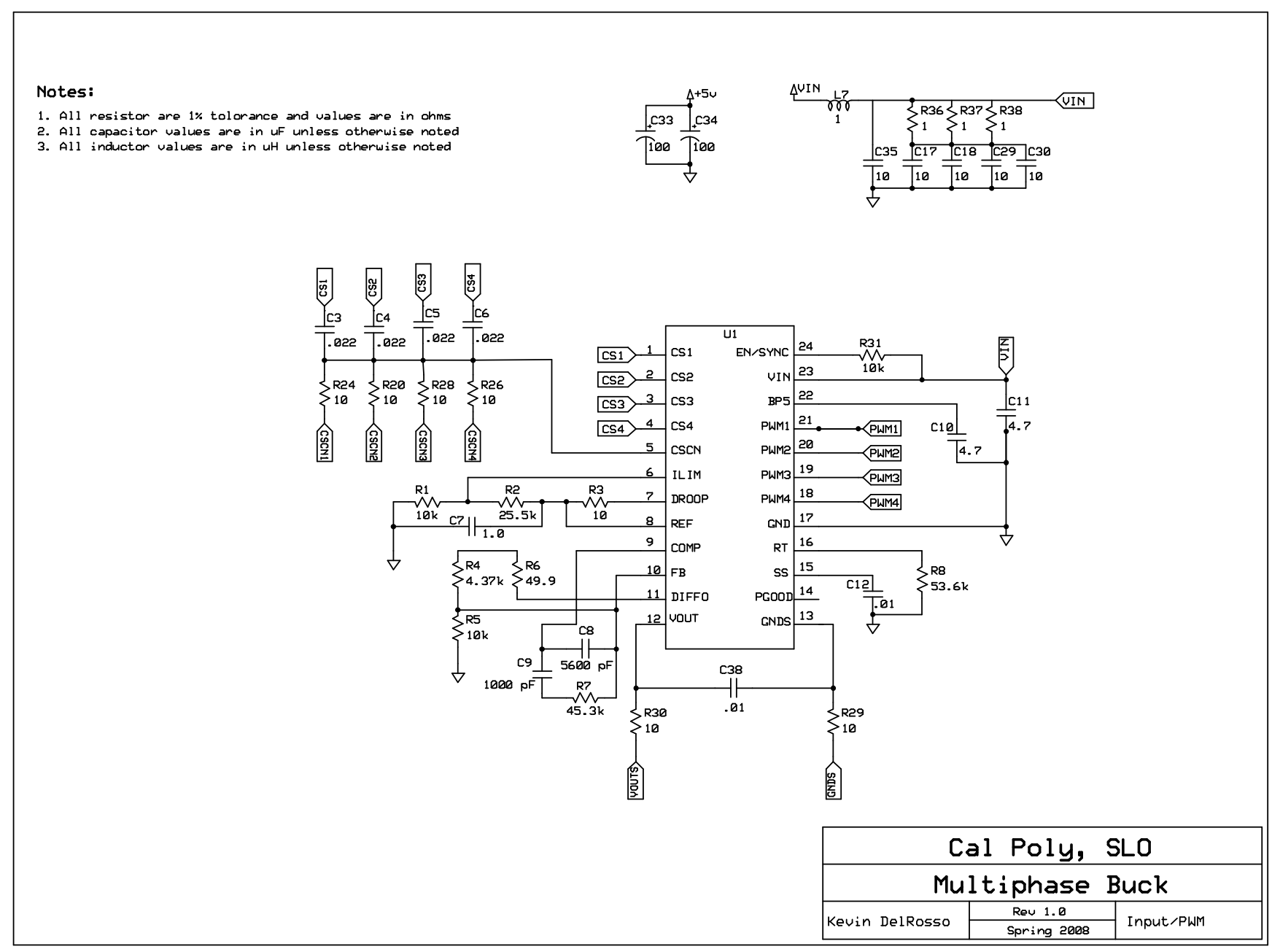

Figure 5-3. Input stage and PWM controller schematic 


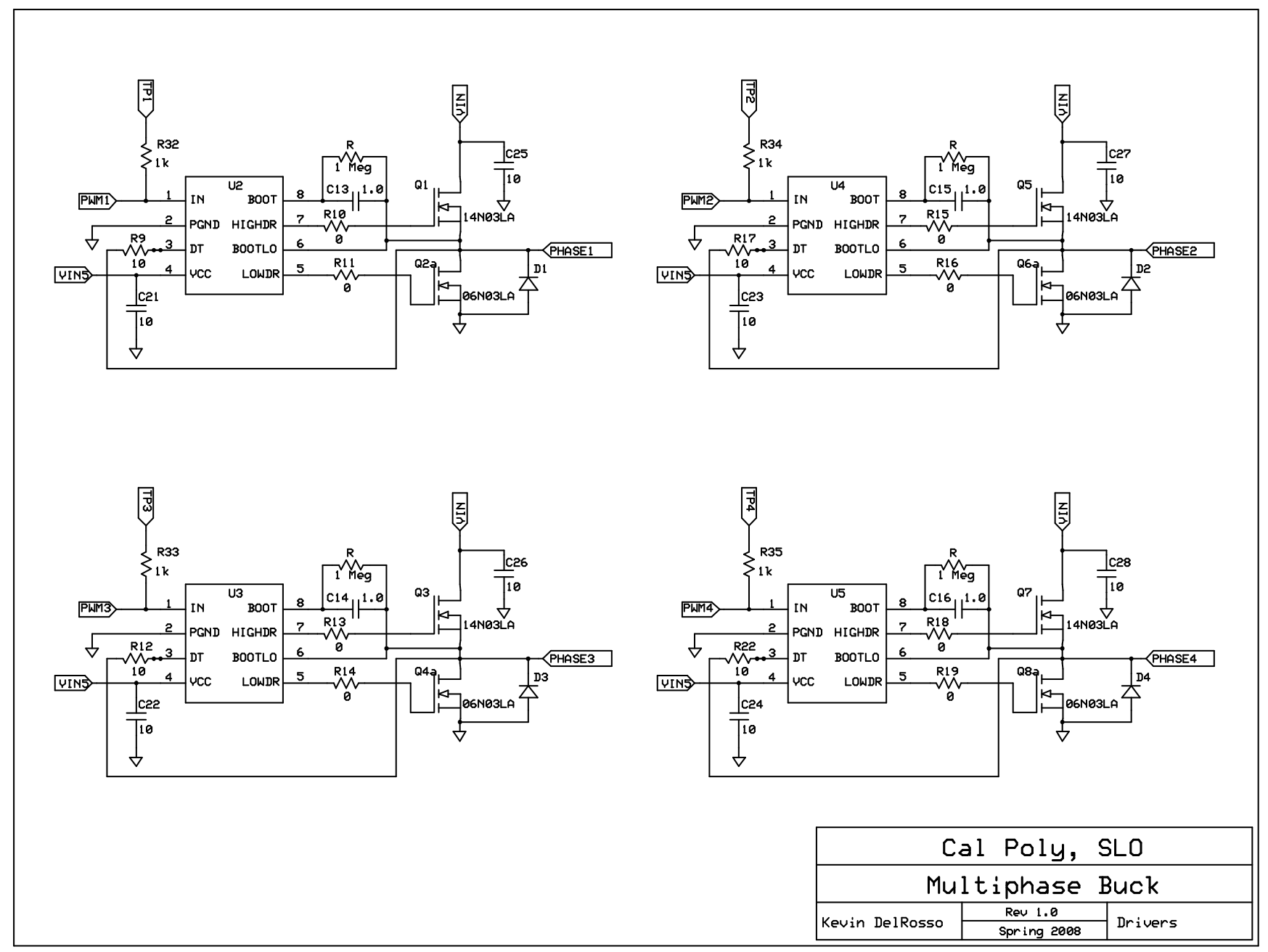

Figure 5-4. Drivers and switches schematic 


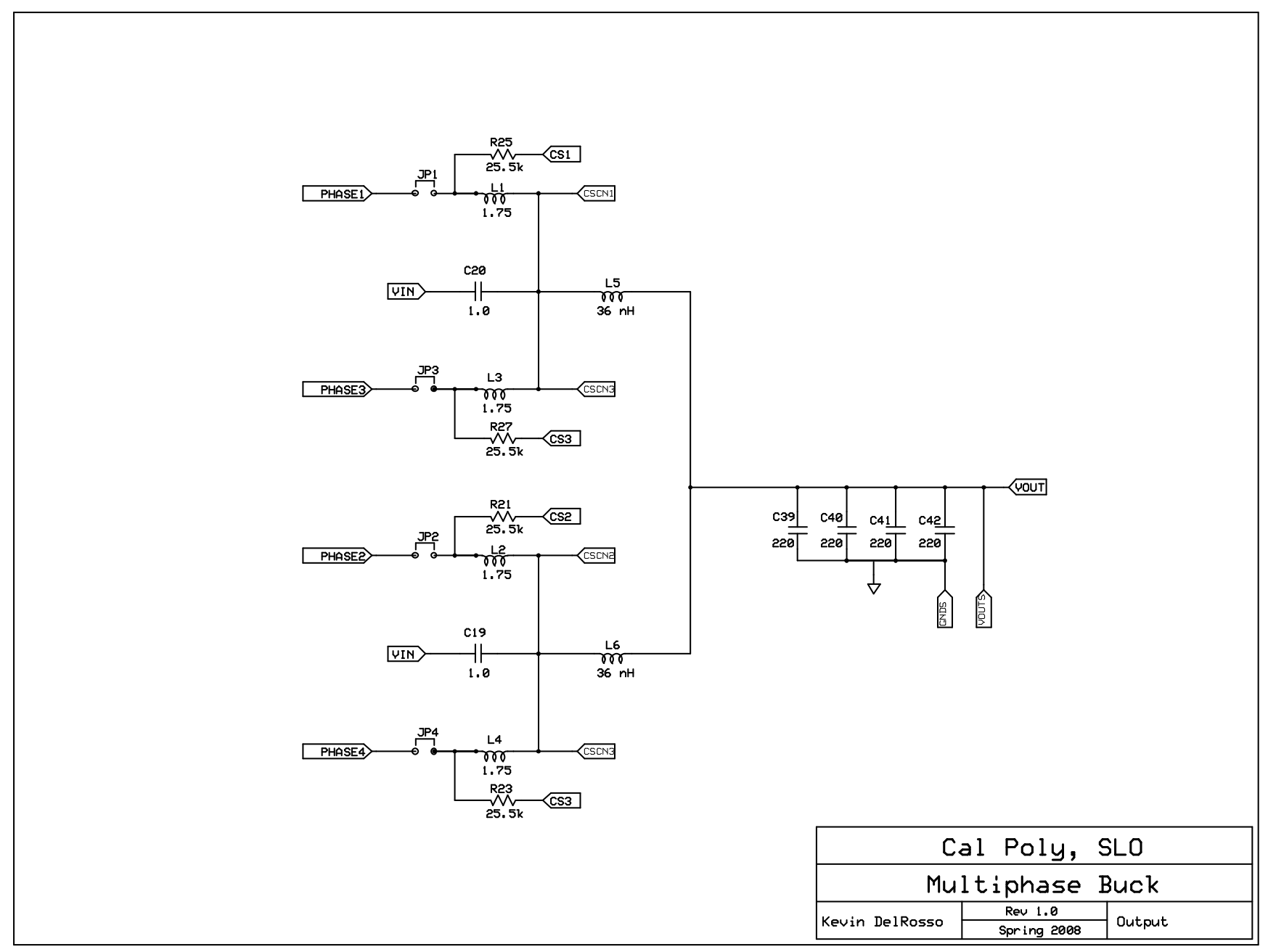

Figure 5-5. Output stage schematic 
The schematic diagrams in Figures 5-3, 5-4, and 5-5 were made into a PCB. The final resultant silkscreen is shown in Figure 5-6, with all the component identifications displayed.



Figure 5-6. Silk screen showing components

A side view of the finished board was photographed and shown in Figure 5-7. It has identified the inputs, output, and test points. The inputs are 5V, $12 \mathrm{~V}$, ground and those connections are made through the blue, red, and black banana plugs respectfully. The output is through two terminal lug connectors that can handle more than $100 \mathrm{~A}$ of current. The output consists of a positive output voltage terminal and a ground terminal for the output. The test points can be used to observe any of the four PWM control signals and are added for ease of use when taking measurements. Figure 5-7 also shows the mount that the board sits on. It consists of eight extenders that lift the board off the Plexiglas, adding ease of handling the board and a convenient location for the inputs and output. 


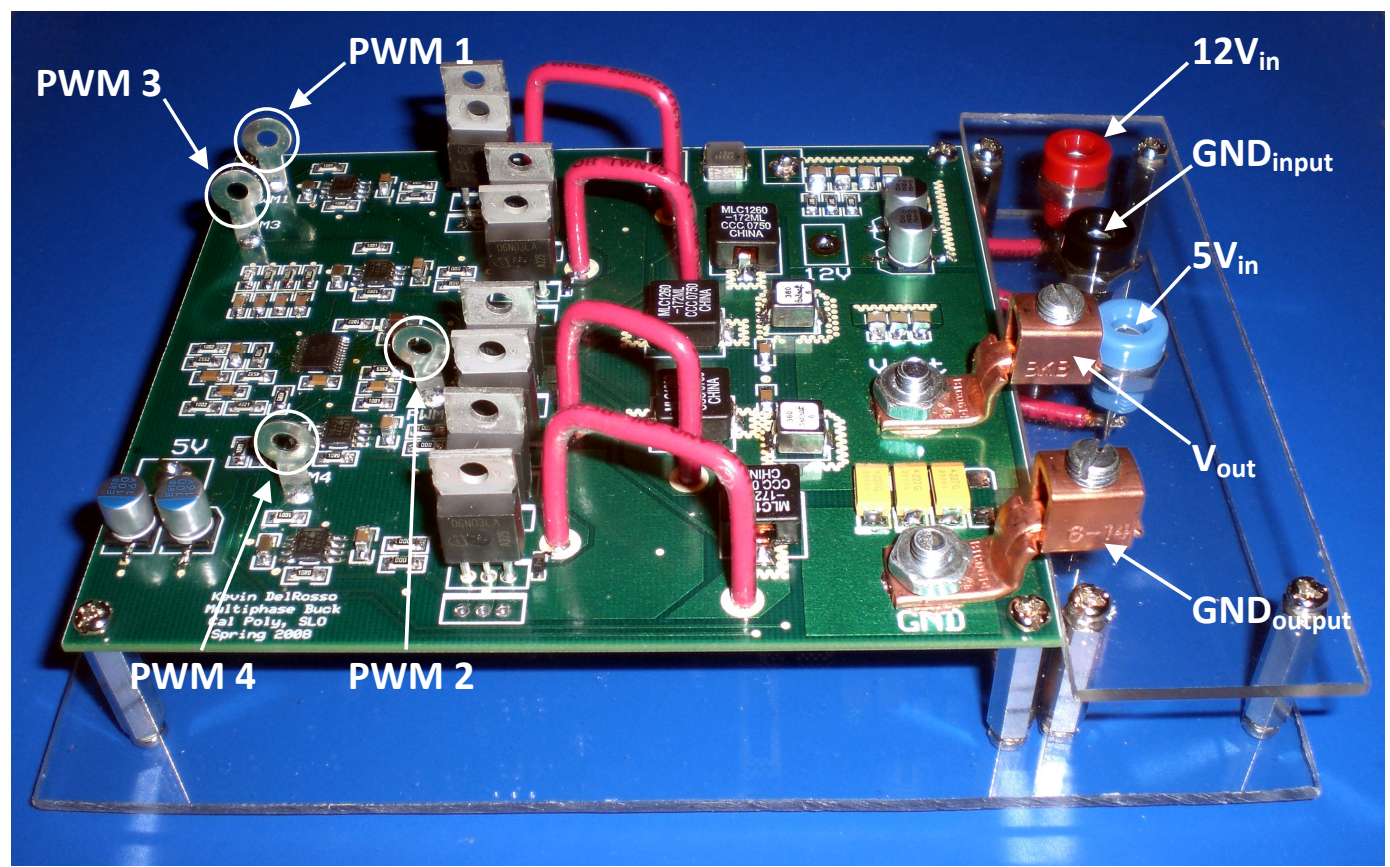

Figure 5-7. Side view of interleaving multiphase buck converter

Figure 5-8 shows an overhead photograph of the interleaving multiphase buck converter. Identified are the four stages of the converter: input, power, control, and output. Further details about each stage are shown in section 2.2.5.

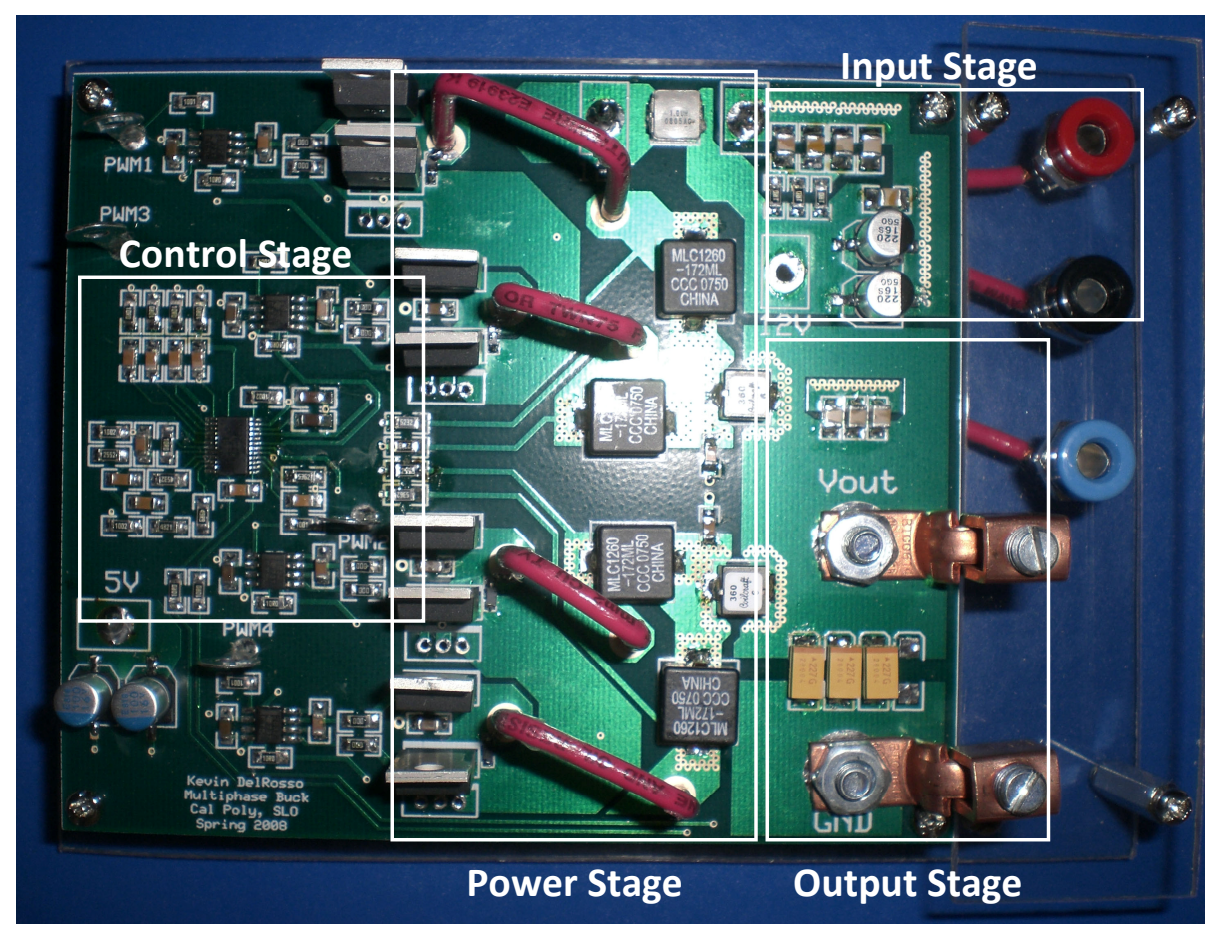

Figure 5-8. Top view of interleaving multiphase buck converter 
Figure 5-9 shows a zoomed in view of Figure 5-8, showing a close up view of the control and power stages. For the control stage, the main control IC, TPS40090, is identified along with two of the gate drivers, TPS2832. For the power stage, one main switch, one synchronous switch, one $1.75 \mu \mathrm{H}$ inductor, and one $36 \mathrm{nH}$ inductor have also been identified. Several of the current probe loops are also identified. The current probe loops are included for ease while measuring the inductor current.

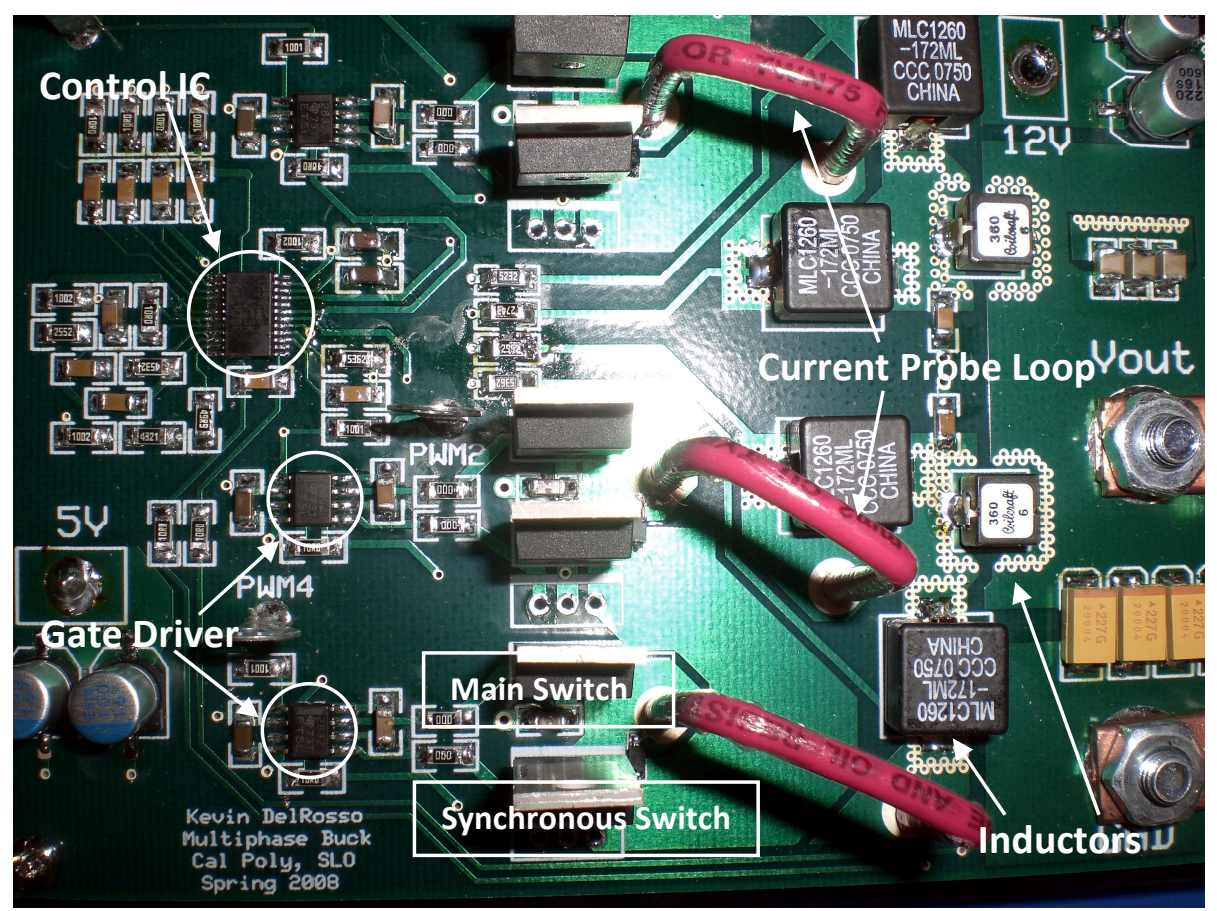

Figure 5-9. Zoomed in top view showing control and power stages 


\subsection{Hardware Testing Setup}

The hardware test setup consists of two separate power supplies each with different ratings. One is required to supply $5 \mathrm{~V}$ with a current limit of $1 \mathrm{~A}$ while the other is required to supple $12 \mathrm{~V}$ with a current limit of $7 \mathrm{~A}$. Digital multimeters were used to observe the input voltage and current while measurements were being taken. A current probe and current probe amplifier were used to measure the current passing through each of the current probe loops, JP1, JP2, JP3, and JP4, which is the same as the inductor current for each phase. The signal obtained from these loops was then outputted to an oscilloscope using a $50 \Omega$ cable and then observed. As a note, the amplification on the current probe amplifier is designed to view signals that are on a $10 \mathrm{mV}$ per division setting on the oscilloscope. The oscilloscope was also used to observe and measure the PWM control signals at the PWM test points, the ripple of the output voltage, and the transient response of the converter. The load used at the output was an electronic load that allows the output current to range from 0 to $60 \mathrm{~A}$ in controlled increments. The leads connecting the output to the electronic load had to be considered because they will be carrying approximately 40A. The leads used were 8 AWG stranded copper wire. The lead length was also approximately 2 feet in order to minimize power loss in the large output leads. During testing, the output voltage was monitored with a digital multimeter. A block diagram of the basic test setup used is shown in Figure 5-10. 


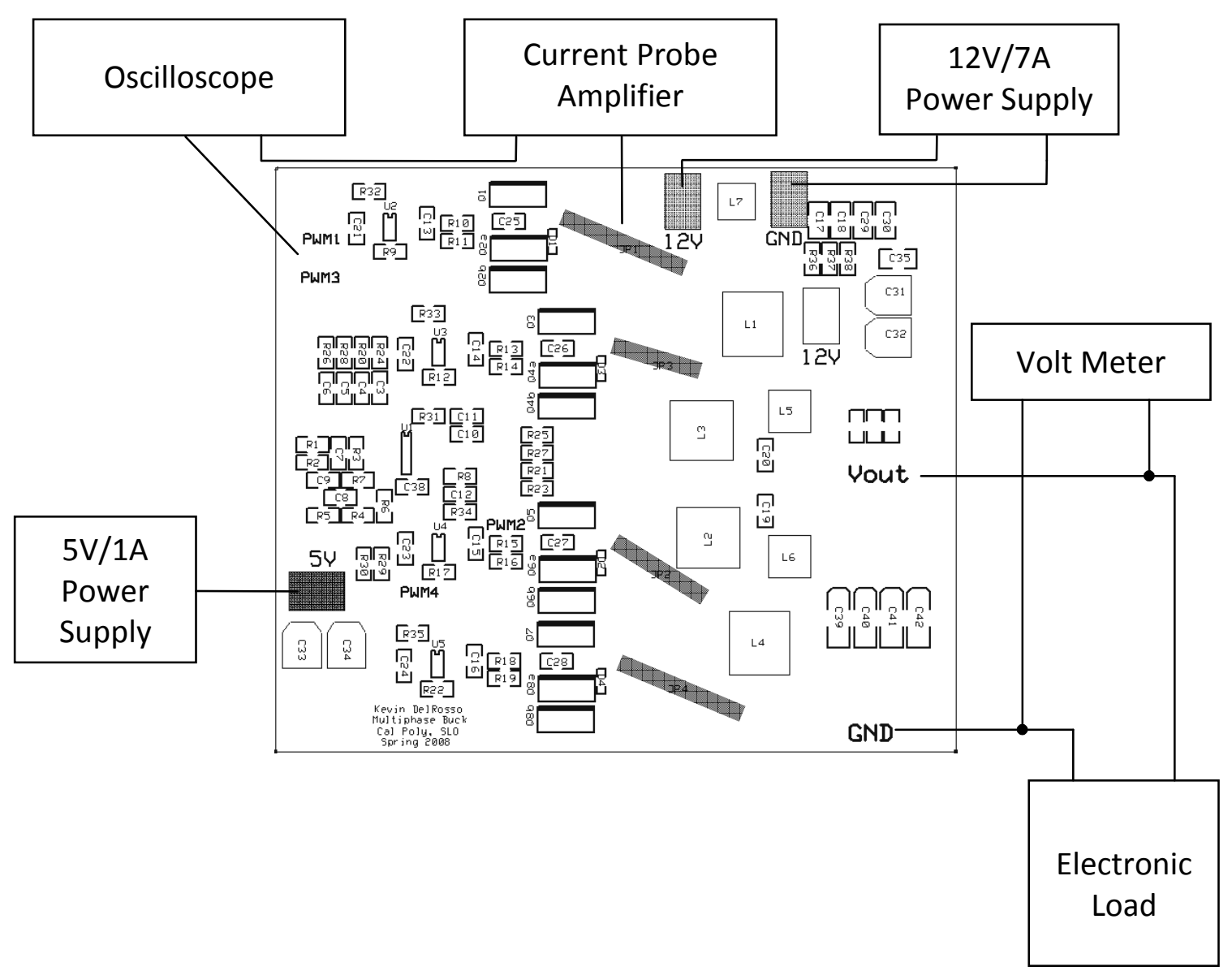

Figure 5-10. Block diagram of test setup for hardware results

Figure 5-10 does not show the test setup for every test run. All exceptions to the basic test setup are explained in the hardware results. The equipment used for the hardware testing is shown in Table 5-2.

\begin{tabular}{|c|l|}
\hline Equipment & \multicolumn{1}{|c|}{ Description } \\
\hline Power Supply & $\begin{array}{l}\text { Hewlett Packard 6574A 0-60V/0-35A DC Power Supply (12V input) } \\
\text { Laboratory DC Power Supply, GW Model GPR-6060D (5V input) }\end{array}$ \\
\hline Oscilloscope & $\begin{array}{l}\text { Hewlett Packard 54610B 2 channel 500MHz Oscilloscope EE serial } \\
\text { number 5669 }\end{array}$ \\
\hline Multimeter & $\begin{array}{l}\text { GW instek GDM-8245 Dual Display Digital Multimeter } \\
\text { Fluke 87 true RMS multimeter EE serial number 5710 } \\
\text { Fluke 87 true RMS multimeter EE serial number 5713 }\end{array}$ \\
\hline Load & Hewlett Packard 6060B 3-60V/0-60A, 300W System DC Electronic Load \\
\hline $\begin{array}{c}\text { Current Probe } \\
\text { Amplifier }\end{array}$ & Tektronix TM502A AM 503 current probe amplifier \\
\hline Current Probe & Tektronix A6302 current probe \\
\hline
\end{tabular}

Table 5-2. Hardware testing equipment 


\section{$\underline{5.4 \text { Hardware Results }}$}

Assuming that the functionality of the multiphase buck converter meets the specifications, as will be shown later in this chapter, the most critical specification that this thesis tries to improve is the efficiency. Figure $5-11$ shows the overall efficiency of the converter.



Figure 5-11. Efficiency versus output current plot

As can be seen from the efficiency plot, the efficiency reaches a maximum value of $78.3 \%$ at a load of $8 \mathrm{~A}$. The efficiency then steadily decreases until we reach the full load efficiency of $60.34 \%$ at $40 \mathrm{~A}$. These results do not meet the specification, but are an improvement over the previous works. The problem lies in the power loss and its relationship to load current, see Figure 5-12. 


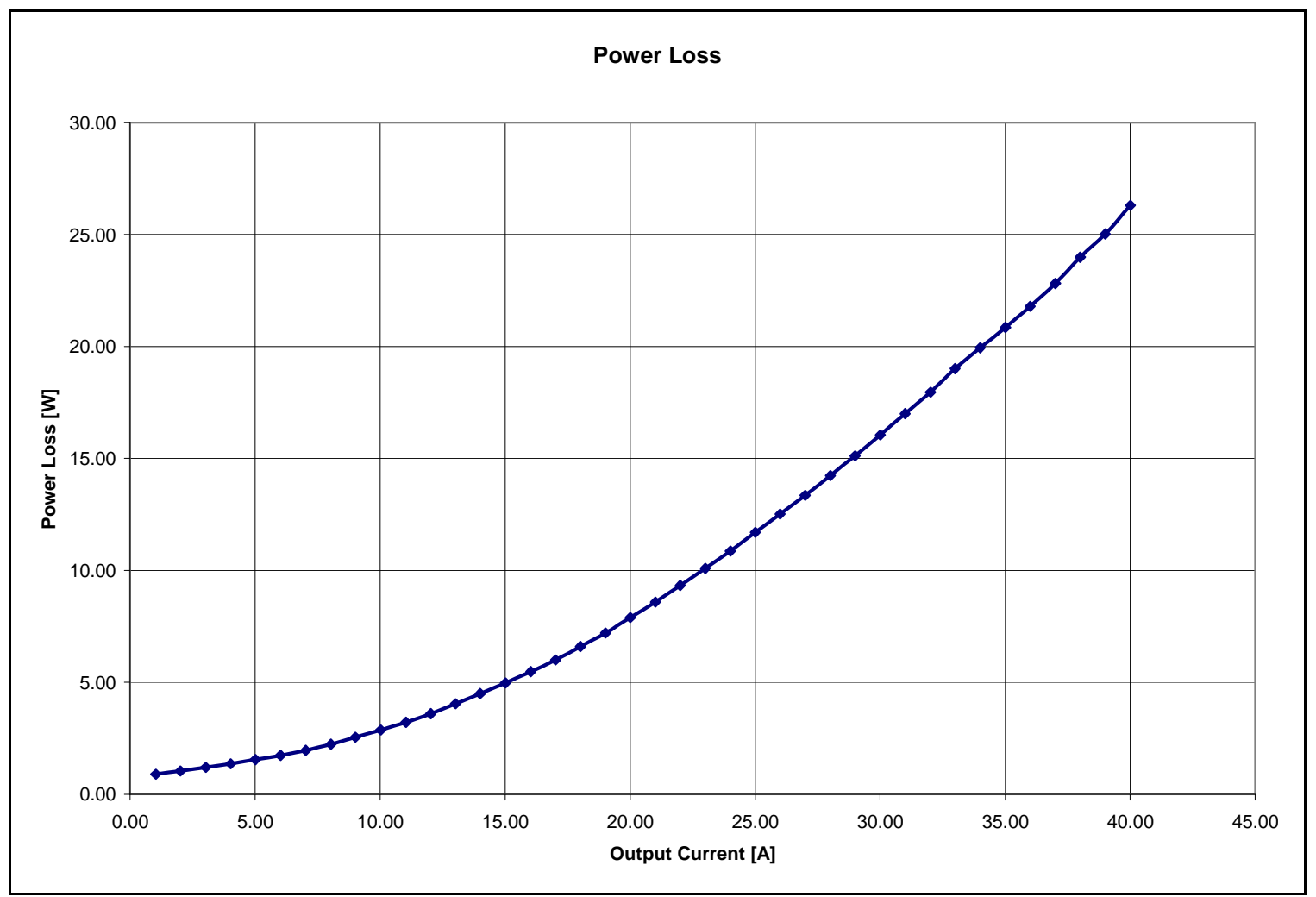

Figure 5-12. Power loss versus output current plot

Figure 5-12 shows a small loss at small load currents and a large power loss for large currents. Conduction losses go by $I^{2} R$ so as the current increases the losses go up as a square of the current. Switching losses are still significant but are dominated by the conduction losses in this case. After these results were found, a second test was run. One of the main reasons for choosing to use TO-220AB packages for the MOSFETs was the ease of placing them in parallel without complete PCB board overhaul. The advantage of placing switches in parallel is the conduction losses are halved, though the switching losses are doubled. The first test made it seem like conduction losses were dominant and reducing conduction losses at the cost of switching losses seemed like a fine tradeoff. However in the second test, the addition of the a second synchronous switch in parallel actually made the efficiency worse which was a result of large 
switching losses and the additional power required by the MOSFET drives to handle the extra MOSFETs. There was no improvement using two MOSFETs in parallel for the synchronous switch, so the results of only the first test were kept.

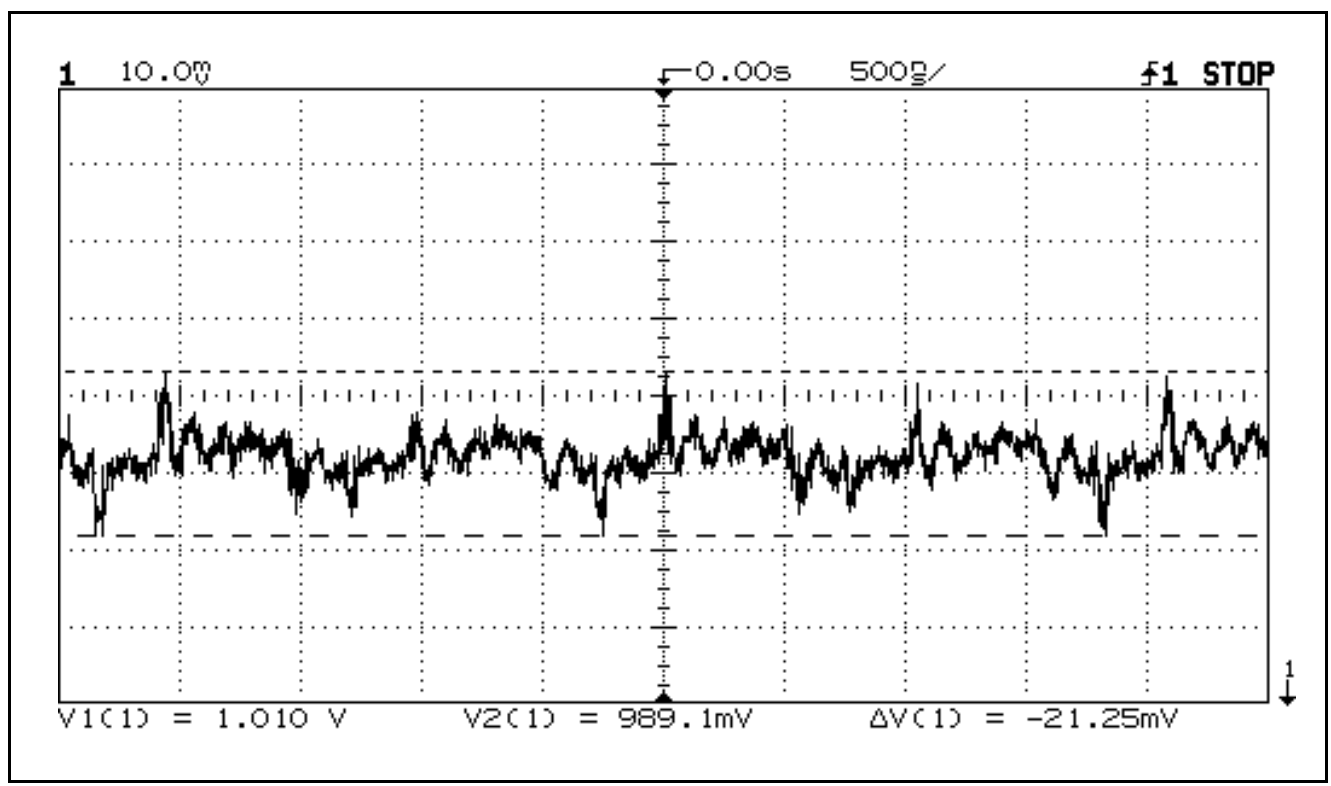

Figure 5-13. Average output voltage and output peak-to-peak ripple

Figure $5-13$ shows the average output voltage and output voltage peak-topeak ripple of the converter at full load. The average output voltage is $V_{0}=$ $1.0004 \mathrm{~V}$ with an output voltage peak-to-peak of $\mathrm{V}_{\mathrm{pp}}=21.25 \mathrm{mV}$. The average output voltage meets the specification of $1 \mathrm{~V}$ shown in Table 3-1, and the output voltage peak-to-peak ripple meets the requirements of less than $50 \mathrm{mV}$ pp.

To illustrate the functionality of the converter, the ability of the circuit to regulate and maintain a steady average output voltage of $1 \mathrm{~V}$ with different loads was tested. Load and line regulation tests were performed during different load current and input voltage conditions. Background on the importance of load regulation can be found in section 2.2.4. The data for the load regulation and the calculation performed are shown in Table 5-3. 


\begin{tabular}{|c|c|c|c|}
\hline $\begin{array}{c}\mathbf{V}_{\text {in }} \\
\text { [V] }\end{array}$ & $\begin{array}{c}\mathbf{V}_{\text {out }} \\
\text { [V] }\end{array}$ & $\begin{array}{c}\mathbf{I}_{\text {out }} \\
{[\mathbf{A}]}\end{array}$ & $\begin{array}{c}\text { Load } \\
\text { Regulation }\end{array}$ \\
\cline { 1 - 3 } 12.01 & 1.0036 & 1.03 & \multirow{2}{*}{$0.32 \%$} \\
\hline 12 & 1.0004 & 40.01 & \\
\hline
\end{tabular}

Table 5-3. Load regulation data

The calculation for load regulation is shown:

Load Regulation $=\frac{V_{o(\text { Full_Load })}-V_{o(\text { No_Load })}}{V_{o\left(\text { Full } \_ \text {Load }\right)}} \times 100 \%=\frac{1.0004-1.0036}{1.0004} \times 100 \%=0.32 \%$

Again looking at the performance specification for the board, the load regulation was $0.32 \%$ which far exceeds the requirement of less than $5 \%$. Line regulation was also found and background on the importance of line regulation can be found in section 2.2.4. The data for the line regulation and the calculation performed are shown in Table 5-4.

\begin{tabular}{|c|c|c|c|}
\hline $\begin{array}{c}\mathbf{V}_{\text {in }} \\
{[\mathbf{V}]}\end{array}$ & $\begin{array}{c}\mathbf{V}_{\text {out }} \\
{[\mathbf{V}]}\end{array}$ & $\begin{array}{c}\mathbf{I}_{\text {out }} \\
{[\mathbf{A}]}\end{array}$ & $\begin{array}{c}\text { Line } \\
\text { Regulation }\end{array}$ \\
\cline { 1 - 3 } 10.8 & 1.0006 & 35.01 & \multirow{2}{*}{$0.02 \%$} \\
\cline { 1 - 2 } 13.2 & 1.0008 & 35.01 & \multirow{2}{*}{$0.02 \%$} \\
\hline 12 & 1.0007 & 35.01 & \\
\hline
\end{tabular}

Table 5-4. Line regulation data

The calculation for line regulation is shown:

Line Regulation $=\frac{V_{o(\text { High_Input })}-V_{o\left(\text { Low_IInput }_{\text {I }}\right.}}{V_{o(\text { nominal_input })}} \times 100 \%=\frac{1.0008-1.0006}{1.0007} \times 100 \%=0.02 \%$ Again looking at the performance specification for the board, the line regulation was $0.02 \%$ which far exceeds the requirement of less than $2 \%$.

Based on the average output voltage results, it seems that the converter is operating as designed. However, it is tough to measure the switching frequency on the output due to its high frequency and limitations in the equipment used. 
For this reason and to confirm the interleaving functionality of the board, the PWM signals were founds, measured, screen captured, and analyzed, see Figure 5-14.

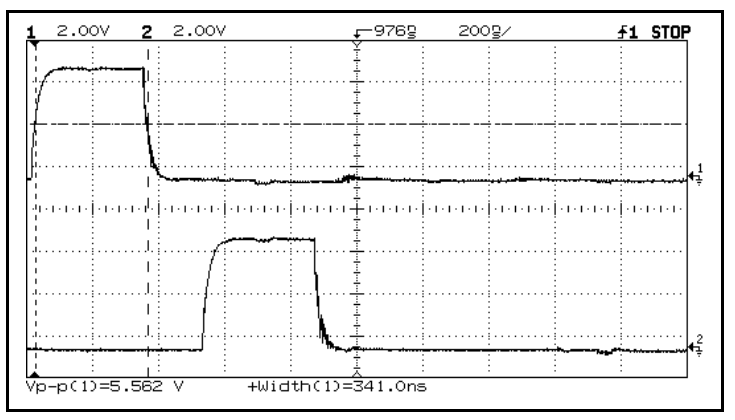

(a) phases $1 \& 2$

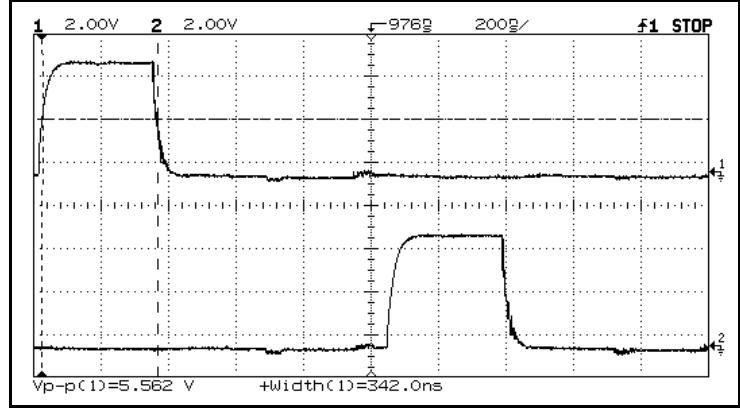

(b) phases $1 \& 3$

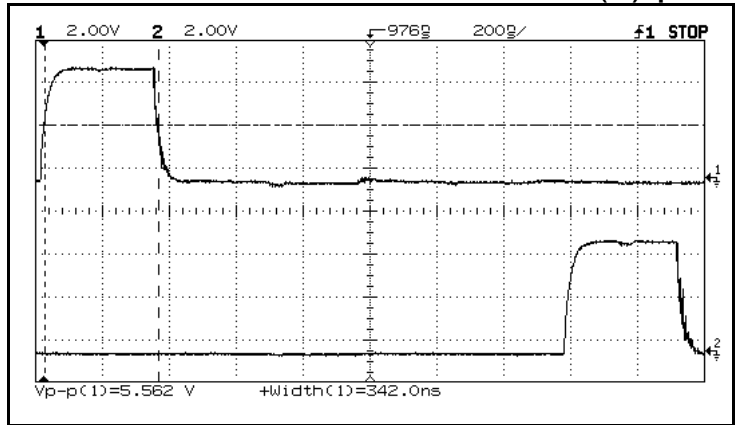

(c) phases $1 \& 4$

Figure 5-14. PWM signals: phase 1 with (a) phase 2 (b) phase 3 and (c) phase 4

Figure 5-14 shows three separate screenshots because the equipment being used was only a two channel oscilloscope. For each shot, (a), (b), and (c), the scope was triggering on channel 1 , which corresponds to phase 1 in each case. For each of the three shots, the other phases were added one by one so that the phase relationship between phases, for example between phase 1 and phase 2, could be preserved. In order to show a complete picture of the PWM signals, the images in Figure 5-14 were captured in picture form and using 250 points of data. The data was then exported to excel and graphed so that all of the phases could be shown on a single plot, see Figure 5-15. 


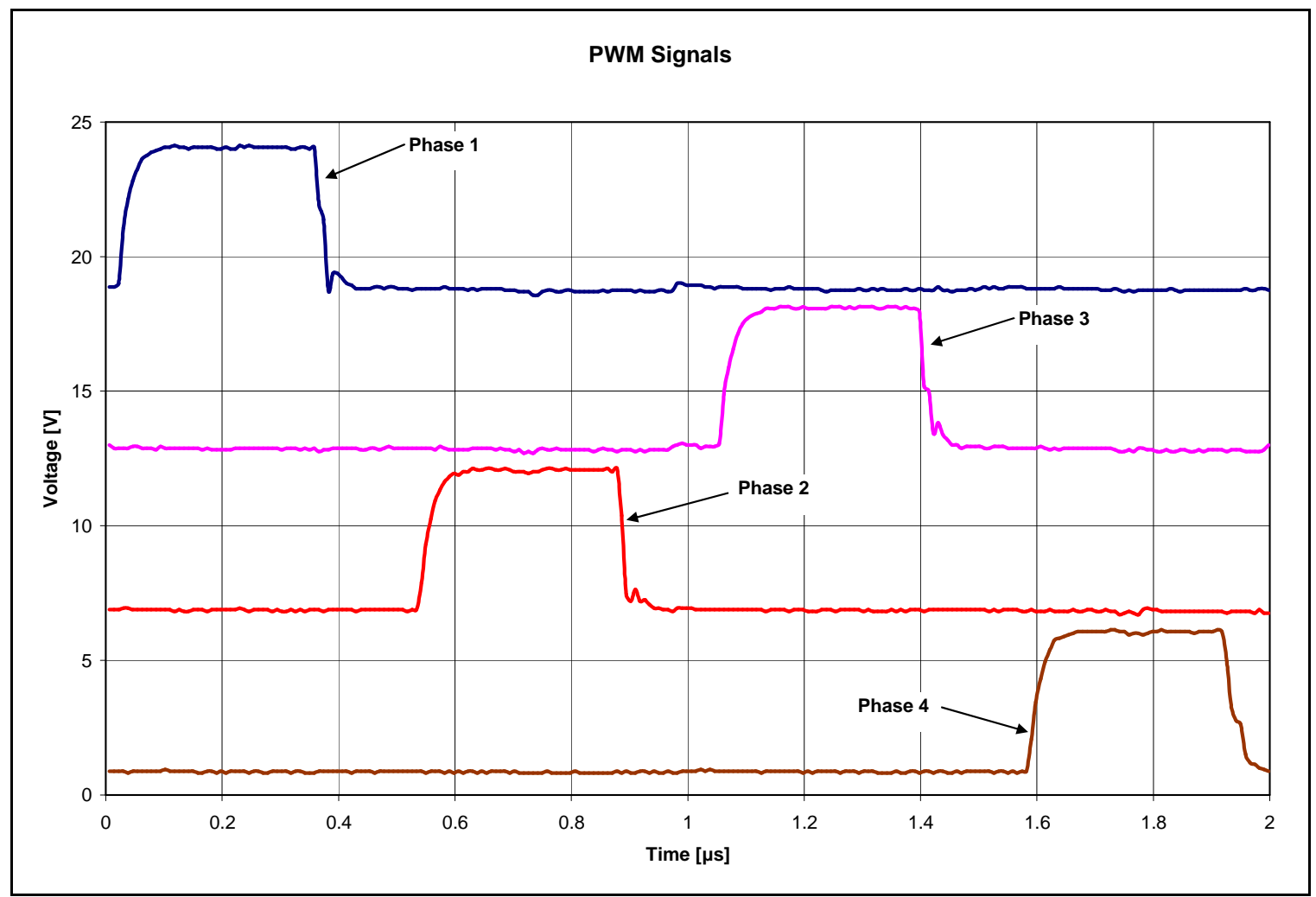

Figure 5-15. Excel composite of PWM signals

Two key pieces of information were found from the measurements shown in Figure 5-14 and 5-15, those being the switching frequency and the on-time of the main switch. The period of the PWM signals is $T=2.056 \mu \mathrm{s}$. This correlates to a switching frequency of $f_{s}=486.4 \mathrm{kHz}$. The on-time of the main switch from the PWM signals for each phase was found to be $t_{\text {on }}=0.341 \mu$ s.

A small amount of data manipulation in excel had to occur in order to show all the pulses in a legible fashion. Because each PWM signal ranges from 0 to $5 \mathrm{~V}$, all of the signals would fall in the same area of the graph and it would be difficult to distinguish exactly what was occurring. For this reason the phases were level shifted up so that they would be separated from one another, but a ground indicator has been added so there is a ground reference for each phase. Another item to note, as it differs from the simulation, is that phase 2 on the real 
circuit board in on the bottom section and is in parallel with phase 4. On the other hand, phase 3 in on the top section and is in parallel with phase 1. It was required by the IC controller to have this type of functionality because the order of the phases cannot be changed by the user, the sequence is always $1,2,3,4$. In the software simulation, the phase sequence was adjustable and was changed to $1,3,2,4$. For both simulation and hardware, the circuit used an interleaving control scheme but in each case the phase sequences were different.

As was true of the PWM signals, the use of a two channel scope when capturing the inductor current data proved challenging and required a creative solution. Data for the inductor current was captured using a current probe and current probe amplifier. The information from the current probe amplifier is then outputted to a scope for viewing and capturing. The method used to create a usable result for the current through each phase inductor is similar to the method used for the PWM signals. First, the current running through each current loop, and hence each inductor, was measured using the current probe and current probe amplifier before finally being outputted to the oscilloscope using a BNC-toBNC cable. The resulting outputs are shown in Figure 5-16, for each case the probe was set to $1 \mathrm{~A}$ per div.

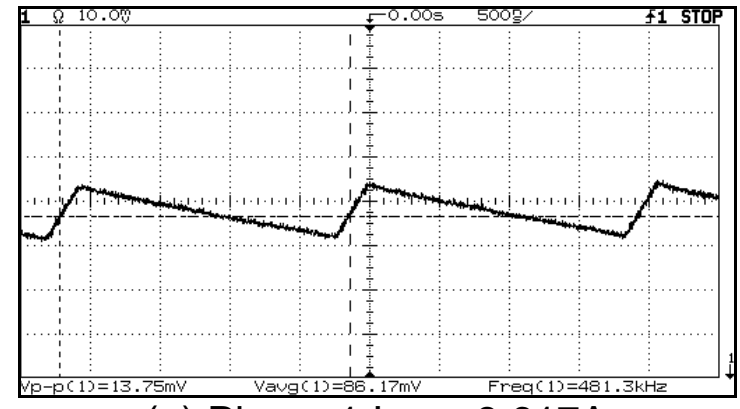

(a) Phase $1 \mathrm{I}_{\text {avg }}=8.617 \mathrm{~A}$

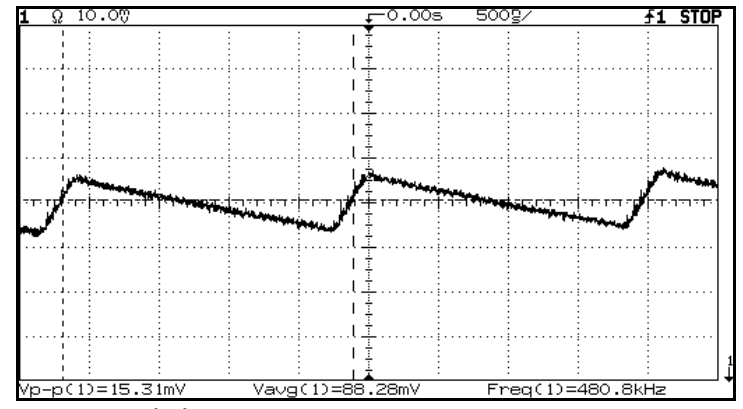

(b) Phase $2 \mathrm{l}_{\text {avg }}=8.828 \mathrm{~A}$ 




(c) Phase $3 I_{\text {avg }}=8.943 \mathrm{~A}$

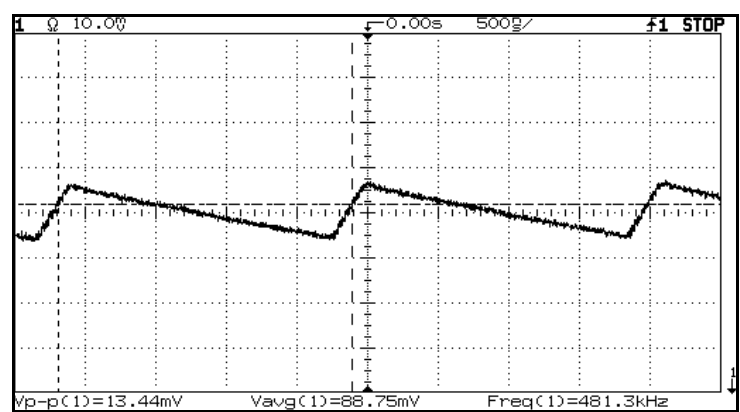

(d) Phase $4 \mathrm{l}_{\mathrm{avg}}=8.875 \mathrm{~A}$

Figure 5-16. Inductor currents

This information is useful when measuring the average and peak value of the inductor current, however it does not give any information about their phase relationships because each phase was triggered on itself. For this reason, another set of scope images was taken and used for analysis purposes, see Figure 5-17.

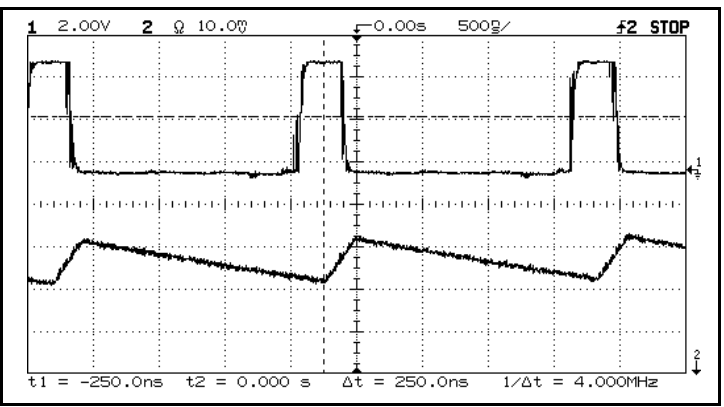

(a) Phase 1 inductor current

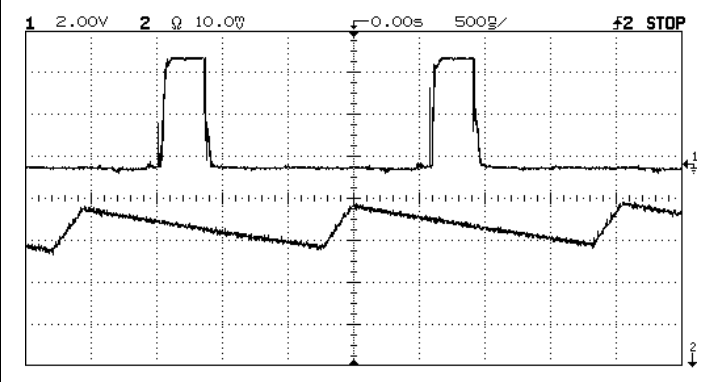

(c) Phase 3 inductor current

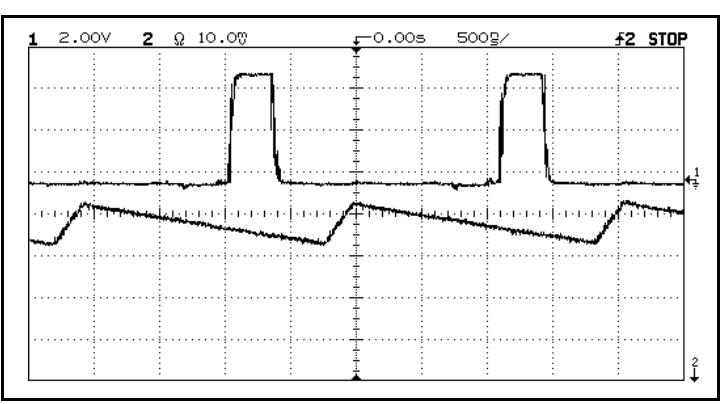

(b) Phase 2 inductor current

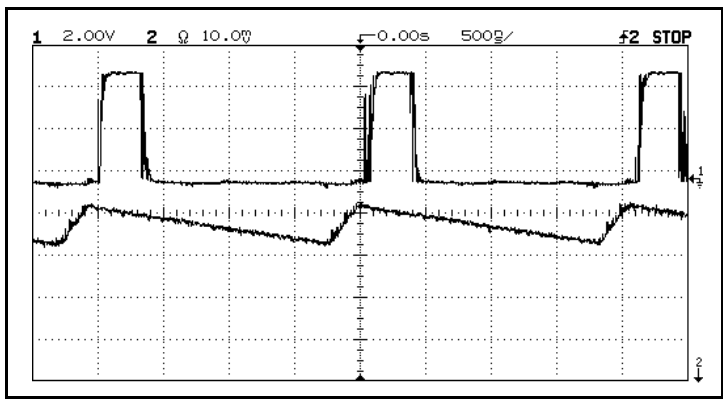

(d) Phase 4 inductor current

Figure 5-17. Phase 1 PWM signal with (a) phase 1 (b) phase 2 (c) phase 3 and (d) phase 4 inductor currents 
The PWM signal was added to each inductor current plot from Figure 5-16 and captured as shown in Figure 5-17. The scope triggered on the trace for the inductor current but a second signal, the PWM signal from phase 1, was added to preserve the phase relationship. In order to show a complete picture of the inductor currents, the images in Figure 5-16 were captured in picture form and using 250 points of data. The data for each inductor phase current was then exported to excel, see Figure 5-18.

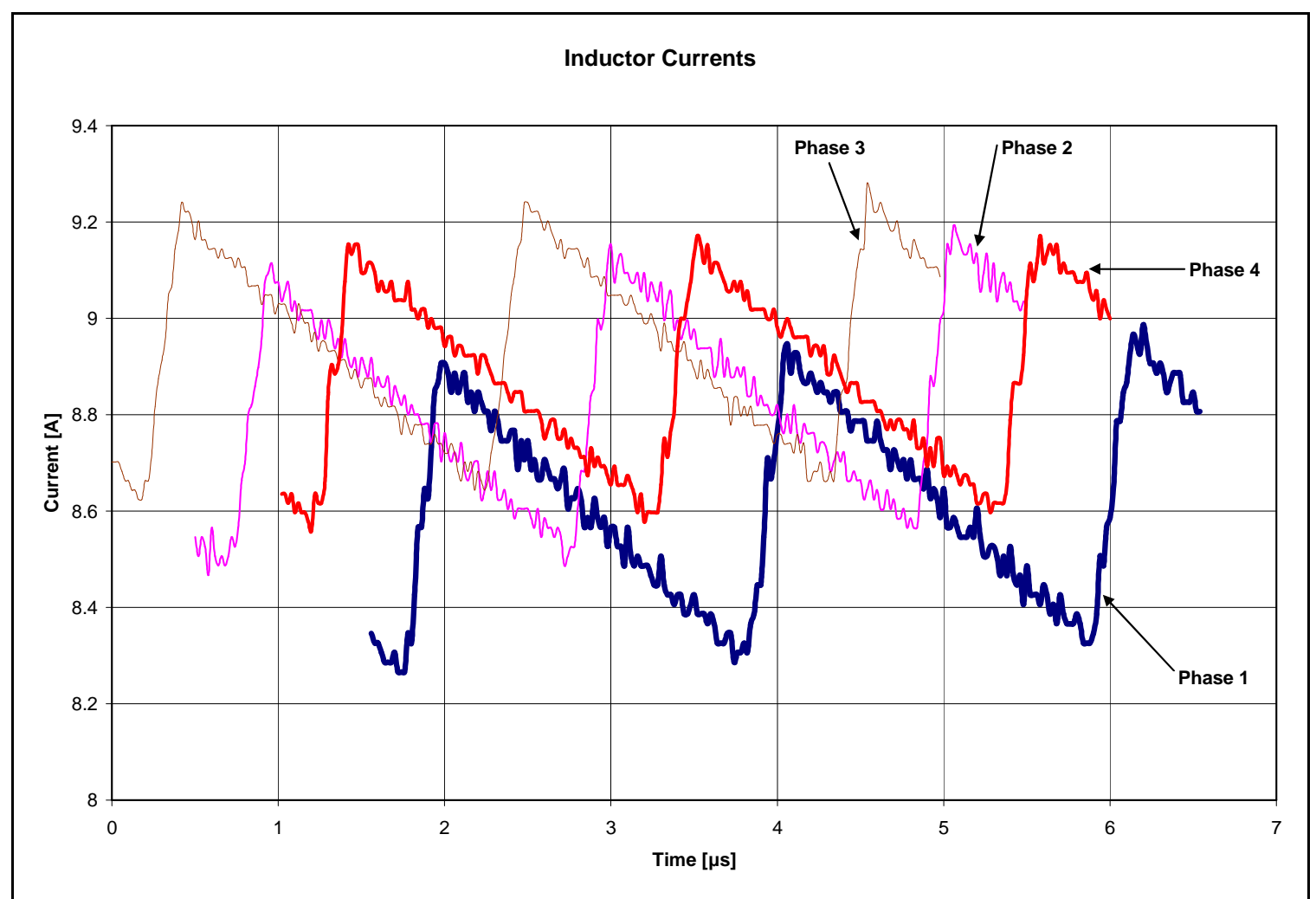

Figure 5-18. Excel composite of inductor currents

Because all of the inductor currents in Figure 5-17 are shown against the same PWM signal, each inductor current waveform can be normalized in excel so that phase 1 through phase 4 are all on the same time reference. The waveforms were time shifted in excel so this would be the case, note that in Figure 5-18, the inductor phase currents do not start at the same point, this is 
due to this time shift. This was done simply for ease of viewing the data, but the most important piece of information from Figure 5-18 is the average value of the inductor currents which will be used to find if equal current sharing is occurring. The average inductor current as well as the peak-to-peak ripple current (see Figure 5-16) for each phase is shown in Table 5-5.

\begin{tabular}{|c|c|c|c|c|c|}
\hline Phase & $\begin{array}{c}\text { Current } \\
{[\mathbf{A}]}\end{array}$ & $\begin{array}{c}\text { Sum of Currents } \\
{[\mathbf{A}]}\end{array}$ & $\begin{array}{c}\text { Total Current } \\
{[\mathbf{A}]}\end{array}$ & $\begin{array}{c}\text { Equal Sharing } \\
\text { Percent Error }\end{array}$ & $\begin{array}{c}\Delta \mathbf{I}_{\mathbf{L} \text {-pp }} \\
{\left[\mathbf{A}_{\text {pp }}\right]}\end{array}$ \\
\hline 1 & 8.615 & \multirow{2}{*}{17.558} & & $2.27 \%$ & 1.38 \\
\cline { 1 - 3 } & & & \multirow{2}{*}{35.261} & $1.45 \%$ & 1.38 \\
\cline { 5 - 6 } & 8.943 & \multirow{2}{*}{17.703} & & $0.14 \%$ & 1.53 \\
\hline 4 & 8.828 & & $0.68 \%$ & 1.34 \\
\hline
\end{tabular}

Table 5-5. Inductor current sharing

In order to gather the information taken in Table 5-5, a load of approximately 35A was used. For equal current sharing to occur, each phase would need to draw $35.3 \mathrm{~A} / 4=8.81 \mathrm{~A}$. Between phase 1 and phase 3 there was a small issue with equal current sharing as phase 3 was taking more current than phase 1 by approximately $330 \mathrm{~mA}$. There is a difference in current sharing but only resulted in a percent error of less than 3\% in the worst case. Phases 2 and 4 were right on with only a difference of approximately $50 \mathrm{~mA}$ between the two phases a percent error for equal current sharing of less than $1 \%$. Also, comparing the two modules (with module 1 consisting of phase 1 and 3 in parallel and module 2 consisting of phase 2 and phase 4 in parallel) their current sharing was quite well, only differing by approximately $150 \mathrm{~mA}$. Looking at the peak-to-peak inductor current ripple $\left(\Delta \mathrm{I}_{\mathrm{L} \text {-pp }}\right)$, phases 1,3 , and 4 are nearly identical and are all around $1.35 \mathrm{~A}_{\mathrm{pp}}$. Phase 2 was slightly higher at $1.53 \mathrm{~A}_{\mathrm{pp}}$. 
Another key component for the functionality of a converter is its ability to not only regulate and keep a constant average output voltage, but also its ability to reach that average output voltage in a short amount of time. We have already shown, in Figure 5-13 and Table 5-3, that the converter can effectively regulate the output voltage, now we will look at the transient response of the converter.

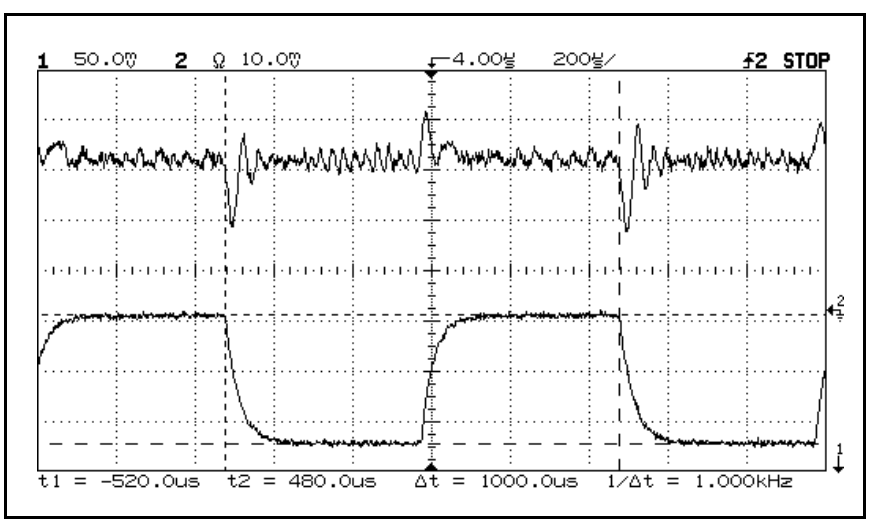

(a) Transient response showing both rising and falling times

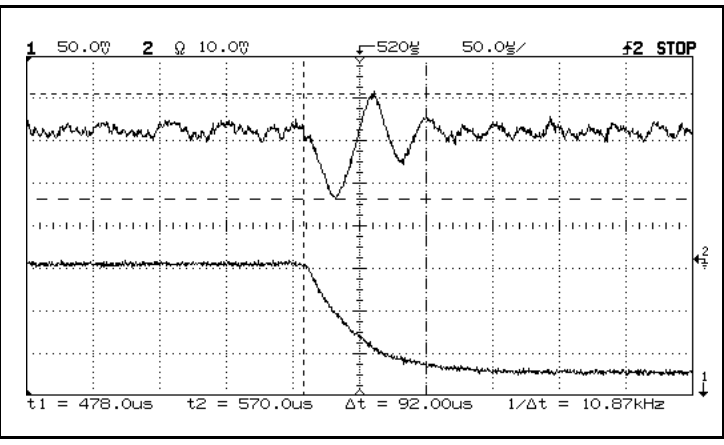

(b) falling time $t_{\text {fall }}=92.0 \mu \mathrm{s}$

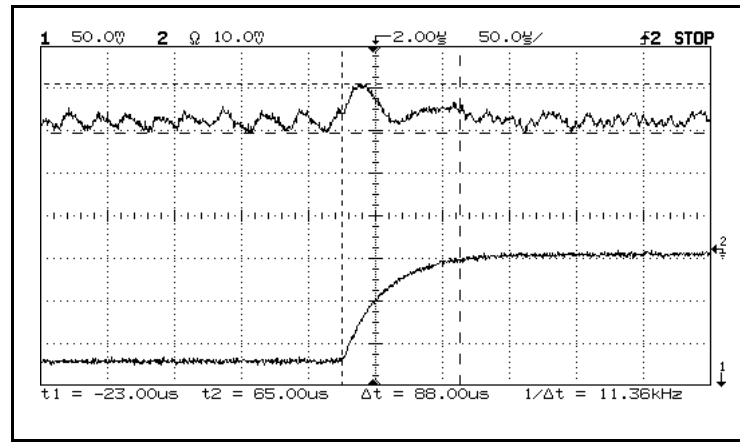

(c) rising time $t_{\text {rise }}=88.0 \mu \mathrm{s}$

Figure 5-19. Transient response to changing loads

The test performed to get the results of Figure 5-19 was to set the electronic load to change from $0 \mathrm{~V}$ to $25 \mathrm{~V}$ every $1 \mathrm{~ms}$. This allows for results to be found for the rising edge and falling edge transient time to a step change in the load. Figure 5-19 (b) shows a transient fall time of $t_{\text {fall }}=92.0 \mu$ s while Figure 5-19 (c) shows a transient rise time of trise $=88.0 \mu \mathrm{s}$. The transient time for both rising and falling is the time it takes for the oscillation due to the step change to return 
to within the limits of the average output voltage peak-to-peak ripple, in this case $V_{p p}=21.25 \mathrm{mV}$, which is taken from Figure 5-13.

The final test was to compare the use of an input filter LC filter with RC damping to a simple electrolytic capacitor. The analysis for the input filter LC filter and capacitor size were performed in section 2.3 of this thesis. The board was designed to run this test, so there were two different areas where an input voltage could be applied. Tests were run using the input that utilized the input LC filter as well as the electrolytic capacitor. For each case the input current was found by using the current probe and current probe amplifier and then output to the scope. Figure 5-20 shows the results of using each type of filter at the input.

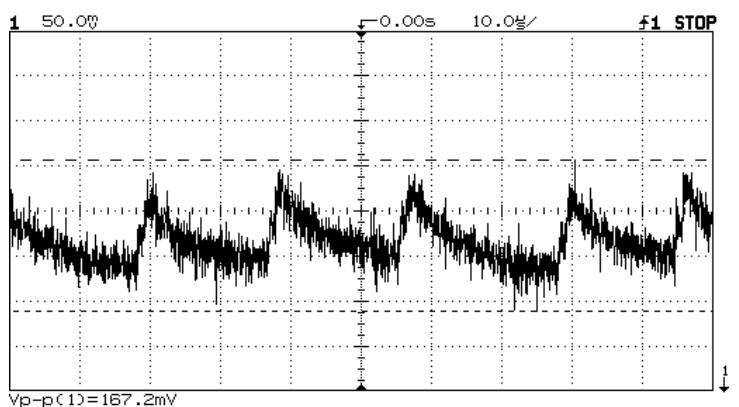

(a) With input LC filter

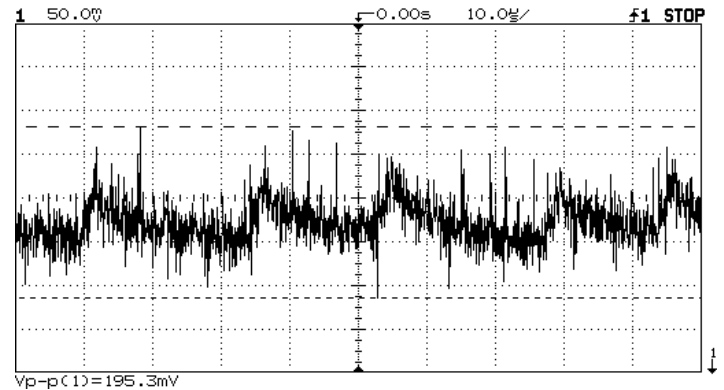

(b) With input electrolytic capacitor

Figure 5-20. Input voltage ripple with (a) LC filter and (b) electrolytic capacitor

It can be seen that the input $L C$ filter with $R C$ damping provides a cleaner signal than does the electrolytic capacitor. Both signals have a similar shape and oscillation frequency, but excess noise that occurs with just the capacitor is removed with the LC addition. It should be noted that this $L C$ filter with $R C$ damping was only added to the $12 \mathrm{~V}$ input and not the $5 \mathrm{~V}$ input, the $5 \mathrm{~V}$ input still used electrolytic capacitors as a filter. Also, the basic functionality of the converter was tested using both the LC filter and the electrolytic capacitor and results for average output current and overall efficiency were identical. 


\section{$\underline{5.5 \text { Hardware Results Summary }}$}

A summary of the key hardware results from section 5.4 are summarized in Table 5-6. The table also shows the simulation results from section 4.3 to provide an easy means to compare the two overall results for the thesis.

\begin{tabular}{|c|c|c|c|}
\hline Parameters & Specification & Simulation Results & Hardware Results \\
\hline Input Voltage Range & $10.8 \mathrm{~V}$ to $13.2 \mathrm{~V}$ & $10.8 \mathrm{~V}$ to $13.2 \mathrm{~V}$ & $10.8 \mathrm{~V}$ to $13.2 \mathrm{~V}$ \\
\hline $\begin{array}{l}\text { Nominal Input } \\
\text { Voltage }\end{array}$ & $12 \mathrm{~V}$ & $12 \mathrm{~V}$ & $12 \mathrm{~V}$ \\
\hline $\begin{array}{l}\text { Nominal Output } \\
\text { Voltage }\end{array}$ & $1 \mathrm{~V}$ & $1.0034 \mathrm{~V}$ & $1.0004 \mathrm{~V}$ \\
\hline Max Output Current & $40 \mathrm{~A}$ & $40.137 \mathrm{~A}$ & $40.01 \mathrm{~A}$ \\
\hline Output Voltage Ripple & $<50 \mathrm{mV}_{\mathrm{pp}}(<5 \%)$ & $483.9 \mu \mathrm{V}_{\mathrm{pp}}(0.05 \%)$ & $21.25 \mathrm{mV}_{\mathrm{pp}}(2.1 \%)$ \\
\hline \% Line Regulation & $<2 \%$ & NA & $0.02 \%$ \\
\hline \% Load Regulation & $<5 \%$ & NA & $0.32 \%$ \\
\hline Full Load Efficiency & $\begin{array}{c}>80 \% @ \text { Full } \\
\text { Load }\end{array}$ & $77.40 \%$ & $60.34 \%$ \\
\hline $\begin{array}{l}\text { Measured Switching } \\
\text { Frequency }\end{array}$ & $\begin{array}{l}500 \mathrm{kHz} \text { per phase } \\
(2 \mathrm{MHz} \text { overall })\end{array}$ & $\begin{array}{l}500 \mathrm{kHz} \text { per phase } \\
(2 \mathrm{MHz} \text { overall })\end{array}$ & $\begin{array}{c}\text { 486.4kHz per phase } \\
\text { (1.95MHz overall) }\end{array}$ \\
\hline $\begin{array}{l}\text { Equal Current } \\
\text { Sharing }\end{array}$ & $\begin{array}{c}\text { 10A each phase } \\
@ \text { Full Load }\end{array}$ & $\begin{array}{c}\text { 10.038A each phase } \\
@ \text { Full Load }\end{array}$ & $\begin{array}{l}\text { Less than } 3 \% \\
\text { error at } 35 \mathrm{~A}\end{array}$ \\
\hline Circuit Board Area & $\begin{array}{l}35 \text { in }^{2}(50 \% \text { of } \\
\text { previous board) }\end{array}$ & NA & $\begin{array}{l}40 \mathrm{in}^{2}(43 \% \text { of } \\
\text { previous board) }\end{array}$ \\
\hline
\end{tabular}

Table 5-6. Summary of hardware results

As Table 5-6 shows, a majority of the specifications for the converter were either met or exceeded. The input voltage range, nominal input voltage, nominal output voltage, and maximum output current parameter requirements were all met while the output voltage ripple, percent line regulation, and percent load regulation parameter requirements were all exceeded and easily met the specifications. The areas of note from the hardware results are the full load efficiency, measured switching frequency, equal current sharing, and circuit board area. Each of these parameters will be examined and further explained. 
The efficiency specification for the converter was greater than $80 \%$ at full load, but this interleaving converter was only able to reach an efficiency of $60.34 \%$ at full load. Reasons for this low hardware efficiency were stated in section 5.4, but overall the board needs some improvements in order to achieve the required efficiency. The measured switching frequency was a little on the low side as well, sitting at $486.4 \mathrm{kHz}$, although this is only a percent error of $2.7 \%$. The resistor used to set the switching frequency has to be very precise and changing only a few kilo-ohms leads to large changes in the switching frequency. Keeping in mind that the resistors used are $1 \%$, the error of $2.7 \%$ is acceptable. Looking at the equal current sharing parameter, two of the phases were nearly perfect at less than $1 \%$ error, while the other two phases were around $2-3 \%$ error. A worst case error of less than $3 \%$ is very good considering the method used. Finally, the circuit board area specification was not met and was 5 square inches too big. Several reasons account for this specification not being met. The PCB was used for experimental and testing purposes and as such it was more economical to try many different new features with the same PCB. The additional features that were added and used board space were: input filter for the $12 \mathrm{~V}$ input, an additional MOSFET socket so that two synchronous MOSFETs could be used in parallel, current probe loops for measuring the inductor currents, and the PWM test points. The current probe loops added the most board space and with those removed the total PCB area was approximately 35 square inches. With all of the other additional test features removed as well, the PCB area can be further reduced to less than 33 square inches and meets the specification. 


\section{Chapter 6. Conclusions \& Future Work}

\section{$\underline{6.1 \text { Conclusions }}$}

One of the biggest challenges that face the designers of future voltage regulator modules is creating a design that can efficiently and effectively convert a typical $12 \mathrm{~V}$ input to a $1 \mathrm{~V}$ output at some high voltage, say $100 \mathrm{~A}$. A multiphase buck topology is the preferred method to accomplish this task, but this type of design suffers from several problems that inhibit ideal performance. Looking at the big picture with this thesis, the main goals were to make changes to a standard multiphase buck converter in an attempt to improve its performance. Changes were made in the form of: adding an interleaving control scheme, investigating the influence of carefully selecting key components, attempting to improve the input current waveform and noise, improving the current shared by each phase, and finally reducing the physical size of the PCB to increase its current density. Each of the goals were attempted and all of them improved the original circuit, but not to the extent that was originally hoped.

Previous design works were created by different multiphase buck topology [15] [24]. The work of this interleaving thesis continued and improved upon the specific design put forth by Topology 2 [24]. For this reason, results will be directly compared to the final results from this interleaving thesis. Topology 1 , developed in [15], is also very similar and its results were included as well. A detailed comparison of the results of this interleaving topology and the results of the previous thesis designs was conducted and shown in Table 6-1. 


\begin{tabular}{|c|c|c|c|}
\hline Parameters & $\begin{array}{c}\text { Topology } 1 \\
\text { Results } \\
\end{array}$ & $\begin{array}{c}\text { Topology } 2 \\
\text { Results } \\
\end{array}$ & Interleaving Results \\
\hline Input Voltage Range & $10.8 \mathrm{~V}$ to $13.2 \mathrm{~V}$ & $10.8 \mathrm{~V}$ to $13.2 \mathrm{~V}$ & $10.8 \mathrm{~V}$ to $13.2 \mathrm{~V}$ \\
\hline Nom Input Voltage & $12 \mathrm{~V}$ & $12 \mathrm{~V}$ & $12 \mathrm{~V}$ \\
\hline Nom Output Voltage & 1.0062 & $1.0034 \mathrm{~V}$ & $1.0004 \mathrm{~V}$ \\
\hline Max Output Current & $38 \mathrm{~A}$ & $33 \mathrm{~A}$ & $40.01 \mathrm{~A}$ \\
\hline $\begin{array}{l}\text { Output Voltage } \\
\text { Ripple }\end{array}$ & $8.8 m \mathrm{mpp}_{\mathrm{pp}}(0.9 \%)$ & $2.8 m V_{p p}(0.3 \%)$ & $21.25 \mathrm{mV}_{\mathrm{pp}}(2.1 \%)$ \\
\hline$\%$ Line Regulation & $0.00 \%$ & $0.04 \%$ & $0.02 \%$ \\
\hline \% Load Regulation & $0.07 \%$ & $0.05 \%$ & $0.32 \%$ \\
\hline Full Load Efficiency & $54.1 \% @ 38 \mathrm{~A}$ & $51.7 \% @ 33 A$ & $\begin{array}{l}61.32 \% @ 38 A \\
63.47 \% @ 33 A\end{array}$ \\
\hline $\begin{array}{l}\text { Measured Switching } \\
\text { Frequency }\end{array}$ & $\begin{array}{c}500 \mathrm{kHz} \text { per } \\
\text { phase } \\
\text { (2MHz overall) }\end{array}$ & $\begin{array}{c}\text { 487.8kHz per phase } \\
\text { (1.95MHz overall) }\end{array}$ & $\begin{array}{c}\text { 486.4kHz per phase } \\
\text { (1.95MHz overall) }\end{array}$ \\
\hline $\begin{array}{l}\text { Equal Current } \\
\text { Sharing }\end{array}$ & $\begin{array}{c}\text { Not equal } \\
\text { (no values given) }\end{array}$ & $\begin{array}{l}\text { Less than } 14 \% \\
\text { error at full load }\end{array}$ & $\begin{array}{c}\text { Less than } 3 \% \\
\text { error at } 35 \mathrm{~A}\end{array}$ \\
\hline Circuit Board Area & $70 \mathrm{in}^{2}$ & $70 \mathrm{in}^{2}$ & $\begin{array}{l}40 \text { in }^{2}(43 \% \text { of } \\
\text { previous board })\end{array}$ \\
\hline
\end{tabular}

Table 6-1. Comparison of results with previous multiphase projects [15][24]

Looking at Table 6-1, the new interleaving topology improved upon every aspect except for output voltage ripple and load regulation. Starting with nominal output voltage of $1 \mathrm{~V}$, the interleaving topology's error was only $0.04 \%$, while the other two had errors of $0.62 \%$ and $0.34 \%$. The maximum output current of both previous works failed to reach the required $40 \mathrm{~A}$, while the interleaving topology reached 40.01A. Looking at efficiency, the interleaving topology resulted in more than $7 \%$ improvement over Topology 1 and nearly a $12 \%$ improvement over Topology 2. The interleaving topology made a significant improvement to the current sharing as well. Data for the current sharing of Topology 1 was only provided in graphical form so error calculations could not be made accurately, but from the plots the currents were clearly not equal. For Topology 2 , the worst case error from perfect current sharing was around $13.6 \%$. The new interleaving 
topology had a worst case error of only $2.7 \%$, a vast improvement over the other two designs. Finally, the interleaving topology reduced the circuit board area from 70 square inches to 40 square inches. The PCB area could have been reduced to less than 35 square inches had investigation and testing of the new circuit not been a top priority [15][24].

The interleaving topology was able to improve upon the previous designs in a number of different ways. The efficiency improvement was most likely due to the interleaving control scheme and the careful selection of key components for the circuit, namely the MOFSETs. The improvement in current sharing was most likely accomplished by moving the $\mathrm{RC}$ filter that is used to match the time constant of the current sensing inductor closer to the control IC to avoid excess noise that can cause disruptions. The reduction in board area was accomplished through strategic component placement and creative PCB layout. The input current waveform was not investigated by either of the other multiphase designs so no direct comparison could be made. The simulation and hardware results show that the addition of an LC filter does have a positive impact on the input current. This design was by no means perfect and further designs into input filters along with several other areas should be investigated in future work. 


\subsection{Future Work}

There are many directions that future work could be continued in this area. Areas specific to this project that could be improved will be addressed first. One area that has been touched on a number of times is concerned with the MOSFETs that are used. A low on-resistance is critical for the synchronous MOSFET, and because of this it makes a lot of sense to place multiple MOSFETs in parallel so that the on-resistance is even further reduced. This thesis attempted to do so but found that the losses actually increased due to an increase in the driver's power and increased switching losses. More exploration into this field is needed, but it is an area that would definitely increase the efficiency of the converter. Another area that could be explored is the use of a resistor for the current sensing rather than the inductor method. Resistance is a value that is highly dependent on temperature and as the temperature of an inductor increase the DCR can also change quite a bit. With a sense resistor this change could be minimized and better current sharing would ensue. More equal current sharing is another key to high efficiency because conduction losses are proportional to the square the current. For this case the current sharing was quite good, but still had slight variations between phases. At higher current it is likely that these variations would become greater and more losses will result.

Another direction that a similar project could attempt to accomplish is to create a completely new control scheme used to control the multiphase operation. My original idea for this project was to use two controllers from Linear Technology that have internal gate drivers and can be daisy chained together and used to control all four phases [13]. A scheme such as this has the 
advantage of needing fewer components and saves power as the controller is optimized for the purpose of controlling and driving MOSFETs. Preliminary designs were made for this scheme, but it was later decided that it makes for a more meaningful investigation when comparing a few specific changes from the previous design to use the same control scheme. This allows for a valuable comparison between the two designs, and meaningful results could be obtained. Adding a completely new controller would not allow for such a meaningful comparison, but would allow for further exploration in methods to improve the current multiphase topology. 


\section{List of References}

[1] Alou, P., J. A. Cobos, O. García, R. Prieto and J. Uceda. "Input Voltage influence on Voltage Regulator Modules based on Multiphase Buck and Multiphase Half Bridge topologies." IEEE Applied Power Electronics Conference and Exposition - APEC, vol. 2, pp. 1282-1288, 2004.

[2] Cooper, Chris. "Choosing the right input caps for your buck converter." Power Management DesignLine, 7 Sept. 2007.

<http://www.powermanagementdesignline.com/howto/2018 04690>.

[3] ExpressPCB, Help and support. <http://www.expresspcb.com/ExpressPCBHtm/Tips.htm>.

[4] ExpressPCB, SCH and PCB software. <http://www.expresspcb.com>.

[5] Gallagher, John. "Coupled Inductors Improve Multiphase Buck Efficiency." Power Electronics Technology, Penton Media Inc., pp. 36-42, Jan. 2006. $<$ www.powerelectronics.com $>$.

[6] Garinto, Dodi. "New Converter Architectures with Multi-interleaving Technique for Future Microprocessors." IEEE INTELEC 2006: 28th Annual International Telecommunications Energy Conference, 2006.

[7] Hegarty, Tim. "Benefits of multiphasing buck converters - Part 1." Power Management DesignLine, 16 Nov. 2007. <http://www.powermanagementdesignline.com/howto/20310 1907>.

[8] Hegarty, Tim. "Benefits of multiphasing buck converters - Part 2." Power Management DesignLine, 23 Nov. 2007. <http://www.powermanagementdesignline.com/howto/20420 2246>.

[9] Hegarty, Tim. "Reducing buck converter input capacitance through multiphasing and clock synchronization." EDN, 28 Jan. 2008. <http://www.edn.com/article/CA6522515.html>.

[10] IPP06N03LA Datasheet, Infineon, August 2007.

[11] IPP14N03LA Datasheet, Infineon, August 2007.

[12] IPS2832 Datasheet, Texas Instruments, January 2001.

[13] LTC3811 Datasheet, Linear Technology www.linear.com.

[14] MLC Series Datasheet, Coilcraft, April 2007. $<\mathrm{http}: / /$ www.coilcraft.com/pdfs/mlc.pdf>. 
[15] Ohn, Kay. "Analysis and Design of Multiphase DC-DC Converter with InputOutput Bypass Capacitor." Thesis. Professor Taufik. California Polytechnic State University. San Luis Obispo, CA. May 2007.

[16] Rashid, Muhammad H. Power Electronics: Circuits, Devices, and Applications. Upper Saddle River, NJ: Pearson Prentice Hall, 2004.

17[17] Saito, Toshimichi, Shin'taro Tasaki and Hiroyuki Torikai. "Interleaved Buck Converters Based on Winner-Take-All Switching." IEEE Transactions on Circuits and Systems I: Regular Papers, vol. 52, no. 8, pp. 1666-1672, Aug. 2005.

[18] Taufik. "Advanced Power Electronics." Lecture Notes. Electrical Engineering/EE411. California Polytechnic State University. San Luis Obispo, CA. Winter 2008.

[19] Taufik. "DC-DC Converter Design." Lecture Notes. Electrical Engineering/EE527. California Polytechnic State University. San Luis Obispo, CA. Spring 2008.

[20] Taufik. "Introduction to Power Electronics." Lecture Notes. Electrical Engineering/EE410. California Polytechnic State University. San Luis Obispo, CA. Fall 2007.

[21] Taylor, Robert and Wei Liu. " Phase Shifting Optimizes Multistage Buck Converters." Power Electronics Technology, Penton Media Inc., pp. 26-31, Jan. 2007. <www.powerelectronics.com>.

[22] TPS40090 Datasheet, Texas Instruments www.ti.com, May 2006.

[23] TPS40090EVM-001 User’s Guide, Texas Instruments, January 2004.

[24] Waters, Ian. "Design and Analysis of a Multiphase DC-to-DC Converter Prototype." Senior Project. Professor Taufik. California Polytechnic State University. San Luis Obispo, CA. 2007.

[25] Xu, Peng, Jia Wei and Fred C. Lee. "Multiphase Coupled-buck Converter A Novel High Efficient 12V Voltage Regulator Module." IEEE Transactions on Power Electronics, vol. 18, no. 1, pp. 74-82, Jan. 2003.

[26] Zhou, Jinghai, Ming Xu, Julu Sun, and Fred C. Lee. "A Self-Driven SoftSwitching Voltage Regulator for Future Microprocessors." IEEE Transactions on Power Electronics, vol. 20, no. 4, pp. 806-814, July 2005. 


\section{APPENDIX}

\section{A.1 Efficiency Data}

\begin{tabular}{|c|c|c|c|c|c|c|c|c|c|}
\hline \multicolumn{4}{|c|}{ System } & \multicolumn{2}{|c|}{ Drivers } & \multicolumn{4}{|c|}{ Calculations } \\
\hline $\begin{array}{l}I_{\text {out }} \\
{[A]}\end{array}$ & $\begin{array}{l}V_{\text {out }} \\
\text { [V] }\end{array}$ & $\begin{array}{l}I_{\text {in }} \\
{[A]}\end{array}$ & $\begin{array}{l}V_{\text {in }} \\
\text { [V] }\end{array}$ & $\begin{array}{c}\mathrm{I}_{\text {in(D) }} \\
{[\mathrm{mA}]}\end{array}$ & $\begin{array}{l}\mathrm{V}_{\text {in(D) }} \\
{[\mathrm{V}]}\end{array}$ & $\begin{array}{l}P_{\text {in }} \\
{[W]}\end{array}$ & $\begin{array}{l}\text { P out } \\
\text { [W] }\end{array}$ & $\begin{array}{l}P_{\text {loss }} \\
{[W]}\end{array}$ & $\begin{array}{c}\text { Efficiency } \\
{[\%]}\end{array}$ \\
\hline 1.03 & 1.0036 & 0.140 & 12.01 & 50.0 & 4.99 & 1.93 & 1.03 & 0.90 & $53.54 \%$ \\
\hline 2.02 & 1.0035 & 0.237 & 12.00 & 45.0 & 4.99 & 3.07 & 2.03 & 1.04 & $66.06 \%$ \\
\hline 3.03 & 1.0034 & 0.336 & 12.01 & 41.9 & 4.99 & 4.24 & 3.04 & 1.20 & $71.63 \%$ \\
\hline 4.03 & 1.0033 & 0.433 & 12.00 & 41.9 & 4.99 & 5.41 & 4.04 & 1.36 & $74.81 \%$ \\
\hline 5.01 & 1.0032 & 0.530 & 12.01 & 41.9 & 4.99 & 6.57 & 5.03 & 1.55 & $76.45 \%$ \\
\hline 6.02 & 1.0031 & 0.631 & 12.00 & 41.9 & 4.99 & 7.78 & 6.04 & 1.74 & $77.61 \%$ \\
\hline 7.02 & 1.0030 & 0.733 & 12.00 & 41.9 & 4.99 & 9.01 & 7.04 & 1.96 & $78.19 \%$ \\
\hline 8.03 & 1.0029 & 0.839 & 12.01 & 41.9 & 4.99 & 10.29 & 8.05 & 2.23 & $78.30 \%$ \\
\hline 9.01 & 1.0029 & 0.948 & 12.00 & 41.9 & 4.99 & 11.59 & 9.04 & 2.55 & $78.00 \%$ \\
\hline 10.02 & 1.0028 & 1.059 & 12.00 & 41.9 & 4.99 & 12.92 & 10.05 & 2.87 & $77.79 \%$ \\
\hline 11.03 & 1.0027 & 1.171 & 12.01 & 41.9 & 4.99 & 14.27 & 11.06 & 3.21 & $77.49 \%$ \\
\hline 12.02 & 1.0026 & 1.287 & 12.00 & 41.9 & 4.99 & 15.65 & 12.05 & 3.60 & $76.99 \%$ \\
\hline 13.01 & 1.0025 & 1.406 & 12.00 & 41.9 & 4.99 & 17.08 & 13.04 & 4.04 & $76.36 \%$ \\
\hline 14.00 & 1.0025 & 1.526 & 12.01 & 41.9 & 4.99 & 18.54 & 14.04 & 4.50 & $75.72 \%$ \\
\hline 15.01 & 1.0024 & 1.651 & 12.00 & 41.9 & 4.99 & 20.02 & 15.05 & 4.98 & $75.15 \%$ \\
\hline 16.02 & 1.0023 & 1.776 & 12.01 & 41.9 & 4.99 & 21.54 & 16.06 & 5.48 & $74.55 \%$ \\
\hline 17.02 & 1.0022 & 1.904 & 12.00 & 41.9 & 4.99 & 23.06 & 17.06 & 6.00 & $73.98 \%$ \\
\hline 18.01 & 1.0022 & 2.037 & 12.00 & 41.9 & 4.99 & 24.65 & 18.05 & 6.60 & $73.21 \%$ \\
\hline 19.02 & 1.0021 & 2.170 & 12.01 & 41.9 & 4.99 & 26.27 & 19.06 & 7.21 & $72.55 \%$ \\
\hline 20.01 & 1.0020 & 2.311 & 12.00 & 41.9 & 4.99 & 27.94 & 20.05 & 7.89 & $71.76 \%$ \\
\hline 21.01 & 1.0020 & 2.452 & 12.00 & 41.9 & 4.99 & 29.63 & 21.05 & 8.58 & $71.04 \%$ \\
\hline 22.00 & 1.0019 & 2.595 & 12.01 & 41.9 & 4.99 & 31.38 & 22.04 & 9.33 & $70.25 \%$ \\
\hline 23.01 & 1.0018 & 2.742 & 12.01 & 41.9 & 4.99 & 33.14 & 23.05 & 10.09 & $69.56 \%$ \\
\hline 24.01 & 1.0017 & 2.890 & 12.01 & 41.9 & 4.99 & 34.92 & 24.05 & 10.87 & $68.88 \%$ \\
\hline 25.01 & 1.0016 & 3.045 & 12.00 & 41.9 & 4.99 & 36.75 & 25.05 & 11.70 & $68.17 \%$ \\
\hline 26.00 & 1.0015 & 3.195 & 12.00 & 41.9 & 4.99 & 38.55 & 26.04 & 12.51 & $67.55 \%$ \\
\hline 27.00 & 1.0015 & 3.349 & 12.00 & 41.9 & 4.99 & 40.40 & 27.04 & 13.36 & $66.94 \%$ \\
\hline 28.01 & 1.0014 & 3.506 & 12.00 & 41.9 & 4.99 & 42.28 & 28.05 & 14.23 & $66.34 \%$ \\
\hline 29.00 & 1.0014 & 3.663 & 12.00 & 41.9 & 4.99 & 44.17 & 29.04 & 15.12 & $65.75 \%$ \\
\hline 30.01 & 1.0013 & 3.824 & 12.00 & 41.9 & 4.99 & 46.10 & 30.05 & 16.05 & $65.19 \%$ \\
\hline 31.00 & 1.0012 & 3.986 & 12.00 & 41.9 & 4.99 & 48.04 & 31.04 & 17.00 & $64.61 \%$ \\
\hline 32.01 & 1.0011 & 4.150 & 12.00 & 41.9 & 4.99 & 50.01 & 32.05 & 17.96 & $64.08 \%$ \\
\hline 33.00 & 1.0010 & 4.320 & 12.00 & 41.9 & 4.99 & 52.05 & 33.03 & 19.02 & $63.47 \%$ \\
\hline 34.00 & 1.0009 & 4.480 & 12.00 & 41.9 & 4.99 & 53.97 & 34.03 & 19.94 & $63.06 \%$ \\
\hline 35.01 & 1.0007 & 4.640 & 12.00 & 41.9 & 4.99 & 55.89 & 35.03 & 20.85 & $62.69 \%$ \\
\hline 36.00 & 1.0006 & 4.800 & 12.00 & 41.9 & 4.99 & 57.81 & 36.02 & 21.79 & $62.31 \%$ \\
\hline 37.01 & 1.0006 & 4.970 & 12.00 & 41.9 & 4.99 & 59.85 & 37.03 & 22.82 & $61.88 \%$ \\
\hline 38.00 & 1.0006 & 5.150 & 12.00 & 41.9 & 4.99 & 62.01 & 38.02 & 23.99 & $61.32 \%$ \\
\hline 39.00 & 1.0005 & 5.320 & 12.00 & 41.9 & 4.99 & 64.05 & 39.02 & 25.03 & $60.92 \%$ \\
\hline 40.01 & 1.0004 & 5.510 & 12.00 & 41.9 & 4.99 & 66.33 & 40.03 & 26.30 & $60.34 \%$ \\
\hline
\end{tabular}

Table A-1. Efficiency data 


\section{A.2 PCB Layout Drawings}

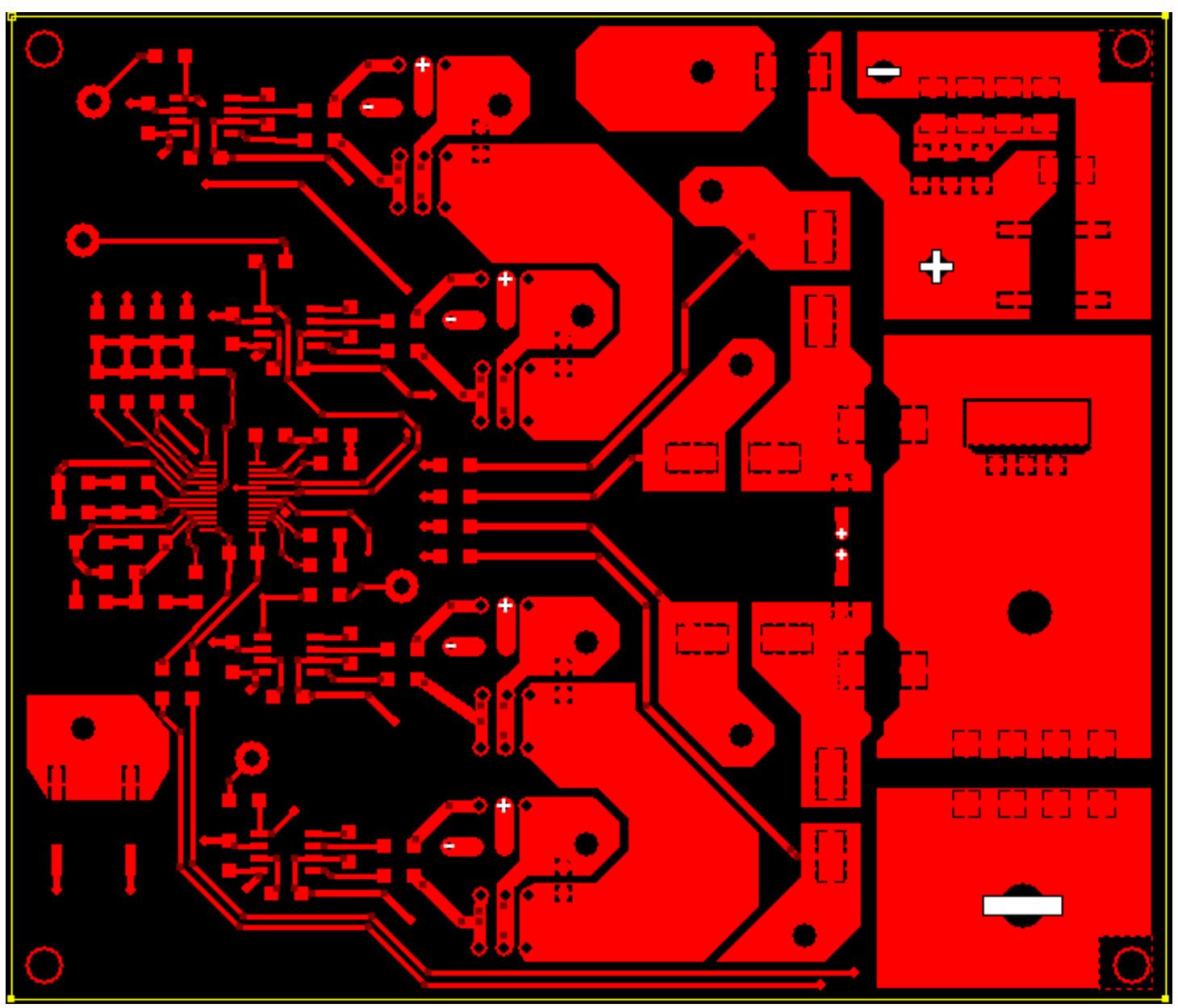

Figure A-1. Top Layer 




Figure A-2. Inner Ground Layer 


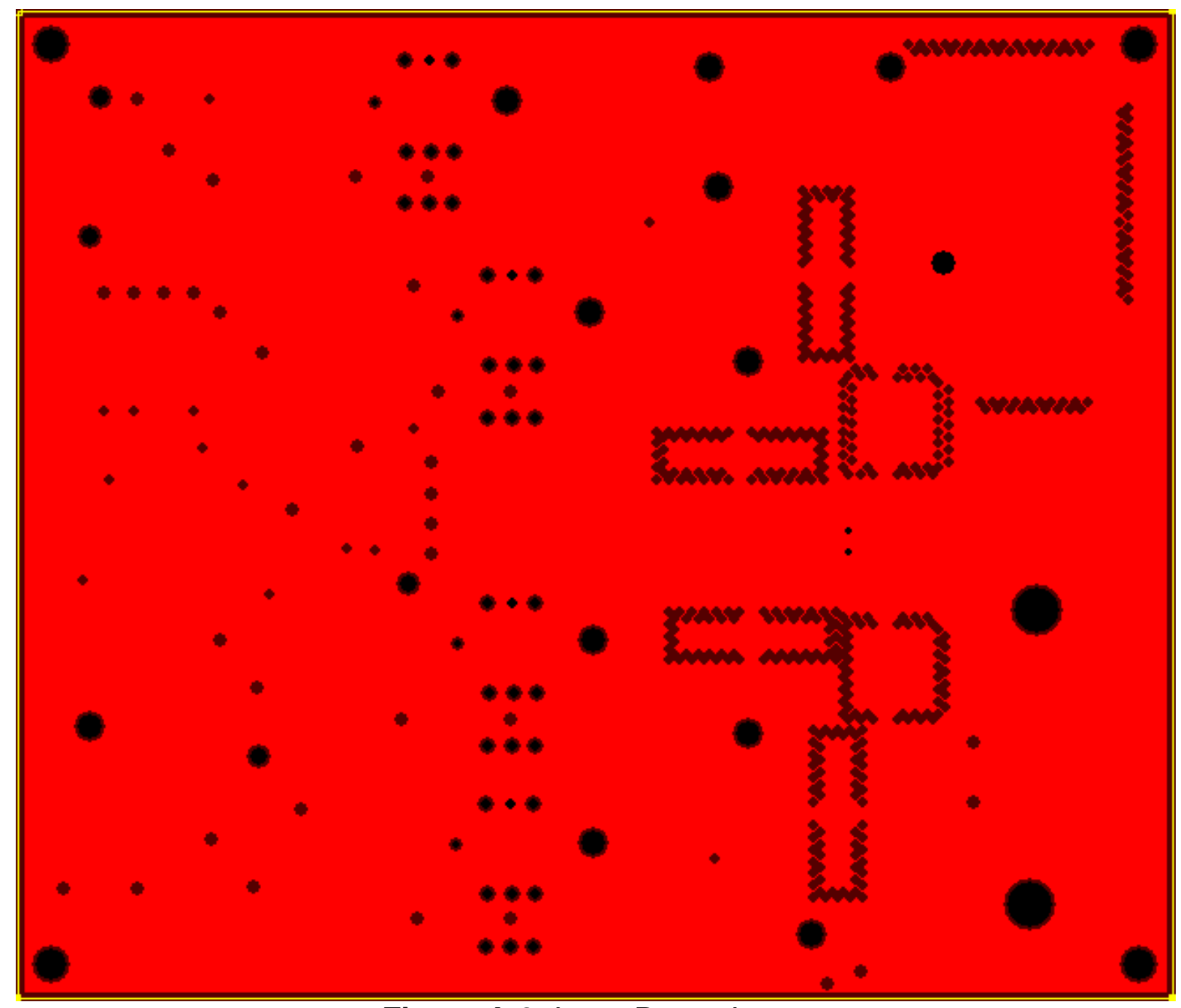

Figure A-3. Inner Power Layer 


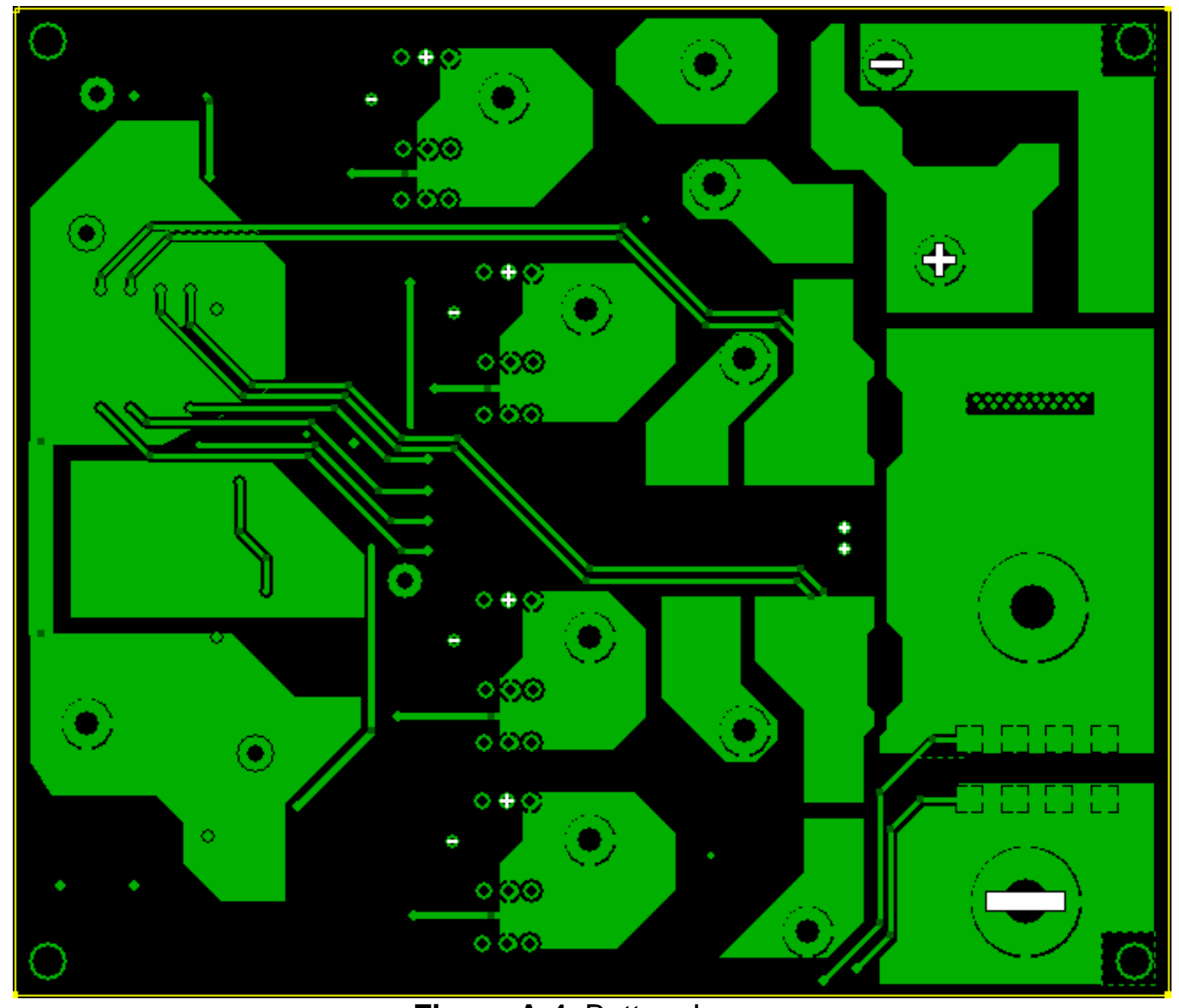

Figure A-4. Bottom Layer 




Figure A-5. Overall 


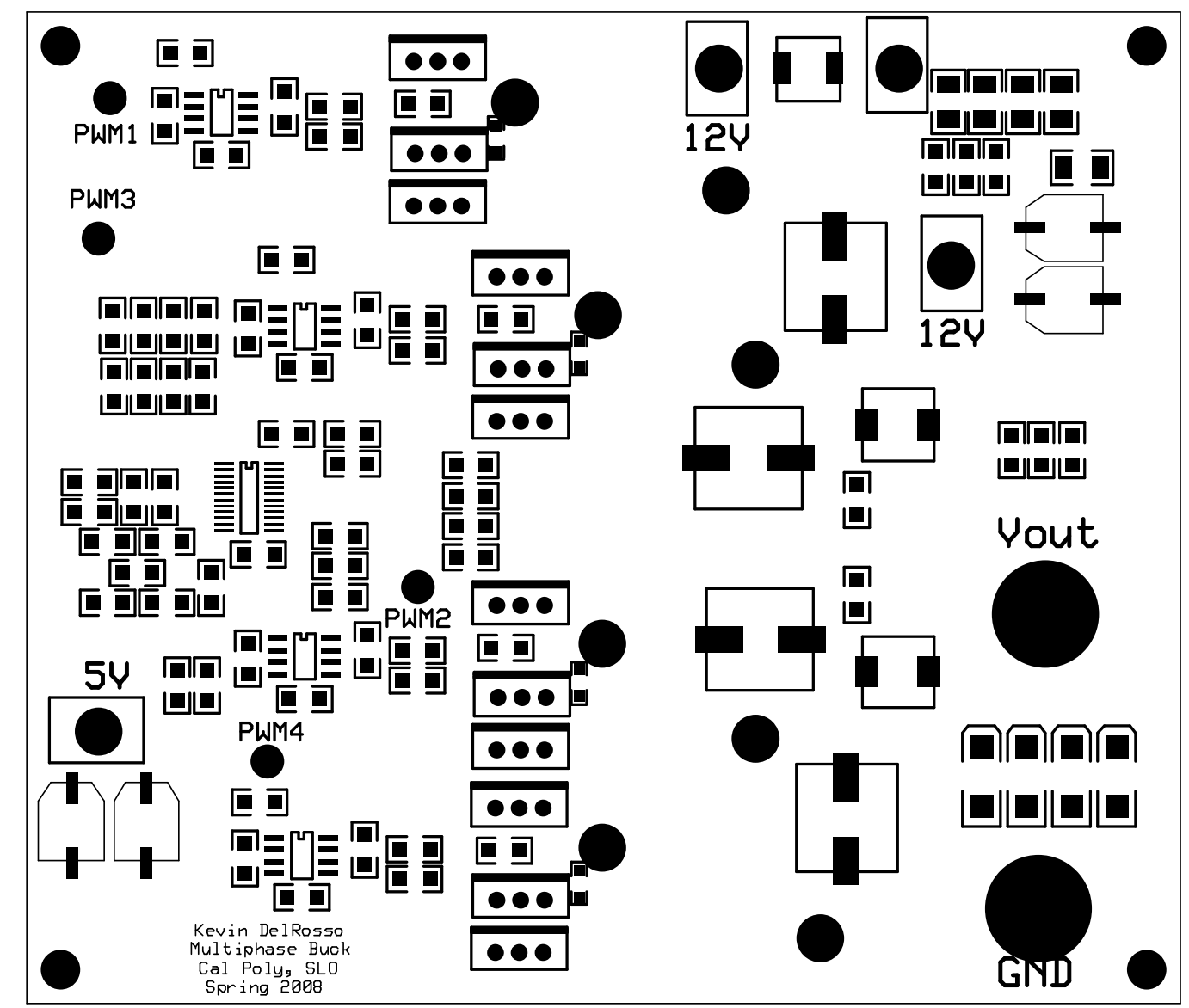

Figure A-6. Board Area

Note: The board area was reduced from the original 70 square inches to 39.89 square inches, a savings of 43 percent. 


\section{A.3 Bill of Materials}

\begin{tabular}{|c|c|c|c|c|}
\hline Reference Designator & QTY & Description & Manufacturer & Part Number \\
\hline $\mathrm{C} 3, \mathrm{C} 4, \mathrm{C} 5, \mathrm{C} 6$ & 4 & Cap 22000pF 50V ceramic X7R 1206 & Kemet & C1206C223K5RACTU \\
\hline $\begin{array}{l}\text { C7, C13, C14, C15, } \\
\text { C16, C19, C20 }\end{array}$ & 7 & 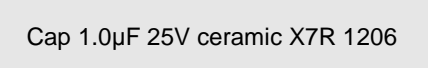 & Kemet & C1206C105K3RACTU \\
\hline $\mathrm{C} 8$ & 1 & Cap 5600pF 50V ceramic X7R 1206 & Kemet & C1206C562K5RACTU \\
\hline C9 & 1 & Cap 1000pF 50V ceramic X7R 1206 & Kemet & C1206C102K5RACTU \\
\hline $\mathrm{C} 10, \mathrm{C} 11$ & 2 & 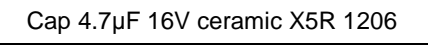 & Kemet & C1206C475K3RACTU \\
\hline $\mathrm{C} 12, \mathrm{C} 38$ & 2 & Cap 10000pF 50V ceramic X7R 1206 & Kemet & C1206C103K5RACTU \\
\hline $\begin{array}{l}\text { C17, C18, C29, C30, } \\
\text { C35, C Cut }\end{array}$ & 8 & Cap 10uF 16V ceramic X5R 1210 & Panasonic - ECG & ECJ-4YB1C06K \\
\hline $\begin{array}{l}\mathrm{C} 21, \mathrm{C} 22, \mathrm{C} 23, \mathrm{C} 24 \\
\mathrm{C} 25, \mathrm{C} 26, \mathrm{C} 27, \mathrm{C} 28\end{array}$ & 8 & 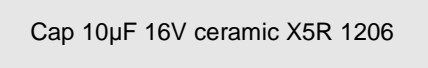 & Kemet & C1206C106K3RACTU \\
\hline C31, C32 & 2 & Cap $220 \mu \mathrm{F} 16 \mathrm{~V}$ elect VS SMD & Panasonic - ECG & ECE-V1CA221XP \\
\hline C33, C34 & 2 & Cap $100 \mu \mathrm{F} 16 \mathrm{~V}$ elect poly SMD & United Chemi-Con & APXE160ARA101MF80G \\
\hline C39, C40, C41, C42 & 4 & $\begin{array}{c}\text { Cap tant LOESR 220 } \mu \mathrm{F} 4.0 \mathrm{~V} 10 \% \\
\text { SMD }\end{array}$ & AVX Corporation & TPSD227K004R0050 \\
\hline D1, D2, D3, D4 & 4 & Schottky rect 10V 3A SOD123F & NXP Semiconductor & PMEG1030EH T/R \\
\hline JP1, JP2, JP3, JP4 & 4 & 14 AWG solid copper wire & & Bulk Wire \\
\hline L1, L2, L3, L4 & 4 & Inductor power $1.75 \mu \mathrm{H} \mathrm{SMT}$ & Coilcraft & MLC1260-172ML \\
\hline L5, L6 & 2 & Inductor power 36nH SMT & Coilcraft & SLC7649S-300KL \\
\hline L7 & 1 & Inductor power $1.0 \mu \mathrm{H} 11 \mathrm{~A}$ SMD & Vishay/Dale & IHLP2525CZER1R0M01 \\
\hline $\begin{array}{l}\text { PWM1, PWM2, PWM3, } \\
\text { PWM4 }\end{array}$ & 4 & PC Test Terminal Lug & Keystone Electronics & 680 \\
\hline Q1, Q3, Q5, Q7 & 4 & MOSFET N-ch 25V 30A TO-220AB & Infineon Technologies & IPP14N03LA \\
\hline Q2a, Q4a, Q6a, Q8a & 4 & MOSFET N-ch 25V 50A TO-220AB & Infineon Technologies & IPP06N03LA \\
\hline $\mathrm{R}$ & 4 & Res $1.00 \mathrm{M} \Omega$ 1/4W $1 \% 1206 \mathrm{SMD}$ & Panasonic - ECG & ERJ-8ENF1004V \\
\hline R1, R5, R31 & 3 & Res $10.0 \mathrm{k} \Omega$ 1/4W 1\% $1206 \mathrm{SMD}$ & Panasonic - ECG & ERJ-8ENF1002V \\
\hline $\begin{array}{l}\text { R2, R21, R23, R25, } \\
\text { R27 }\end{array}$ & 5 & Res $25.5 \mathrm{k} \Omega$ 1/4W 1\% $1206 \mathrm{SMD}$ & Panasonic - ECG & ERJ-8ENF2552V \\
\hline $\begin{array}{l}\text { R3, R9, R12, R17, R20, } \\
\text { R22, R24, R26, R28, } \\
\text { R29, R30 }\end{array}$ & 11 & Res $10 \Omega$ 1/4W 1\% 1206 SMD & Panasonic - ECG & ERJ-8ENF10R0V \\
\hline R4 & 1 & Res $4.32 \mathrm{k} \Omega$ 1/4W 1\% $1206 \mathrm{SMD}$ & Panasonic - ECG & ERJ-8ENF4321V \\
\hline R6 & 1 & Res $49.9 \Omega$ 1/4W 1\% 1206 SMD & Panasonic - ECG & ERJ-8ENF49R9V \\
\hline $\mathrm{R} 7$ & 1 & Res $45.3 \mathrm{k} \Omega 1 / 4 \mathrm{~W} 1 \% 1206 \mathrm{SMD}$ & Panasonic - ECG & ERJ-8ENF4532V \\
\hline $\mathrm{R} 8$ & 1 & Res $53.6 \mathrm{k} \Omega 1 / 4 \mathrm{~W} 1 \% 1206 \mathrm{SMD}$ & Panasonic - ECG & ERJ-8ENF5362V \\
\hline $\begin{array}{l}\text { R10, R11, R13, R14, } \\
\text { R15, R16, R18, R19 }\end{array}$ & 8 & Res zero ohm 1/4W 5\% 1206 SMD & Panasonic - ECG & ERJ-8GEY0R00V \\
\hline R32, R33, R34, R35 & 4 & Res $1.00 \mathrm{k} \Omega$ 1/4W 1\% $1206 \mathrm{SMD}$ & Panasonic - ECG & ERJ-8ENF1001V \\
\hline R36, R37, R38 & 3 & Resistor $1.0 \Omega$ 1/4W 5\% 1206 & Panasonic - ECG & ECJ-8GEYJ1R0V \\
\hline U1 & 1 & IC sync buck ctrl LO-V 24-TSSOP & Texas Instruments & TPS40090PW \\
\hline U2, U3, U4, U5 & 4 & IC sync buck FET driver 8-SOIC & Texas Instruments & TPS2832D \\
\hline Red banana input (12V) & 1 & Conn jack banana insul nylon bla & $\begin{array}{l}\text { Emerson Network } \\
\text { Power Conn }\end{array}$ & $108-0903-001$ \\
\hline $\begin{array}{l}\text { Black banana input } \\
\text { (GND) }\end{array}$ & 1 & Conn jack banana insul nylon red & $\begin{array}{l}\text { Emerson Network } \\
\text { Power Conn }\end{array}$ & $108-0902-001$ \\
\hline $\begin{array}{l}\text { Blue banana input } \\
(5 \mathrm{~V})\end{array}$ & 1 & Conn jack banana insul nylon blu & $\begin{array}{l}\text { Emerson Network } \\
\text { Power Conn }\end{array}$ & $108-0904-001$ \\
\hline Output Connectors & 2 & Terminal Lug, copper & Thomas \& Betts & BTC0614-B2 \\
\hline
\end{tabular}

Table A-2. Bill of materials (BOM) 